\title{
UNTERSUCHUNGEN ÜBER KORRELATIONEN VON KNOSPEN UND SPROSSEN
}

\begin{abstract}
INAUGURAL-DISSERTATION
ZUR ERLANGONG DER DOKTORWÜRDE DER HOHEN PHILOSOPHISCHEN FAKULTÄT DER UNIVERSITÄT LEIPZIG
\end{abstract}

VORGELEGT

voN

WALTHER MัOGK

MIT 19 FIGUREN IM TEXT UND 15 TABELLEN

LEIPZIG UND BERLIN

WILHELM ENGELMANN 
Angenommen von der III. Sektion auf Grund der Gutachten der Herren Pfeffer und Chun.

Leipzig, den 25. November 1913.

Der Procancellar.

KirChNer.

Sonderabdruck aus dem >Archiv für Entwicklungsmechanik.\& Bd. 38, Heft 4. 


\section{M7 $2 u$}

$\sum_{\infty}$ REMOTE STORAGE

\section{Untersuchungen über Korrelationen von Knospen und Sprossen.}

Von

Walther Mogk.

Mit 19 Figuren im Text und 15 Tabellen.

Eingegangen am 24. Dezember 1913. 
In dieser Arbeit soll der erste Teil von Untersuchungen dargestellt werden, die ich vom Sommer 1909 bis zum Sommer 1911 am Botanischen Institut der Universität Leipzig ausführte.

Ehe ich mich der Darstellung dieser Untersuchungen zuwende, sei es mir gestattet, meinem hochverehrten Lehrer, Herrn Geh. Rat Prof. Dr. W. Pfeffere, für die Anregung und Beratung, womit er stets den Fortgang meiner Arbeit tatkräftig unterstützte, herzlich zu danken. Ebenso bin ich Herrn Prof. Dr. H. Mrene zu großem Danke verpflichtet.

\section{A. Einleitung.}

Wie Pfeffer an Keimlingen von Vicia Faba nachgewiesen hat $\left.{ }^{1}\right)$, wirkt die mechanische Wachstumshemmung des Hauptsprosses auf die korrelativ von ihm abhängigen Axillarsprosse in gleicher Weise wie seine Entfernung: Die normalerweise ruhenden Axillarknospen treiben aus ${ }^{2}$ ) und wachsen, als ob der Hauptsproß abgeschnitten wäre. Weitere Versuche an Sproßsystemen sowie auch an Wurzelsystemen und Blättern führten zu dem gleichen Ergebnis ${ }^{3}$ ): Ein Organ, das an seinem Wachstum gewaltsam verhindert wird, ist während

1) Pfeffer, 1893, S. 347 f., 382.

2) Das Austreiben beginnt bei eingegipstem Hauptsproß einige Zeit später als nach Entfernung desselben (Pisum sativum, Hering, S. 156).

3) Hering, S. 142, 152, 1577; Winkler, 1902, S. 83; Goebel, 1903, S. 134. 
dieser Zeit ohne Einfluß auf das Wachstum anderer, normalerweise von ihm abhängigen Organe $\left.{ }^{1}\right)$.

Es liegt eine Reihe von Beobachtungen vor, wo ein Sproß oder eine Wurzel gewaltsam am Wachstum verhindert wurde, bis normalerweise weniger entwickelte Sprosse oder Wurzeln an Ausbildung überlegen waren. Wurde dem gehemmten Organ dann die Möglichkeit gegeben, weiter zu wachsen, so nahm es sein Wachstum wieder auf ${ }^{2}$. Hallbauer fand sogar ${ }^{3}$, daß der Hauptsproß von Phaseolus-Keimlingen, den er längere Zeit durch einen Gipsverband am Wachstum verhindert hatte, nach dem Entgipsen die Kotyledonaraxillare, die ihn bedeutend an Länge übertrafen, in ihrem Wachstum zum Stillstand brachte. Indes finden sich Angaben, die zeigen, daß die Verhältnisse auch anders liegen können. So sagt Nordhausen ${ }^{4}$ ), daß die zeitweise eingegipste Hauptwurzelspitze von Lupinus-Keimlingen bisweilen bald nach dem Entgipsen ihr wieder aufgenommenes Wachstum unter dem korrelativen Einfluß der geförderten Seitenwurzeln einstellt.

Eingehender ist die Frage über die Korrelationen nach der zeitweisen mechanischen Hemmung eines Organs nicht erörtert worden, weder nach dem Einfluß korrelativ geförderter Organe auf das normalerweise ihnen ïberlegene, noch nach dessen Einfluß auf jene.

Meine Aufgabe ist es nun, diese Frage für eine Anzahl typischer Sproßsysteme ${ }^{5}$ ) zu beantworten.

1) Pfeffer, 1904, S. 202. Wenn Hering die starke und langanhaltende Wachstumsverzögerung der Hauptwurzel von Keimlingen bei gehemmtem Hauptsproß auf dauernde Wachstumsbestrebungen des Hauptsprosses im Gipsverband zuriickzuführen sucht (HERING, S. 141), so steht diese Annahme mit seinen eigenen Versuchen uiber das Wachstum der Kotyledonaraxillare bei eingegipstem Hauptsproß nicht in Einklang (HeRING, S. 156). Vielmehr machen es die Beobachtungen KnYs (KNy, S. 272 ff.), die denen Herings durchaus nicht in dem Maße widersprechen, wie es nach dessen unvollständiger Erörterung derselben scheint (Hering, S. 138, KNY, S. 275), wahrscheinlich, daß die Wachstumshemmung der Hauptwurzel allein eine Folge der Ausschaltung des Hauptsprosses ist. Vgl. ferner die Ausführungen von KLeBs (1903, S. 116). Daß die Ausschaltung eines Organs ein anderes zunächst korrelativ fördern kann, und dessen Wachstum gleichwohl im wesentlichen retardiert, zeigen die Untersuchungen PorTHeims 1907, S. 1435) und JACOBIs (S. $280 \mathrm{ff}$.) mit teilweise entfernten Kotyledonen. Vgl. dazu SACHS, 1859 (1892, S. 597).

2) Vöchting, 1878, S. 174; Pfeffer, 1893, S. 356; Mc Callum, S. 243, 249, 250 ; u. a.

3) Hallbauer, S. $54 \mathrm{f}$.

4) Nordhausen, S. 578 .

5) Unter einem System verstehe ich die Gesamtheit der Zweige, die den Knospen eines Mutterzweiges entwachsen. 
Da sich durch die zeitweise mechanische Hemmung eines Sprosses vor allem das gegenseitige Verhältnis der Entwicklungszustände der korrelativ voneinander abhängigen Sprosse des betreffenden Systems ändert, handelt es sich bei den vorliegenden Untersuchungen in erster Linie um die Bedeutung der Entwicklungszustände der einzelnen Sprosse für ihre gegenseitige Abhängigkeit ${ }^{1}$ ).

Im Laufe meiner Arbeiten erweiterte sich die Fragestellung. Vor allem drängte sich mir die eine Frage auf: Handelt es sich bei den zwischen Sprossen bestehenden Korrelationen tatsächlich um Wachstumskompensationen ${ }^{2}$, sodaß das Verhalten des einen das Verhalten des andern in jeder Phase der Entwicklung neu bestimmt, oder wirken die Sproßkorrelationen in bedeutend höherem Maße induzierend ${ }^{3}$ ), als man bisher im allgemeinen annahm ${ }^{4}$ )?

An diese Frage schlossen sich weitere an, von denen ich nur eine noch anführen will: Wird ein mechanisch am Wachstum verhinderter Sproß oder eine Knospe durch das geförderte Wachstum der übrigen während der Hemmung korrelativ beeinflußt?

Die Versuche wurden an Keimlingen und an Zweigen von Bäumen ausgeführt, und zwar sowohl an solchen, wo die mechanische Hemmung eines $\mathrm{Z}$ weiges eine sichtbare korrelative Reaktion anderer Zweige auslöst, als auch an solchen, wo dies - wie bei den plagiotropen Verzweigungssystemen einer Reihe von Coniferen - nicht der Fall ist.

Zur Hemmung verwandte ich den Gipsverband, der vor andern Methoden den Vorzug hat, daß er bei den verschiedensten Organen anwendbar ist, daß er im wesentlichen keine schädigenden Nachwirkungen erkennen läßt, während er gleichzeitig das Wachstum entschiedener hemmt als z. B. Inversstellung ${ }^{5}$ ), und daß er am einfachsten zu handhaben und darum ebenso bei Zweigen, die am Baum wachsen, zu verwenden ist wie bei Pflanzen im Laboratorium ${ }^{6}$ ).

1) Vgl. SACHS, 1893, S. 220.

2) Goebel, 1898-1901, S. 178; 1908, S. 71.

3) Vgl. Vöchting, 1906, S. 131.

4) Herbst, S. $722 \mathrm{ff}$.

5) Küster, 1904, S. 299. Vgl. hierzu Vöchting, 1906, S. 356.

6) Weitere Methoden zur zeitweisen Hemmung von Organen sind folgende: Sauerstoffentzug (VöchтіNG, 1878, S. 130 f.), Veränderung der Stellung des Organs zum Erdradius (Vöchting, 1878, S. 173 f.), Wassersto (McCallum, S. 243, 249), 
Bei Keimlingen benutzte ich den von Pfeffer beschriebenen doppelten Gipsguß 1). War die Sproßachse unterhalb des Gipsverbandes noch wachstumsfähig, so wurde in der von Hering angegebenen Weise ${ }^{2}$ ) rom Gipsverband ein Faden über eine vertikal gelegene Rolle geleitet, an dessen anderem Ende sich ein Gewicht von der Schwere des Gipsverbandes befand $(a)$. War die Sproßachse unterhalb des Gipsverbandes nicht mehr wachstumsfähig, so wurde dieser von drei Drahtfüßen gestützt, die in ihn eingelassen waren und bis in die Erde hinabreichten (b).

Die Keimlinge wurden bis zu Beginn des Versuchs in Sägemehl kultiviert und nach dem Entgipsen in Erde (Töpfe) gepflanzt. Aus dieser wurden sie nur kurze Zeit zum Entgipsen herausgenommen, und zwar möglichst mit dem ganzen Ballen.

Die Vergleichspflanzen und solche, die erst in späteren Stadien untersucht werden sollten, wurden gleichfalls in früher Jugend in Erde verpflanzt.

Sollten Verzweigungssysteme von Bäumen untersucht werden, so wurden diejenigen Sprosse, deren Wachstum mechanisch gehemmt werden sollte, als Knospen eingegipst, und zwar im zeitigen Frühjahr vor dem Austreiben.

Eigneten sich die zu untersuchenden Zweige nicht zu Stecklingen, weil sie nicht fähig waren, sich durch Wurzelbildung selbständig zu machen, so wurden die Versuche am Baum ausgeführt.

Beim Eingipsen der Knospen wandte ich folgende Methode an: Aus Glasröhren schnitt ich Zylinder, die oben und unten offen waren. Ihre Länge betrug für die Knospen von Torreya und Picea $15 \mathrm{~mm}$, für die von Tilia $30 \mathrm{~mm}$. Der Durchmesser war nicht viel größer als der der betreffenden Knospe; für Torreya und Picea nahm ich ihn $7 \mathrm{~mm}$, für Tilia $10 \mathrm{~mm}$. Nachdem ich eine Öffnung des Zylinders mit einem flachen Pfropfen von Watte oder plastischem Ton geschlossen hatte, füllte ich ihn mit einem Gipsbrei von der von

Eintauchen in Wasser (Sproß, Mc Callum, S. 109), mechanische Krümmung (VöcHTing, 1884, S. 49; Nolu, 1900, S. 381; Goebel, 1908, S. 84), für Wurzeln Abkühlung (Pfeffer, 1893, S. 376; Goebel, 1908, S. 176), oder Trockenheit (Pfereer, 1893, S. 376). Willkürliche Förderung von Organen läßt sich u. a. durch erhöhte Feuchtigkeit (MC CALLUM, S. 250) erzielen, oder durch lokales Ätherisieren (Mc Callum, S. 253; Johannsen, 1906, S. 35 ff.), oder durch Warmwasserbad (MOHLISCH, 1908).

1) Pfeffer, 1893, S. 238 ff.

2) Hering, S. 155. 
Pfeffer ${ }^{1}$ ) angegebenen Konsistenz und fuhrte die Knospe heinein. Bei Coniferen mußte darauf geachtet werden, daß auch die Zone des Zweiges, der die Knospe aufsaß, vom Gips eingeschlossen (Endknospe) oder umgriffen (Seitenknospe) wurde. Bei den Laubbäumen wurde außer der Endknospe noch die Spitze des Mutterzweiges von der Gipshülle umschlossen. Sollten Knospen eingegipst werden, die tiefer am Zweige saßen, so wurde zunächst die Glashülle über die betreffende Knospe und die zugehörige Zweigzone gestullpt, eine Öffnung des Zylinders mit Watte oder Ton verschlossen und der Gipsbrei von der offenen Seite hineingegossen.

Auf diese Weise wurde der Gipsverband so leicht, daß er die Zweige nicht aus ihrer normalen Stellung brachte und so durch außergewöhnliche Einwirkungen der Schwerkraft die normalen Verhältnisse hätte verschieben können. Die Glashüllen schützten den Gips vor mechanischen Einwirkungen, besonders vor Zerbrechen und Lösung durch Regen, während sie an ihren beiden offenen Enden die Luft genügend diffundieren ließen, um der Knospe das Leben zu ermöglichen.

Sollte die Hülle entfernt werden, so wurde das Glas zunächst zerschlagen. Die Scherben lösten sich in Wasser dann leicht vom Gips. Und auch dieser ließ sich durch stïckweises Abbrechen gut entfernen.

Bei den Salix-Arten, deren Zweige leicht Stecklinge bilden, wurden solche zu den Versuchen verwandt.

Den Gipfel, dessen Knospen im Austreiben gehemmt werden sollten, gipste ich (Anfang Februar 1910) auf gleiche Weise ein wie die Sprosse von Keimlingen. Die Stecklinge wurden mit einem im oberen Ende des Gipsblockes eingelassenen Haken an einem Gestell senkrecht aufgehängt und ihr basaler Teil in ein verdunkeltes Gefäß mit Wasser eingelassen, wo er Wurzeln bildete. Nach dem Entgipsen (Ende April) setzte ich die reichbewurzelten Zweige in Erde. Die Vergleichspflanzen wurden in gleicher Weise zuerst in Wasser, später in Erde kultiviert.

Infolge der Wurzelbildung hatte der Zweig jederzeit die genügende Nahrung, um die in den Knospen ruhenden Fähigkeiten zu entwickeln, und es war ausgeschlossen, daß bei eingegipsten Endknospen die basalen Triebe etwa alle Nahrung verbrauchten, so daß ein etwaiges Nichtaustreiben der akralen Knospen nach dem Ent-

1) Preffer, 1893, S. 243. 
gipsen auf allgemeinen Nahrungsmangel hätte zuriickgeführt werden können.

Die Isolierung der Sprosse vom Gesamtorganismus bietet den Vorteil, daß eine korrelative Beeinflussung durch fremde Systeme des gleichen Organismus ausgeschaltet ist. Außerdem sind besonders bei Salix fragilis die Zweige so schmächtig und schwach, daß selbst ein leichter Gipsverband durch sein Gewicht die natürliche Richtung der Zweige und dadurch ihren normalen Zustand verändert.

Um zwei Sprosse miteinander zu vergleichen, wurde ihre Länge gemessen. Diese wurde nach unten bei Keimlingen durch die Basis des epikotylen Gliedes begrenzt, bei Zweigen durch die Basis der Knospenspur 1). Als obere Grenze diente bei Keimlingen der oberste Knoten, der nicht mehr von den noch unentwickelten Blättern umschlossen wurde, bei den Zweigen der Laubbäume die Basis der Endknospe. Da die Spitze der Coniferenzweige ziemlich lange von den Nadeln umschlossen wird, begrenzte ich hier den Zweig zunächst durch die Spitze der obersten Nadeln, wenigstens soweit das Wachstum in seinem Verlaufe verfolgt werden sollte. Um die endgültige Länge festzustellen, wählte ich gleichfalls die Basis der Endknospe als obere Grenze ${ }^{2}$ ).

Zur Veranschaulichung der Wachstumsverhältnisse der untersuchten Systeme habe ich das Wachstum der einzelnen Sprosse graphisch in Kurven dargestellt. Ich habe hierzu stets tatsächlich gegebene Fälle verwendet, die - soweit das Gegenteil nicht ausdriicklich vermerkt ist - typisch und aus einer Reihe gleichartiger Fälle herausgegriffen sind.

Es haben diese Kurvensysteme lediglich den Zweck, zeitlich einander ablösende Vorgänge in einem einzigen Bilde gleichzeitig zu veranschaulichen. Um die einzelnen typischen Kurvensysteme miteinander zu vergleichen, bezeichne ich sie als Typus I, II usw. Zur Erklärung der Kurven selbst ist noch zu sagen, daß die Abszisse die Tage angibt, die Ordinate die Länge des betreffenden Sprosses in Millimetern. Die ausgezogene Kurve stellt das Wachstum des Hauptsprosses bzw. des obersten Sprosses dar, die punktierte Linie das des Seitensprosses. Nur bei Tilia sind die Kurven für sämtliche

1) Berthold, 1904, S. 255.

2) Daß bei Beginn des Wachstums die Nadeln rascher wachsen als der Zweig, dagegen das Wachstum der Nadeln eher verklingt als das des Zweiges, ist hierbei unwesentlich. 
wiedergegebenen Sprosse ausgezogren; die Länge der Sprosse nimmt hier basipetal ab. Die Vertikale zeigt den Tag an, an dem der mechanisch gehemmte Sproß entgipst wurde. -

Zum Schluß muß ich noch einige Bemerkungen für die Darstellung vorausschicken.

Die Ausdrücke oben und unten habe ich nach der normalen Stellung der Keimlinge orientiert, so daß sich beim Sproß die Spitze (apex) oben, der Grund (basis) unten befindet. Das gleiche gilt für die Zweige.

Zur Unterscheidung gleicher, etagenartig aufeinander folgender Organe habe ich dieselben mit Zahlen belegt, und zwar bei Keimlingen stets in akropetaler Reihenfolge. Handelt es sich um Internodien, so habe ich bei Keimlingen das epikotyle Glied als das erste Glied bezeichnet. Bei Blättern schließe ich die Kotyledonen ganz allgemein nicht in die Zählung ein, sondern beginne mit dem untersten Primärblatt.

An Verzweigung:ssystemen von Bäumen beginne ich mit der Zählung an der Spitze, da die basalen Glieder infolge ihrer geringen Länge und späteren Blattlosigkeit (Knospenspur) vielfach nur undeutlich gegeneinander abgegrenzt sind.

\section{B. Experimenteller Teil.}

I. Untersuchungen an Sproßsystemen von Keimlingen.

1. Vicia Faba f. maior.

Die Keimlinge von Vicia Faba erwiesen sich als besonders giunstig für die Versuche, da sie einerseits infolge ihres kräftigen Wachstums Wachstumsveränderungen deutlicher zum Ausdruck bringen als minder rasch wachsende Pflanzen, anderseits ein längeres Verweilen im Gipsverband ohne nachträglich sich offenbarende Schädigungen gut aushielten.

Del Sproß ist monopodial gebaut, und zwar wächst zunächst die Hauptachse allein, während die Nebenachsen als Knospen im Ruhezustand bleiben. Dies Verhalten ist bei so jugendlichen Pflanzen, wie ich sie zu meinen Untersuchungen verwandte, die Regel, von der ich Abweichungen nie feststellte. Erst in späterem Alter trieben bisweilen die ruhenden Knospen des ersten Primärblattes aus.

Die Versuche wurden so angestellt, daß der Gipfel des Sprosses, der eine Länge von 35 bis $90 \mathrm{~mm}$ hatte, bis unterhalb der wachstums- 
fähigen Zone eingegipst wurde, d. h. etwa bis zur Mitte des ersten Gliedes. Hatten die infolge der Hemmung des Hauptsprosses austreibenden Kotyledonaraxillare eine gewisse Länge erreicht, so wurde der Hauptsproß entgipst.

Damit zwischen Haupt- und Kotyledonarsproß Unterschiede ausgeschaltet würden, wie sie durch Verschiedenheiten in der Beleuchtung verursacht werden, führte Hering ${ }^{1}$ ) sowohl wie Hallibauer ${ }^{2}$ ) seine Versuche mit etiolierten Pflanzen im Dunkeln aus. Um jedoch zu seheu, ob Unterschiede in der assimilatorischen Tätigkeit bei Haupt- und Nebensproß nach dem Entgipsen des ersteren ihr gegenseitiges Wachstumsverhältnis beeinflussen ${ }^{3}$ ), modifizierte ich die Versuche inbezug auf Beleuchtung nach folgender Tabelle:

Tabelle I.

\begin{tabular}{c|c|c|l}
\hline \hline & $\begin{array}{c}\text { Keimung bis } \\
\text { Hemmung }\end{array}$ & $\begin{array}{c}\text { Während der } \\
\text { Hemmung }\end{array}$ & $\begin{array}{c}\text { Nach der } \\
\text { Hemmung }\end{array}$ \\
\hline 1. & dunkel & dunkel & dunkel \\
2. & dunkel & dunkel & hell \\
3. & dunkel & hell & hell \\
4. & hell & hell & hell \\
5. & hell & dunkel & hell \\
6. & hell & dunkel & dunkel
\end{tabular}

Diese Modifikationen der Versuchsanordnung beeinflußten die prinzipiellen Verhältnisse nicht. Und so kann ich bei einer Schilderung der einzelnen Versuche die Beleuchtungsverhältnisse zunächst außer acht lassen.

Die Kotylodenaraxillare gelangen bei mechanisch gehemmtem Hauptsproß ein wenig später zur Entwicklung als bei Entfernung des Hauptsprosses ${ }^{4}$ ). Für den Beginn ihres Wachstums ist es gleichguiltig, ob die Pflanze hell oder dunkel kultiviert wird ${ }^{5}$ ). Dagegen stellen sich im Verlauf des weiteren Wachstums Verschiedenheiten ein: Die etiolierten Sprosse gliedern sich langsamer als die in zerstreutem Tageslicht kultivierten. Wenn der tägliche Zuwachs bei etiolierten

1) Hering, S. 155 .

2) Hallbauer, S. $15 \mathrm{f}$.

3) S. 601.

4) Hering, S. 156.

5) Die hier mitgeteilten Untersuchungen habe ich an Pflanzen mit entferntem Hauptsproß angestellt. 
Pflanzen gleichwohl größer ist als bei belichteten, so hat dies seine Ursache in der abnormen Streckung der Internodien. Die Anzahl der Internodien war im Dunkeln stets geringer als im Hellen. Desgleichen waren die Kotyledonen im Dunkeln im allgemeinen weniger entleert als bei gleichaltrigen Parallelversuchen im Licht.

Außer diesen durch den Einfluß des Lichtes bedingten Unterschieden zeigten sich auch bei völlig gleichen Außenbedingungen individuelle Verschiedenheiten in der Geschwindigkeit des Wachstums der Kotyledonarsprosse.

Um nach dem Entgipsen das Wachstum des Hauptsprosses mit dem der Kotyledonaraxillare vergleichen zu können, muß ich zunächst nach dem Maße suchen, das einen möglichst einwandfreien Vergleich für das Wachstum des Hauptsprosses mit dem der beiden physiologisch gleichwertigen $\left.{ }^{1}\right)$ Kotyledonaraxillare ermöglicht.

Das gegenseitige Wachstumsverhältnis der Kotyledonaraxillare gestaltet sich verschieden, und zwar bestehen drei Möglichkeiten:

1) Ein Axillar stellt sein Wachstum schon in einem sehr frühen Stadium ein, während der andere weiter wächst.

2) Beide Axillare wachsen eine Strecke mit gleicher Intensität; dann stellt der kleinere sein Wachstum allmählich ein, während der größere ohne Beschleunigung weiter wächst.

3) Beide Axillare wachsen mitgleicherstetiger Geschwindigkeit, ohnedaß einer sein Wachstum - wenigstens in dem fii r meine Untersuchungen in Betracht kommenden Stadium der Entwicklung - einstellt.

Der größere Kotyledonaraxillar zeigt also eine weitgehende Unabhängigkeit vom kleineren, die auch darin zum Ausdruck kommt, daß die Wachstumsintensität des größeren Axillars in allen drei Fällen gleich sein kann. Ich habe infolgedessen allein den größeren Axillar ins Auge gefaßt, wenn es sich um einen Wachstumsvergleich von Hauptsproß und Kotyledonaraxillaren handelt.

Ich wende mich nun den Versuchen selbst zu, indem ich den Verlauf des Wachstums nach dem Entgipsen des Hauptsprosses darstelle.

Hat der größere Kotyledonaraxillar die Länge des Hauptsprosses noch nicht erreicht, so ist ein wesentlicher Einfluß

1) Berthold, 1904, S. 2. 
desselben auf das Wachstum des Hauptsprosses ${ }^{1}$ nicht wahrzunehmen 2). Hat sich jedoch während der mechanischen Hemmung des Hauptsprosses das Längenverhältnis von Kotyledonaraxillar und Hauptsproß zugunsten des ersteren soweit verschoben, daß jener mindestens etwa dreimal so lang ist wiedieser, sowird das Wachstum des Kotyledonaraxillars nach dem Entgipsen vom Hauptsproß nicht mehr beeinflußt ${ }^{3}$ ). Im ersten Fall stellt der Kotyledonaraxillar sein Wachstum bald ein ${ }^{2}$, im zweiten der Hauptsproß $\left.{ }^{3}\right)$.

Ist der Kotyledonaraxillar beim Entgipsen länger als der Hauptsproß, ohne in seinem Längenverhältnis zu diesem die Grenze erreicht zu haben, wo sein Wachstum vom Entgipsen des Hauptsprosses unabhängig ist, so beeinflussen sich Hauptsproß und Kotyledonaraxillar gegenseitig, und zwar tritt der Einfluß des Hauptsprosses auf den Kotyledonaraxillar deutlicher zutage als der des Kotyledonaraxillars auf den Hauptsproß: Der Kotyledonaraxillar vermindertseine Wachstumsgeschwindigkeit mehr oder weniger rasch und stellt schließlich sein Wachstum ein, während der Hauptsproß zunächst mit steter, aber verminderter Wachstumsintensitätwei-

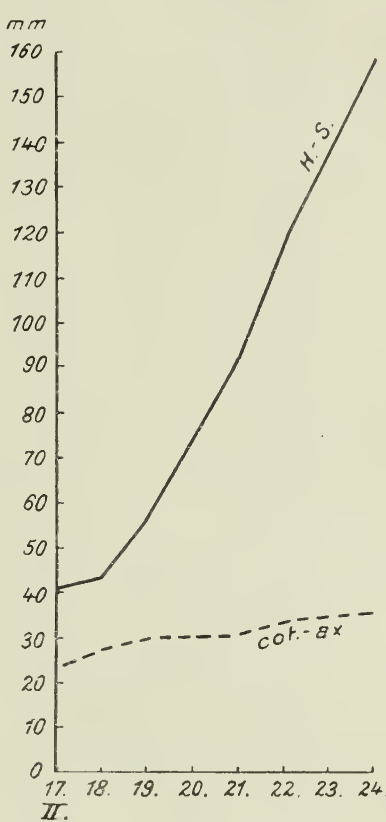

Fig. 1. Typus I.

Am 17. II. wurde der Hauptsproß entgipst. terwächst4). Nur in den Fällen, wo sich der Einfluß des Hauptsprosses auf den Kotyledonaraxillar und des Kotyledonaraxillars auf den Hauptsproß das Gleichgewichthält—das Längenverhältnis des Kotyledonaraxillars zum Hauptsproß ist in diesem Falle etwa $3: 1$ - stellt sowohl der Kotyledonaraxillar als auch der Hauptsproß sein

1) Pfeffer, 1893, S. $351 \mathrm{f}$.

2) Tab. II, Fig. $1=$ Typus $I$.

3) Tab. V, 1-3, Fig. $6=$ Typus IV.

4) Tab. III, Fig. $2-4=$ Typus II. Vgl. dazu Tab. II. 
Wachstum ein ${ }^{1}$. Falls die Pflanze nicht zugrunde geht, treibt dann die Axillarknospe des Primärblattes am Hauptsproß aus.

Der vom HauptsproB in seinem Wachstum gehemmte Kotyledonaraxillar stellt zwar nicht durchweg, doch im allgemeinen sein

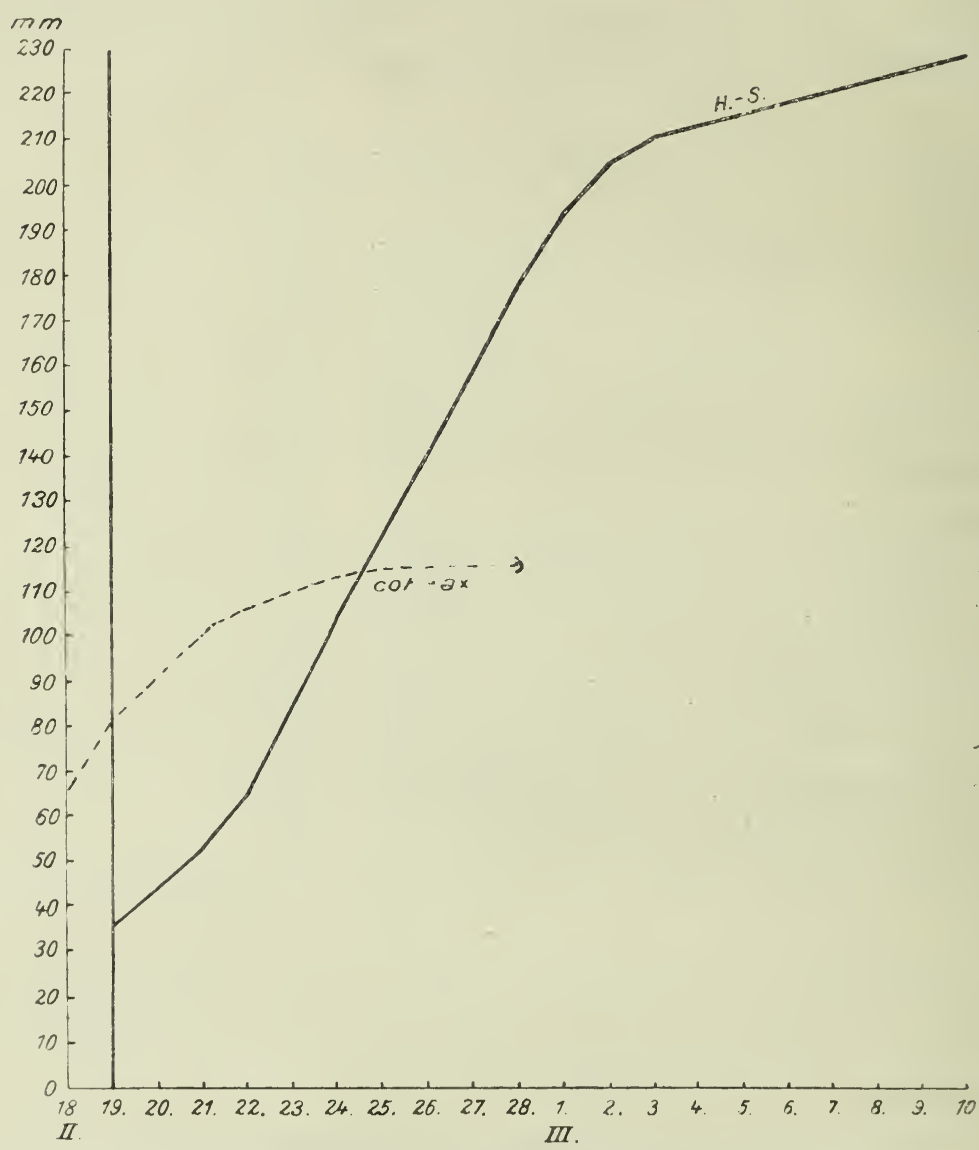

Fig. 2. Typus II a. Am 28. II. wurde der Kotyledonaraxillar entfernt.

Wachstum um so langsamer ein, je mehr er dem Hauptsproß an Länge überlegen ist 2 . Ist er bedeutend länger als dieser, so behält er zunächst die Wachstumsgeschwindigkeit bei, die er vor dem Entgipsen des Hauptsprosses hatte, und verlangsamt sie erst allmählich ${ }^{3}$ );

1) Tab. V, 4-6, Fig. 5 = Typus III.

2) Vgl. bes. Tab. III.

3) Fig. 3 und 4 = Typus II b. Vgl. auch Fig. 6 . 
Untersuchungen iiber Korrelationen von Knospen und Sprossen. 595 ist der Längenunterschied jedoch geringer, so beginnt er sofort sein Wachstum zu verlangsamen ${ }^{1}$ ).

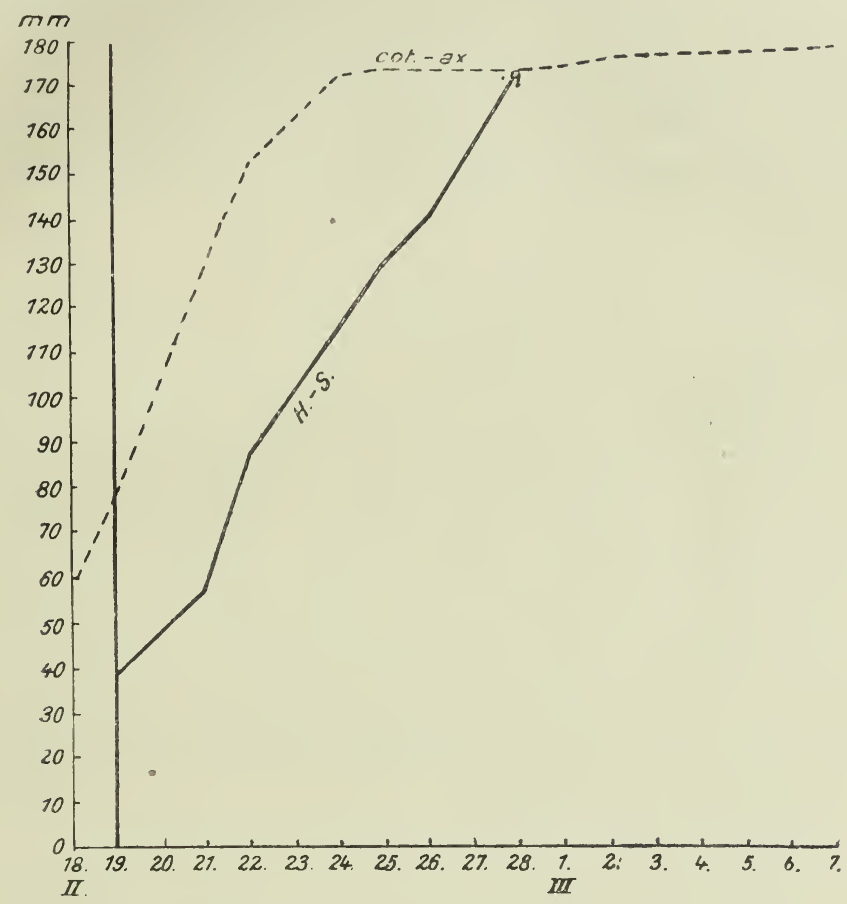

Fig. 3. Typus II b. Am 28. II. wurde der Hauptsproß entfernt.

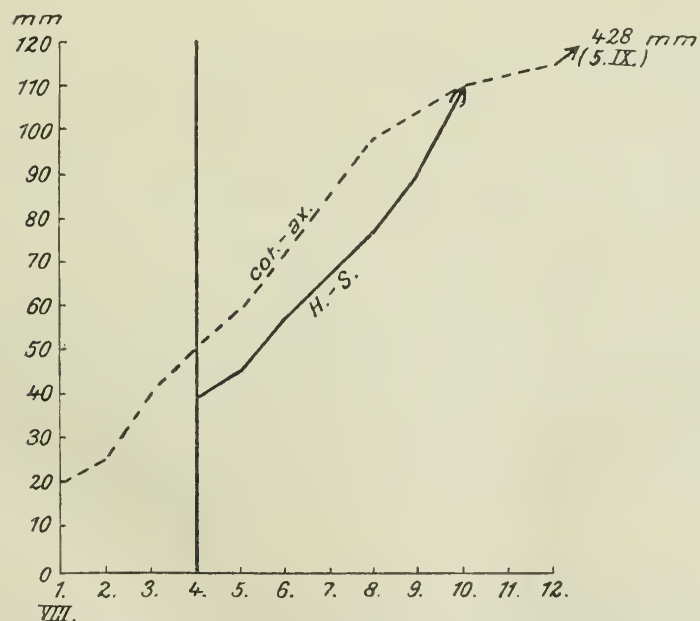

Fig. 4. Typus II b. Am 10. VIII. wurde der Hauptsproß entfernt.

1) Fig. 2 = Typus II a. 
Gleichviel ob die Pflanze nach dem Entgipsen des Hauptsprosses ihr Wachstum durch diesen oder durch einen Kotyledonaraxillar fortsetzt, beginnt der Hauptsproß zu wachsen, und zwar zunächst ziemlich langsam 1). Während er im letzteren Falle sein Wachstum sehr bald einstellt, beschleunigt er es in jenem Falle mehr oder minder rasch und erreicht nach 1-2 Tagen eine konstante Wachstumsintensität, die er dann beibehält ${ }^{2}$. Diese ist im allgemeinen umso

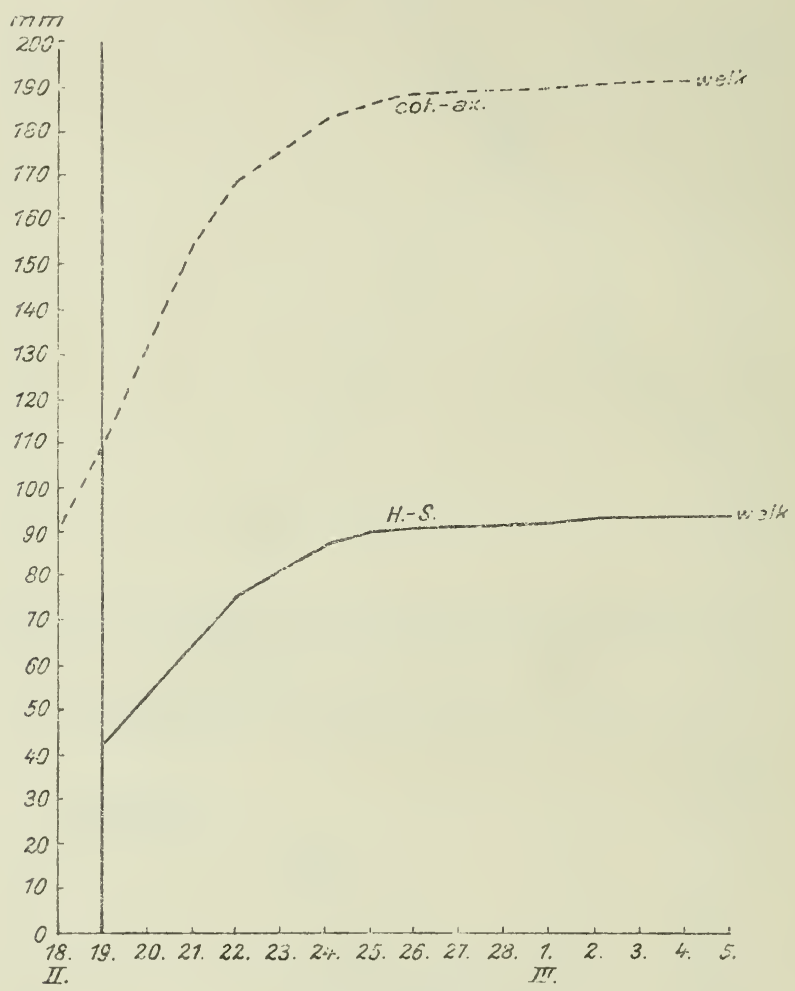

Fig. 5. Typus III.

höher, je früher der Kotyledonaraxillar aufhört zu wachsen ${ }^{3}$. Hat der Hauptsproß nach dem Entgipsen Stetigkeit in seiner Wachstumsintensität erreicht, so wird diese nicht erhöht, wenn der noch wachsende Kotyledonaraxillar entfernt wird, oder wenn dieser korrelativ sein Wachstum einstellt4). Die

1) Tab. II, III, V, Fig. 1-6.

2) Vgl. bes. Fig. 6, 1-4.

3) Vgl. Fig. 2 und 4 .

4) Fig. 2. 
Wachstumsgeschwindigkeit des Hauptsprosses, der eine Zeitlang mechanisch gehemmt war, wird also in einer frühen Phase seines wieder aufgenommenen Wachstums rom Wachstum des Kotyledonaraxillars vorausbestimmt. Dies gilt auch für die Fälle, wo das Wachstum des Hauptsprosses vom Kotyledonaraxillar unterdrückt wird, seine Wachstumsintensität also gleich Null ist. Schnitt ich bei solchen Pflanzen die Kotyledonaraxillare ab, nachdem der Hauptsproß sein Wachstum eingestellt hatte, so nahm dieser dasselbe nicht wieder auf ${ }^{1}$ ); tat ich dies jedoch noch vor Ablauf des ersten Tages nach dem Entgipsen des Hauptsprosses, so erhöhte dieser seine Wachstumsgeschwindigkeit und wuchs weiter. Ich wählte zu diesen Versuchen solche Pflanzen, wo der größere Kotyledonaraxillar mindestens viermal so lang war wie der Hauptsproß.

Nach dem Entgipsen nimmt also der Hauptsproß sein Wachstum auf jeden Fall zunächst wieder auf, und zwar ist sein Zuwachs in der ersten Zeit im großen und ganzen der gleiche, gleichviel ob der Kotyledonaraxillar sein späteres Wachstum nicht beeinflußt, oder dies bereits nach 24 Stunden zum Stillstand bringt.

Es handelt sich hierbei nicht nur um eine Spannung der Membranen, wie sie Pfeffer nach dem Entgipsen nachgewiesen hat ${ }^{2}$, sondern um tatsächliches Wachstum. Die Verlängerung durch Spannung beträgt am Sproß von Faba-Keimlingen nur 0,2-0,7 mm ${ }^{3}$, während ich bei meinen Versuchen eine Verlängerung von 8-21 mm feststellte ${ }^{4}$.

Die Übereinstimmung im Anklingen des Wachstums bei korrelativ in verschiedenem Grade beeinflußtem Hauptsproß zeigt, daß die erste Phase des Wachstums nach dem Entgipsen vom Kotyledonaraxillar unabhängig ist. Da der Hauptsproß in dieser Phase seine Wachstumsfähigkeit noch nicht verloren hat, auch wenn ihm der Kotyledonaraxillar an Länge bedeutend überlegen ist, geht ferner daraus hervor, daß ein im Wachstum mechanisch gehemmter Hauptsproß von dem wachsenden Kotyledonaraxillar während dieser erzwungenen Ruhe zum

1) Fig. 6. S. 599, Anm. 2.

2) Pfeffer, 1893, S. $315 \mathrm{ff}$.

3) Pfeffer, 1893, S. 378.

4) Außerdem markierte ich erst einige Zeit nach dem Entgipsen und stellte am nächsten oder iibernächsten Tage die Verlängerung der markierten Strecke fest. Eine solche fand allein in der wachstumsfähigen Zone statt. Vgl. hierzu die unter ${ }^{3}$ ) angegebene Stelle. 


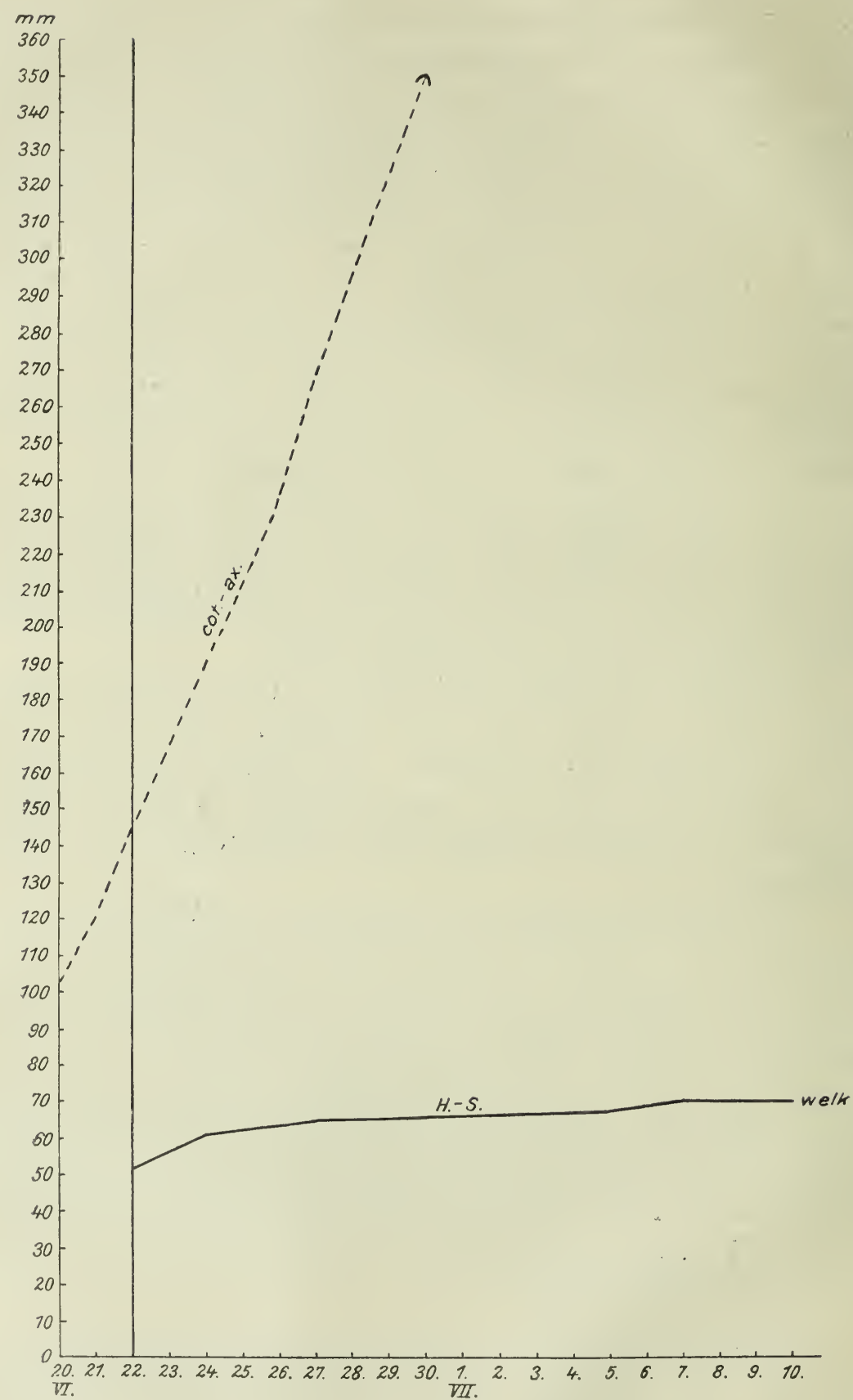

Fig. 6. Typus IV. $\Lambda \mathrm{m}$ 30. VI, wurde der Kotyledonaraxillar entfernt. 
mindesten in viel geringerem Maße abhängig ist, als ein wachsender Hauptsproß ${ }^{1}$ ).

Inbezug auf den Verlust des Wachstums verhalten sich die Kotyledonaraxillare, die nach dem Entgipsen des Hauptsprosses ihr Wachstum korrelativ einstellen, ähnlich wie der Hauptsproß. Haben sie aufgehört zu wachsen, so haben sie damit zugleich ihre Wachstumsfähigkeit verloren²), gleichviel ob der Hauptsproß weiter wächst oder abgeschnitten wird $\left.{ }^{3}\right)$. Wird der Hauptsproß jedoch in der Zeit entfernt, wo der Kotyledonaraxillar sein Wachstum allmählich verklingen läßt, so wird dessen Wachstumsgeschwindigkeit wieder erhöht4). Dies gilt ebenso für die Kotyledonaraxillare, die ihr Wachstum nach dem Entgipsen des Hauptsprosses unmittelbar mehr und mehr verlangsamen, als auch für solche, die zunächst noch eine Zeitlang die Wachstumsgeschwindigkeit beibehalten, die sie vor dem Entgipsen des Hauptsprosses hatten.

Ebenso wie die Wachstumsintensität - wobei der Stillstand des Wachstums als besonderer Fall einbegriffen ist wird auch die Wachstumsdauer des Hauptsprosses durch das Wachstum des Kotyledonaraxillars induzierend bestimmt: Nachdem der Hauptsproß Stetigkeit in seiner Wachstumsgeschwindigkeit erreicht hatte, entfernte ich den Kotyledonaraxillar, der nach dem Entgipsen des ersteren zunächst noch weiter gewachsen war. Der Hauptsproß wuchs anfangs mit gleicher Intensität, stellte jedoch nach einigen Tagen sein Wachstum ungewöhnlich früh ein ${ }^{5}$.

Wird nach dem Entgipsen das Wachstum eines Sprosses durch einen andern korrelativ unterdrückt, so entwickelt jener entweder noch einige Glieder, die aber nach der Spitze zu an Länge abnehmen, oder es wächst allein das oberste Glied mehr oder weniger aus, das sich beim Entgipsen bereits zu strecken begonnen hatte. Dieses ist der Fall beim Hauptsproß, wenn die Pflanze ihr Wachstum

1) Daher ist es an und für sich gleichguiltig, ob der Hauptsproß 8 oder 14 Tage eingegipst war. Die Zeit der mechanischen Hemmung ist im wesentlichen nur insofern von Bedeutung, als währenddessen einseitig die Axillare in ihrem Wachstum gefördert werden.

2) Bisweilen findet nach Einstellung des Wachstums noch eine geringc Dehnung statt, die jedoch so minimal ist - im Laufe von Tagen betrug sie nur wenige Millimeter -, daß ich sie hier völlig außer acht lassen kann und sie auch sonst nicht näher untersucht habe. Vgl. Fig. 1 und 6.

3) Fig. 3 und 5 .

4) Fig. 4 .

5) Fig. 2, Tab. III. 
durch einen Kotyledonaraxillar fortsetzt, oder beim Kotyledonaraxillar, wenn dieser sein Wachstum sehr bald einstellt ${ }^{1}$ ), jenes dagegen, wenn das Wachstum des korrelativ gehemmten Sprosses allmählich verklingt.

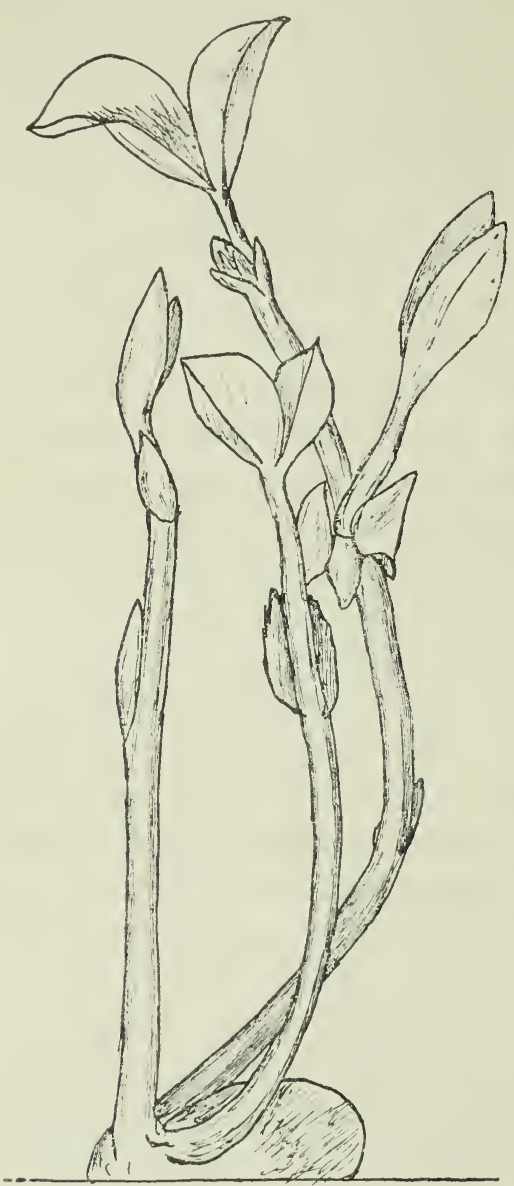

Fig. 7. Vicia Faba-Keimling nach 14 tägiger mecha. nischer Hemmung des etiolierten Hauptsprosses. Die $\Lambda$ xillare sind bei normaler Beleuchtung ausgetrieben und gewachsen.

Die definitive Ausbildung rückt in einem korrelativ gehemmten Sprosse unabhängig von dieser Verzögerung und Sistierung der Streckung vor ${ }^{2}$ ), sodaß die normalerweise zwischen der streckungsfähigen und ausgereiften Zone ${ }^{3}$ ) bestehende Entfernung immer geringer wird, bis sie schließlich gleich Null ist.

Die Reifung wird nach oben zu durch einen Knoten begrenzt, bis zu dem sich z. B. sämtliche Blätter wie an einer normal wachsenden Pflanze entfalten. Die noch unentfaltete Spitze oberhalb dieses Grenzknotens bleibt kümmerlich und hat ein krankes Aussehen.

Hatte ein Sproß sein Wachstum korrelativ eingestellt und damit seine Wachstumsfähigkeit verloren, so ging er vielfach nach einiger Zeit zugrunde; und zwar war es gleichguiltig, ob der hemmende Sproß noch mit dem gehemmten in organischem Zusammenhange stand, oder ob jener entfernt wurde.

Das Absterben erfolgt nicht wie bei Mangel an Nahrung'4) oder bei Wassermangel ${ }^{5}$ ) von der Basis nach

1) Fig. 7.

2) Hallbauer, S. $47 \mathrm{f}$, $54 \mathrm{f}$.

3) Berthold, 1904, S. 145.

4) Oder wenigstens in Fällen, wo man bisher Nahrungsmangel als das Wahrscheinlichste ansah. SAchs, 1863, S. 198; Vöchtung, 1891, S. 136; AMELUNG, S. 205 ff.; Jost, 1895, S. 441 ff.; Berthold, 1904, S. 185 f., 199, 237 f.

5) Berthold, 1904, S. 175. 
der Spitze hin, sondern umgekehrt. In der Regel wird der Sproß welk, und wird auch in einer feuchten Glocke nicht wieder turgeszent. In andern Fällen werden zuerst die Spreiten der obersten Blätter abgeworfen, an den Abwurfflächen bildet sich ein Kallus, dann werden die Blattstiele abgestoßen, und schließlich welkt der Sproß von der Spitze her.

Geht der korrelativ sistierte Sproß jedoch nicht zugrunde, so kann er ebenso wie ein ungehemmter Sproß Blïten ansetzen, sofern er nur eine gewisse Größe erreicht hat. -

Wenn der Hauptsproß durch sein Wachstum nach dem Entgipsen das Wachstum des Kotyledonaraxillars unterdriickt, so hat dies seine Ursache nicht etwa in einer kräftigeren Entwicklung des Hauptsprosses. Vielmehr sind die Kotyledonaraxillare im Bau sowie im Durchschnitt der Sproßachse bisweilen sogar kräftiger als der Hauptsproß. Desgleichen braucht die Anzahl der Glieder beim Hauptsproß nicht größer zu sein als beim Kotyledonaraxillar, damit jener allein weiterwächst ${ }^{1}$. - -

Um festzustellen, ob die Korrelationen zwischen Hauptsproß und Kotyledonaraxillar von der Assimilation abhängig sind, und insbesondere $o b$ und inwiefern eine erhöhte assimilatorische Tätigkeit eines Sprosses das gegenseitige Verhältnis von Hauptsproß und Kotyledonaraxillar beeinflußt, änderte ich die Versuche nach dem in Tabelle I angegebenen Schema ${ }^{2}$ ) ab. Es zeigte sich, daß die Assimilation ohne wesentliche Bedeutung für die Korrelationen zwischen Hauptsproß und Kotyledonaraxillar ist. Die Ergebnisse waren bei allen Modifikationen die gleichen. Am augenfälligsten ist die Bedeutungslosigkeit der Assimilation außer bei völlig etiolierten Pflanzen in den Fällen, wo der Hauptsproß im Dunkeln gekeimt ist und die Kotyledonaraxillare im Licht ausgetrieben sind. Der Hauptsprof wuchs ebenso, als ob auch die Axillare etioliert gewachsen seien, obwohl er erst allmählich nach dem Entgipsen zu ergriunen begann; und diese stellten ihr Wachstum ein, wenn sie nicht wenigstens dreimal so lang waren wie der Hauptsproß, obwohl ihr in der Assimilation bedingtes Übergewicht über den Hauptsproß noch dadurch erhöht wurde, daß sie ihre Blätter bereits entfaltet hatten, und daß sie nur ein schuppenförmiges Primär-

1) Tab. IV. Die Kotyledonaraxillare sind bei gleicher Gliederzahl mit dem Hauptsproß schon an und für sich lïnger als dieser, da besonders ihre untersten Glieder stairker gestreckt sind.

2) S. 591 . 
blatt tragen, das zweite Blatt also bereits normal ist, während dies beim Hauptsproß erst am dritten Knoten der Fall ist ${ }^{1}$ ).

Nur insofern zeigte sich ein Unterschied im Verhalten etiolierter und nichtetiolierter Axillare, als jene in ihrem Verhältnis zum Hauptsproß vielfach länger sein mußten, um dessen Wachstum zu sistłeren ${ }^{2}$ ). Dies ist offenbar darin mit bedingt, daß ein etiolierter Sproß mit gleichviel Internodien wie ein nichtetiolierter länger ist als dieser ${ }^{3}$ ), und der Zustand der beiden Sprosse, von dessen Unterschied ihr korrelatives Verhalten abhängig ist, nicht nur in ihrer Länge, sondern auch in der Anzahl ihrer Glieder zum Ausdruck kommt.

Daß auch die Transpiration auf die Gestaltung des korrelativen Wachstums von Hauptsproß und Kotyledonaraxillar im wesentlichen ohne Einfluß ist, geht schon daraus hervor, daß Kotyledonaraxillare, die vom Hauptsproß gehemmt werden, infolge der reichlicheren Belaubung stärker zu transpirieren vermögen als dieser, daß dies aber auch dann noch der Fall ist, wenn sie den Hauptsproß hemmen. Auch zeigten Pflanzen, bei denen durch Kultur im ziemlich dampfgesättigten Raume die Transpiration herabgesetzt war, die gleichen Erfolge wie solche, die unter normalen Bedingungen gehalten wurden ${ }^{4}$ ).

Um, zu untersuchen, ob die Ernährung der gesamten Pflanze das korrelative Verhältnis von Hauptsproß und Kotyledonaraxillar beeinflußt, etwa in dem Sinne, daß der Hauptsproß die dem gesamten Sproßsystem zukommende Nahrung reichlicher und leichter erlange als die Kotyledonaraxillare, schnitt ich kurz nach dem Entgipsen des Hauptsprosses die Kotyledonen ab. Obwohl meine Versuche nicht sehr zahlreich waren, geht daraus doch hervor, daß ein Entfernen der Kotyledonen die Korrelationen zwischen Hauptsproß und ausgetriebenen Kotyledonaraxillaren ebensowenig im Wesen beeinflußt5) wie nach den Versuchen Mc Callums ${ }^{6}$ ) die Korrelationen zwischen Hauptsproß und ruhenden Knospen der Kotyledonaraxillare.

1) Fig. 7.

2) Tab. III, 8-10.

3) S. 592.

4) Ganz ohne Einfluß ist auch bei Faba-Keimlingen weder Dunkelheit noch Feuchtigkeit auf die Sproßkorrelationen, doch tritt dieser Einfluß im Vergleich zu andern Fällen (Vöchting, 1893, S. 190 ff.; GoebeL, 1908, S. 128) völlig zurück. Phaseolus verhält sich hierin anders, indem bei etiolierten Pflanzen die Axillare leichter austreiben als bei belichteten.

5) Tab. II, 3 und 5.

6) Me Callum, S. $102 \mathrm{ff}$. 
Allerdings werden die Verhältnisse durch die allgemeine Schwächung der Pflanze ein wenig verschoben. Abgesehen davon, daß das Wachstum ganz allgemein bedeutend verlangsamt wird ${ }^{1}$, fand ich unter andern ein Sproßsystem, wo es zunächst schien, als ob der Kotyledonaraxillar sein Wachstum korrelativ einstellen, der Hauptsproß aber mit geschwächter Wachstumsintensität weiter wachsen wollte. Sowohl aus dem Verlauf des Wachstums während der ersten Tage als auch aus dem hohen Verhältnis von Hauptsproß zu Kotyledonaraxillar beim Entgipsen geht hervor, daß sich das Wachstum unter normalen Bedingungen so gestaltet hätte. Da jedoch die Kotyledonen entfernt wurden, stellten nach einigen Tagen beide Sprosse ihr Wachstum ein ${ }^{2}$ ). Man könnte meinen, dies habe seine Ursache in einem Mangel an den zum Weiterbau nötigen Stoffen. Dieser Anschauung stehen jedoch schon durch die reiche Entwicklung: des Wurzelsystems Bedenken entgegen. Vergleicht man außerdem mit diesem Fall andere Fälle $\left.{ }^{3}\right)$, wo die Kotyledonen an dem gleichen Tage entfernt wurden, und nur das Übergewicht des Hauptsprosses uiber den Kotyledonaraxillar bedeutend stärker war, der Haupt-

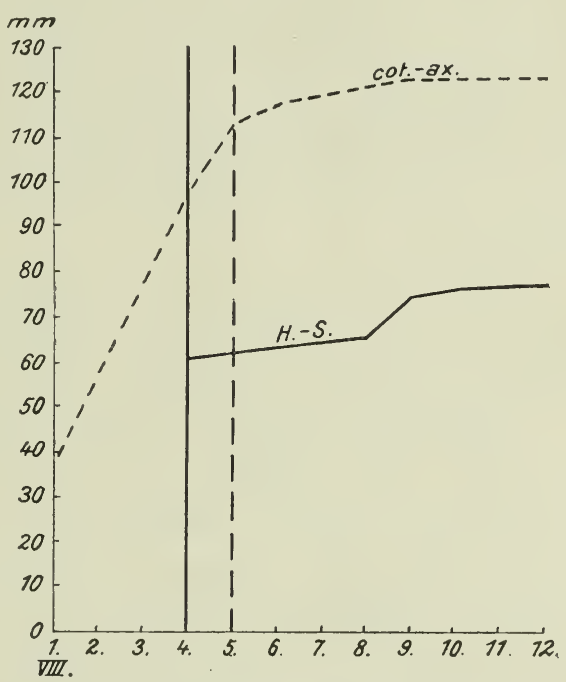

Fig. 8. Mischtypus nach Entfernung der Kotyledonen (am 5. VIII.). sproß sein Wachstum aber nicht einstellte, so folgt daraus, daß die Entfernung der Kotyledonen einen Mangel an den zum Weiterbau nötigen Materialien nicht bedingt, d. h. natürlich nur bei dem hier in Frage kommenden Entwicklnngsstadium der Pflanze. Das Verhalten der Sprosse in dem erwähnten Fall ${ }^{2}$ ) ist vielmehr in einer größeren Empfindlichkeit des Hauptsprosses gegenüber dem Einfluß des Kotyledonaraxillars begründet, und diese Empfindlichkeit ihrerseits in einer Schwächung der gesamten Pflanze, wie sie aus der Entfernung der Kotyledonen folgt.

1) Vgl. Tab. II, 3 und 5. SAchs, 1859 (1892, S. 5.97).

2 Fig. 8, Tab. V, $7 . \quad 3$ ) Tab. II, 3 und 5. 
Die Korrelationen zwischen Hauptsproß und Primärblattaxillar gestalten sich nach zeitweiser mechanischer Hemmung des Hauptsprosses im wesentlichen ähnlich.

Ich gipste Keimlinge oberhalb des ersten Primärblattes ein $\left.{ }^{1}\right)$ und regte so die Axillarknospe desselben zum Wachstum an, nachdem ich vorher die Kotyledonarknospen entfernt hatte, um eine etwaige Beeinflussung der Primärblattaxillare durch das Austreiben jener zu vermeiden.

Die Keimlinge, die ich zu diesen Versuchen verwandte, waren von den Kotyledonen bis zum obersten Knoten 60 bis $70 \mathrm{~mm}$ lang. Die Zone vom ersten Primärblatt bis zur unteren Fläche des Gipsverbandes betrug etwa $15 \mathrm{~mm}$, damit der Primärblattaxillar nicht in Raume behindert würde. Waren die Keimlinge kleiner, so befand sich die Zone der größten Streckung leicht noch unterhalb des Gipses. Infolge der Streckung krïmmte sich dann der Hauptsproß und zog auf diese Weise die eingegipsten Teile allmählich aus dem Gipsverband. Dadurch wurde zunïchst der Primärblattaxillar im Wachstum bedeutend gehemmt. Mit der Zeit buißte jedoch auch der Hauptsproß seine Wachstumsfähigkeit ein.

Den Axillar des ersten Primärblattes ließ ich wachsen, bis seine Länge die des Hauptsprosses oberhalb des ersten Primärblattes um etwa $100-200 \%{ }^{2}$ ) uibertraf, und entgipste dann den Hauptsproß.

Nach dem Entgipsen stellten sich Hauptsproß und Axillar etwa parallel ${ }^{3}$. Der Hauptsproß nahm sein Wachstum wieder auf und verlangsamte dadurch das Wachstum des Primärblattaxillars. Doch wurde auch sein Wachstum von diesem bedeutend verzögert. Bald setzte die Pflanze ihr Wachstum durch den Hauptsproß fort, während das Wachstum des Primärblattaxillars sistiert wurde, bald verhielt sie sich umgekehrt. In letzterem Falle wurde der Hauptsproß nach einigen Tagen vom Primärblattaxillar seitlich verdrängt und stellte darauf sein Wachstum ziemlich plötzlich ein.

An Verzweigungssystemen von Bäumen hat Vöchisivat) gefunden, daß ein Seitentrieb dadurch, daß er den Endtrieb seitlich verdrängt, ein intensiveres Hemmungsvermögen erlangt. Da in dem vorliegenden Fall von Vicia der Hauptsproß ziemlich intensiv wächst, bis er seitlich verdrängt wird, dann aber sein Wachstum fast plötzlich einstellt, scheint auch hier die gleiche Regel zu gelten.

1) Nach Methode a (S. 587).

2) Bei einem Vergleich mit dem ersten Primärblattaxillar habe ich den Hauptsproß nur vom ersten Primärblatt an gemessen, da das darunter befindliche Glied beiden Sprossen gemeinsarn ist.

3) Dekapitiert man den Hauptsproß oberhalb des ersten Primärblattes, so stellt sich der Primairblattaxillar in der Richtung der Hauptachse ein, indem er den Stummel derselben oberhalb des Primärblattes seitlich verdrängt.

4) Vöсhting, 1884, S. 54 ff. Vgl. auch Vöchting, 1884, S. 59. 
Natïrlich is,t die Verschiebung des Primärblattaxillarwinkels zur Hauptachse erst die Folge des korrelativen Übergewichts des Primärblattaxillars, d. h. nur ein

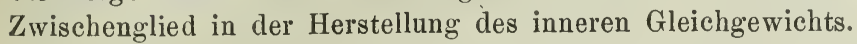

Während die Korrelationen zwischen Hauptsproß und Kotyledonaraxillar von dem Längenverhältnis der beiden Sprosse in hohem Grade abhängig zu sein scheinen, sodaß sie sich je nach diesem ziemlich regelmäßig gestalten, ist dies bei den Korrelationen zwischen Hauptsproß und Primärblattaxillar nicht der Fall.

Dasselbe gilt von den Korrelationen zwischen verschiedenen Axillaren.

Wird der Hauptsproß in beliebiger Höhe dekapitiert, so treiben meist mehrere Axillare aus; doch wächst der Keimling in der Regel schließlich allein durch den Primärblattaxillar weiter, während die übrigen Sprosse ihr Wachstum einstellen. Der Primärblattaxillar ist also derjenige Sproß, der nächst dem Hauptsproß in seinem Wachstum am wenigsten korrelativ gehemmt wird.

Ich habe mich bei

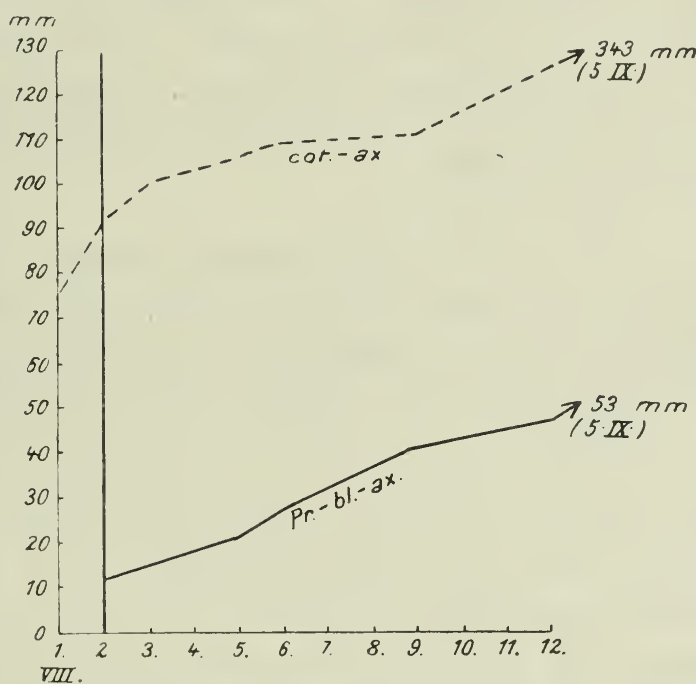

Fig. 9. Der Kotyledonaraxillar nimmt sein Wachstum wieder auf, nachdem er es korrelativ eingestellt hat. Vom 9.-12. VIII. wurde nicht gemessen; infolgedessen ist die Kurve in der Zwischenzeit nicht genau.

meinen Versuchen auf die Korrelationen zwischen dem Primärblattaxillar und den Kotyledonaraxillaren beschränkt.

Dekapitiert man Keimlinge über dem ersten Primärblatt, so beginnen häufig zunächst die Kotyledonaraxillare zu wachsen, bald jedoch setzt das Wachstum des Primärblattaxillars ein. Durch diese Zeitfolge des Austreibens steht der Primärblattaxillar in seiner Entwicklung zunächst hinter dem Kotyledonaraxillar zurück, und es wird so auf natürliche Weise ein Erfolg erzielt, der einem zeitweisen Eingipsen des korrelativ überlegenen Sprosses im wesentlichen gleichkommt: Primärblattaxillar und Kotyledonaraxillar beeinflussen sich gegenseitig. Verhältnismäßig selten kommt es vor, daß das Wachs- 
tum des Primärblattaxillars sistiert wird, während die Kotyledonaraxillare weiter wachsen; in solchen Fällen sind meist beide Kotyledonaraxillare gleich stark entwickelt $\left.{ }^{1}\right)$. In der Regel stellen die Kotyledonaraxillare ihr Wachstum ein, während der Primärblattaxillar weiter wächst.

Überließ ich über dem ersten Primärblatt dekapitierte Pflanzen zunächst sich selbst (6 Tage), bis der Primärblattaxillar begonnen hatte zu wachsen, und etwa 10-20 mm lang war, und gipste diesen dann für 7-14 Tage ein, so waren die Verhältnisse nach dem Entgipsen im wesentlichen die gleichen, nur daß naturgemäß solche Fälle häufiger waren, wo der Primärblattaxillar sein Wachstum einstellte und ein Kotyledonaraxillar allein weiter wuchs ${ }^{2}$ ).

$\mathrm{Da}$ bei der geringen Größe dieser Axillare auch die Basis derselben sehr intensiv wächst, mußte ich den Primärblattaxillar mitsamt der Hauptachse, der er entwuchs, eingipsen, da er sich sonst infolge seines basalen Wachstums aus dem Gipsverband zog.

Waren die Kotyledonaraxillare bereits vor dem Eingipsen ausgetrieben, so begann der Primärblattaxillar nach dem Entgipsen im allgemeinen etwas langsamer zu wachsen, als wenn dies nicht der Fall war; tiefere Unterschiede zeigten sich hierbei nicht.

Hatte ich den Primärblattaxillar dekapitierter Keimlinge nicht eingegipst, so behielt derjenige Sproß, der sein Wachstum korrelativ eingestellt hatte, in der Regel noch einige Zeit seine Wachstumsfähigkeit. Das gleiche gilt bei den Korrelationen zwischenden beiden Kotyledonaraxillaren, wenn der Hauptsproß unmittelbar über den Kotyledonen entfernt wurde. Hatte ich jedoch den Primärblattaxillar dekapitierter Keimlinge einige Zeit mechanisch gehemmt, so verhielten sich die Axillare nach dem Entgipsen inbezug. auf den Verlust ihrer Wachstumsfähigkeit scheinbar durchaus willkürlich: Bald behielt der sistierte Sproß zunächst noch seine Wachstumsfähigkeit, sodaß in Fällen, wo beide Sprosse ihr Wachstum korrelativ eingestellt hatten, der eine nach einiger Zeit dasselbe wieder aufnahm ${ }^{2}$ ); bald verlor der Sprol seine Wachatumsfähigkeit mit dem korrelativen Einstellen des Wachstums und ging unter Umständen in der oben dargestellten Weise ${ }^{3}$ ) zugrunde; hatten

1) Diese haben dann teilweise keine Primiirblätter, sondern an deren Stelle. anormal ansgebildete (unsymmetrische) Laubblïtter.

2) Fig. 9 .

3) S. $600 \mathrm{f}$. 
beide Sprosse ihr Wachstum korrelativ eingestellt, so begann in solchen Fällen keiner derselben wieder zu wachsen.

Von besonderer Bedeutung sind zwei Fälle, wo die Kotyledonaraxillare beim Entgipsen des Primärblattaxillars oder am Tage nach dem Entgipsen abgeschnitten wurden, und der Primärblattaxillar gleichwohl nur sehr langsam wuchs und sein Wachstum bald einstellte. Es geht daraus hervor, daß Sprosse von andern wachsenden Sprossen auch dann korrelativ bee influßtwerden können, wenn siemechanisch am Wachstum gehemmt sind.

Während sich bei den Versuchen uiber die Korrelationen zwischen Hauptsproß und Kotyledonaraxillar regelmäßig bald nach dem Entgipseu des ersteren an einem Sprosse oder auch an beiden eine Verlangsamung des Wachstums bemerkbar machte, war das bei den Korrelationen zwischen Primärblattaxillar und Kotyledonaraxillar mit der gleichen Regelmäßig-

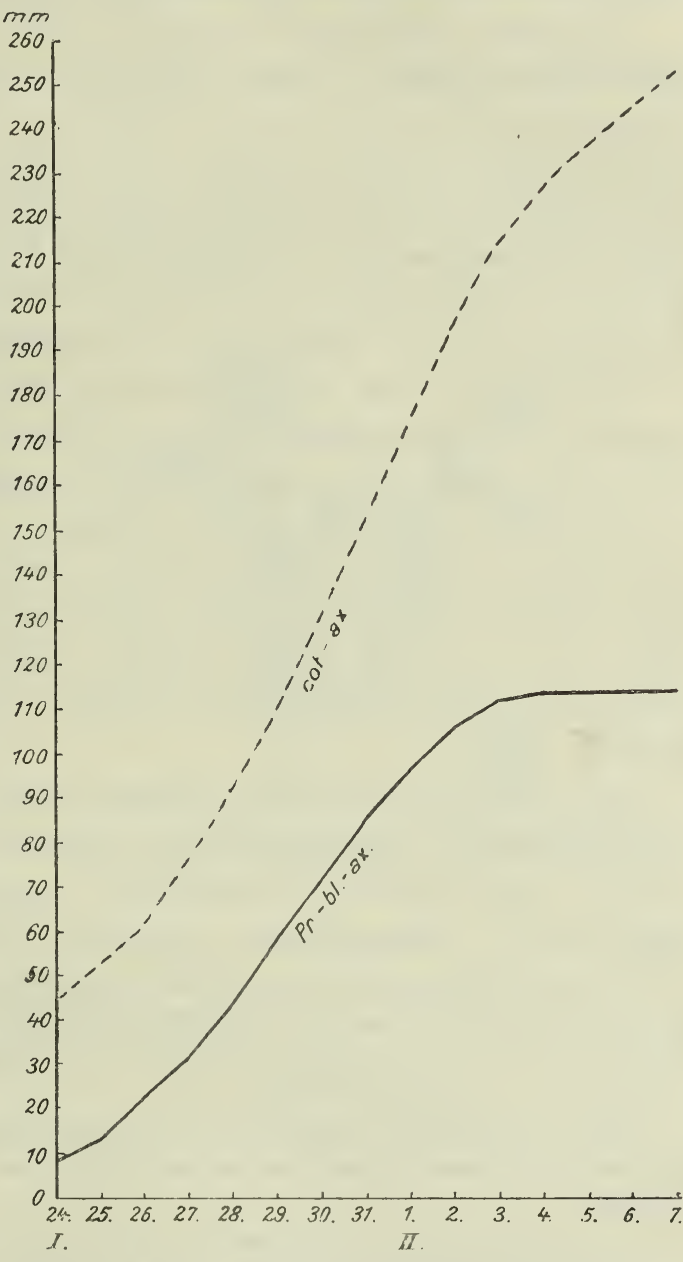

Fig. 10. Typus V. Der Primärblattaxillar wurde am 24. I. entgipst.

keit nicht der Fall. Vielmehr wuchsen hier öfter beide Axillare eine Reihe von Tagen mit konstanter Intensität, ehe der eine sein Wachstum verlangsamte ${ }^{1}$ ), ebenso wie dies auch die beiden Kotyledonaraxillare häufig tun, wenn der Keimling über den Kotyledonen dekapitiert ist.

1) Fig. 10. 


\section{Phaseolus multiflorus.}

Zur Ergänzung der bei Vicia Faba gewonnenen Ergebnisse wurden die wichtigsten der Versuche mit Phaseolus multiflorus wiederholt. Und zwar wurden diese Versuche bei Tageslicht ausgeführt.

Phaseolus multiflorus ist wie Vicia Faba monopodial gebaut. In jugendlichen Stadien wächst allein die Hauptachse, während die Nebenachsen im Knospenzustand verharren. In seltenen Fällen treiben die Kotyledonaraxillare spontan aus ${ }^{1}$, doch stellen diese ibr Wachstụm regelmäßig infolge der Hemmung durch den wachsenden Hauptsproß bald wieder ein. Häufiger als bei Vicia Faba treiben auch die Axillare der Primärblätter spontan aus, bisweilen überflügeln sie dann den Hauptsproß und sistieren sein Wachstum.

Dekapitiert man junge Keimlinge ïber den Primärblättern, so wachsen die Primärblattaxillare aus, während die Kotyledonaraxillare sich in der Regel iuberhaupt nicht entwickeln.

Entfernte ich jedoch die Primärblätter, so trieben bei etwa $70^{\prime}{ }_{i 0}$ gleichzeitig mit den Primärblattaxillaren die Kotyledonaraxillare aus. Doch stellten diese bald ihr Wachstum korrelativ ein, wenn sie eine Länge von $3-15 \mathrm{~cm}$ erreicht hatten. Nur in einem einzigen Falle beobachtete ich einen Kotyledonaraxillar, der den Primärblattaxillar sistierte.

Es läßt sich also bei Phaseolus durch das Abschneiden der Primärblätter im wesentlichen der gleiche Erfolg erzielen, wie er sich bei Faba mit ihren rudimentären Primärblättern nach dem Dekapitieren des Hauptsprosses von selbst einstellt ${ }^{2}$.

Um zu untersuchen, ob etwa die assimilatorische Tätigkeit der Primärblätter die Primärblattaxillare gegenüber den Kotyledonaraxillaren begünstigt, wiederholte ich die Versuche im Dunkeln. Der Erfolg war jedoch der gleiche wie bei den belichteten Pflanzen.

Auch scheint die Transpiration der Primärblätter ohne Bedeutung zu sein, wie ich bei Pflanzen feststellte, die ich in ziemlich dampfgesättigter Luft kultivierte.

Setzte nach dem Dekapitieren nur ein Primärblattaxillar das Wachstum des Hauptsprosses fort, so wurde das Primärblatt zuerst abgestoßen, dessen Winkel der Axillar entwuchs ${ }^{3}$.

Hatte ich den Hauptsproß von Phaseolus-Keimlingen zeitweise eingegipst, so schienen die Pflanzen nach dem Entgipsen in der

1) Mc Callum, S. 101.

2) S. 605 .

3) Über die Bedeutung der Axillarknospen für die Lebensdaner der Blätter, in deren Achseln sie sitzen, vgl. Berthold, 1904, S. 200. 
Regel völlig gesund; doch vertrockneten vielfach nach 1-2 Tagen die zarten Primärblätter. Indes blieb die Plumula fürs erste stets gesund, und wenn beim Entgipsen des Hauptsprosses die Kotyledonaraxillare entfernt wurden, so nahm jener regelmäßig sein Wachstum wieder auf, gleichgültig ob die Primärblätter vertrocknet waren oder nicht.

Die von mir verwandten Bohnen neigten zur Bildung verbänderter Kotyledonaraxillare ${ }^{1}$ ).

Gipste ich den Hauptsproß in einem ziemlich jungen Stadium ein ${ }^{2}$ ), ehe sich das epikotyle Glied noch aus seiner Krümmung gestreckt hatte ${ }^{3}$, so wuchsen die Axillare - in ihren basalen Regionen wenigstens - meist verbändert, sodaß jeder der beiden Kotyledonaraxillare sich aus einer Gesellschaft von Sprossen zusammensetzte. Im Laufe der weiteren Entwicklung löste sich die Verbänderung meist früher oder später ${ }^{4}$ ), und bei einer jeden einem Kotyledonaraxillar entsprechenden Sproßgesellschaft wurden die meisten Sprosse kor-

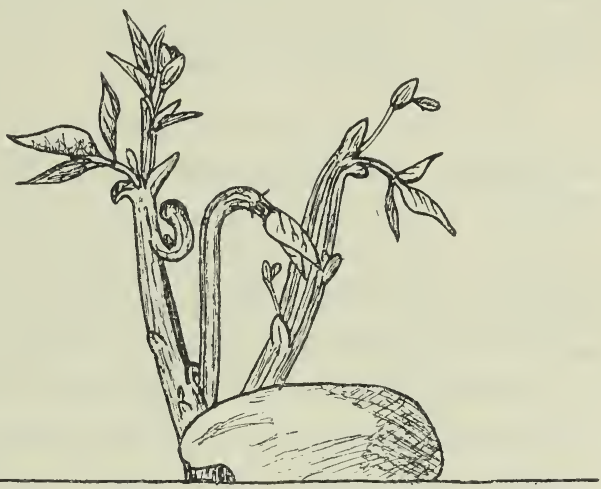

Fig. 11. Phascolus multiflorus mit künstlich retardiertem Hauptsproß und verbänderten Kotyledonaraxillaren.

relativ sistiert oder ihr Wachstum verlangsamt. In der Regel wuchsen an einem Kotyledonaraxillar ein oder zwei Sprosse weiter. Doch kam es auch vor, daß sämtliche Sprosse ihr Wachstum einstellten und eine Achselknospe auszutreiben begann.

Die Neigung zur Bildung verbänderter Axillare besaßen die von mir verwandten Bohnen auch in den Achselknospen der Primärblätter, wenn auch hier nicht so häufig. Vor allem aber löste sich die Verbänderung der Primärblattaxillare stets sehr bald auf, dergestalt, daß jeder Axillar durch einen einzigen,

1) Fig. 11.

2) Abschneiden des Hauptsprosses hat bekanntlich den gleichen Erfolg. SACHS, 1859, S. 87; Goebel, 1898, S. 158; Loprione, S. 396 f.

3) Es war also durchaus nicht nötig, daß sich die Plumula noch zwischen den Kotyledonen befand, wie dies SACHS (1859, S. 87; LOPRIORE, S. 397) angibt; wohl aber wurde die Verbänderung um so ausgesprochener, je jünger der inaktivierte Hauptsproß war.

4) LOPRIORE, S. 311. 
seine Nebenknospen schon vor dem Austreiben hemmenden Sproß dargestellt wurde.

In der Beblätterung zeigen verbänderte Axillare tiefgreifende Unterschiede von nichtverbänderten. Das erste Glied des Hauptsprosses von Phascolus multiflorus trïgt bekanntlich zwei einfache herzförmige Primärblätter. Die höheren Glieder tragen dreizählige Blätter. Unverbänderte Kotyledonaraxillare haben zwischen den dreizähligen Blättern und den Kotyledonen nur e in Primärblatt, das in der Gestalt ein wenig von denen des Hauptsprosses abweicht, bisweilen auch Neigung zur Zwei- bis Dreilappigkeit zeigt. Die verbänderten Axillare hingegen tragen am basalen T'eil eine ziemliche Anzahl von Schuppenblïttern, und über diesen sogleich dreizählige normale Blätter. Blätter von der Gestalt der Primärblätter des Hauptsprosses fand ich an verbänderten Axillaren nie ${ }^{1}$.

Die spontan austreibenden Kotyledonaraxillare waren nie verbändert. Und wenn die Anzahl der Fälle mit spontan austreibenden Kotyledonaraxillaren auch sehr gering war ${ }^{2}$ ), kann man hierbei doch das Fehlen der Verbünderung als Regel ansehen, da verbänderte Axillare nach Entfernung des Hauptsprosses bei weitem in der Überzahl waren.

Auch bei Phaseolus gestalteten sich Korrelationen zwischen dem Hauptsproß und den Axillaren in der Hauptsache denen bei Faba ähnlich, wenn ich die Axillare durch zeitweises Eingipsen des Hauptsprosses zum Wachsen gebracht hatte: Hauptsproß und Axillare hemmten ihr Wachstum gegenseitig; der Einfluß des Hauptsprosses auf die Axillare war stärker als umgekehrt, und zwar trat dies bei den Korrelationen von Hauptsproß und Kotyledonaraxillaren augenscheinlicher zutage, als bei den Korrelationen von Hauptsproß und Primärblattaxillaren, wenn auch nicht in gleichem Maße und so allgemein wie bei Faba.

Daß der Hauptsproß allein das Wachstum der Pflanze fortsetzt, tritt bei ausgetriebenen Primärblattaxillaren in der Regel schon dann nicht mehr ein, wenn die Primärblattaxillare noch nicht die doppelte Länge des Hauptsprosses erreicht haben. Sind die Kotyledonaraxillare ausgetrieben, liegen die Verhältnisse ähnlich, doch kann es bisweilen vorkommen, daß der Hauptsproß das Wachstum der Pflanze auch dann noch fortsetzt, wenn er bedeutend kleiner ist als die Kotyledonaraxillare (41 mm : $315 \mathrm{~mm}$ ).

Die korrelative Hemmung äußert sich in verzögertem Wachstum und ungewöhnlich frühem Verklingen desselben. Bei einer großen Anzahl von Versuchen stellten sowohl der Hauptsproß wie die. Axillare

1) Infolge des verschieden raschen Wachstums der einzelnen Verbandsindividuen bestehen in den Verbänden große Spannungsdifferenzen, was in häufigem Zerreißen und Aufrollen der Gewebeteile zum Ausdruck kommt. Fig. 11. Vgl. SACHS, 185̃9, S. 76; Lopriore, S. 396.

2) S. 608 . 
ihr Wachstum ein. Da jedoch ein Sproß, dessen Wachstum korrelativ verklungen ist, bei Phaseolus seine Wachstumsfähigkeit länger behält als bei Faba, so nimmt bisweilen einer der sistierten Sprosse sein Wachstum wieder auf; doch kommt es auch vor, daß ein solcher Sproß, nachdem er sein Wachstum wieder aufgenommen hat, von einer neuaustreibenden Axillarknospe abermals sistiert wird.

Hat ein Sproß seine Wachstumsfähigkeit infolge korrelativer Hemmung eingebüßt, so tritt dies bei Phaseolus augenscheinlicher noch zutage als bei $F a b a$, insofern als ein korrelativ wachstumsunfähig gewordener Sprob seine Spitze und oft auch noch einige tiefer liegende Glieder abstößt.

Es handelt sich hier um einen Vorgang, der in der Erscheinung dem Zweigspitzenabwurf ${ }^{1}$ ) unserer Laubbäume gleicht.

\section{Lathyrus odoratus.}

Den bisher dargestellten Untersuchungen an Papilionaceenkeimlingen will ich eine Beobachtung noch anfügen, die ich im Frühjahr 1912 an jungen Pflanzen der Gartenwicke ${ }^{2}$ ) machte.

Fast regelmäßig trieb hier der Axillar eines Primärblattes spontan aus. Dieser sowie der Hauptsproß wuchsen zunächst beide bis zu beträchtlicher Länge; dann ging der eine der beiden Sprosse - in ähnlicher Weise wie dies wachstumsunfähig gewordene Sprosse von Faba taten - zugrunde, indem er zunächst bleichte und dann von der Spitze her welkte; meist war dies der Hauptsproß. Der andere Sproß wuchs weiter.

\section{Untersuchungen an monopodialen Zweigsystemen von Coniferen.}

1. Torreya nucifera.

Die Untersuchungen wurden an einem weiblichen Baum im Botanischen Garten zu Leipzig angestellt, der frei stand, und zwar sämtlich an der südlichen Hälfte des Baumes, damit Unterschiede in den Ergebnissen infolge der Verschiedenheit äußerer Einflüsse wie Licht und Wind, ausgeschlossen würden.

Das Verzweigungssystem von Torreya ist so gebaut, daß an der Spitze eines jeden Zweiges drei Knospen sitzen, deren mittlere sich zum Haupttrieb entwickelt, während die beiden seitlichen die kürzeren Seitentriebe bilden. Diese sind fast stets gleich lang oder doch nur

1) Goebel, 1898, S. 179; Pfeffer, 1904, S. 203.

2) Eckfords neue Hybriden. 
um wenige Millimeter verschieden. Tiefer am Mutterzweige werden nur selten Knospen angelegt, und zwar meist infolge irgendwelcher äußeren Eingriffe; sie entfalten sich in der Regel erst viel später als die normalen Knospen.

Die Blüten befinden sich meist an den jungen Seitenzweigen, seltener an diesen und am Endzweig ${ }^{1}$ ).

Beim Austreiben im Frühjahr schwellen zunächst die fertilen Knospen und entfalten ihre Triebe. Etwa 14 Tage später treiben die sterilen Knospen aus. Sowohl das Austreiben der fertilen einer-

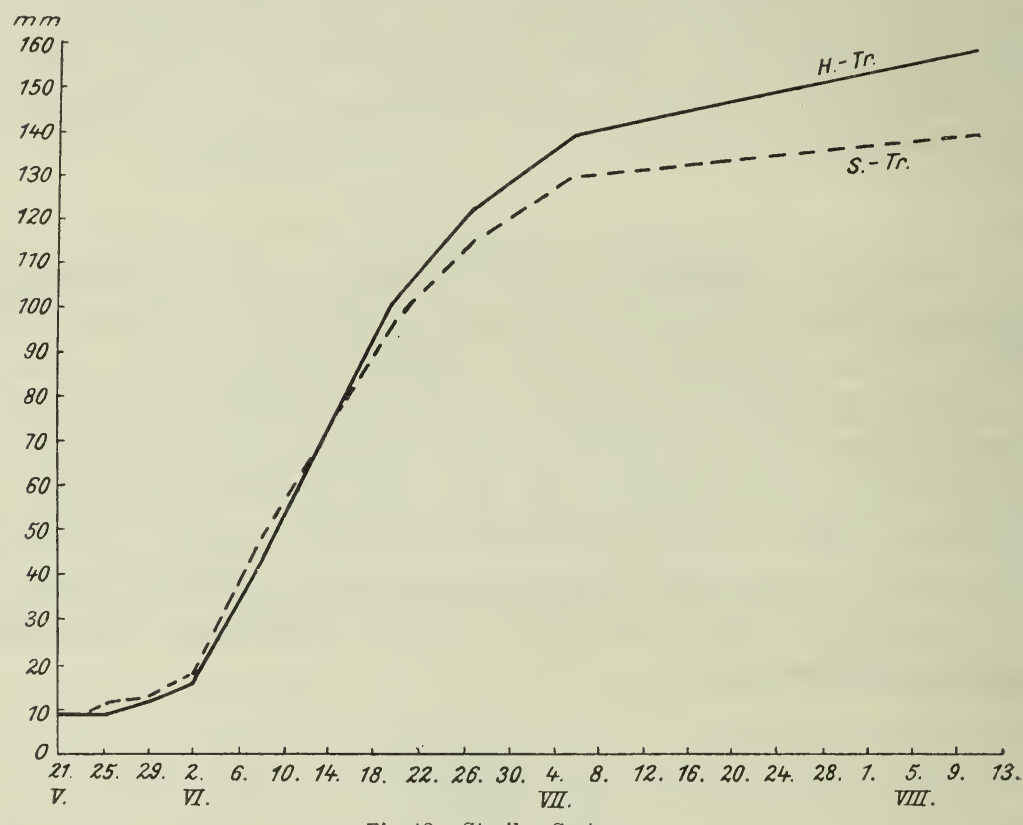

Fig. 12. Steriles System.

seits wie auch der sterilen Knospen anderseits, erfolgt am ganzen Baum etwa gleichzeitig, gleichviel ob die Knospen eines Mutterzweiges gleichartig sind, d. h. sämtlich fertil oder sämtlich steril, oder ob die Endknospe steril, die Seitenknospen fertil sind 2). Doch treiben die Endknospen meist ein klein wenig später aus als gleichartige Seitenknospen. Die Wachstumsgeschwindigkeit des Endtriebes ist der gleichartiger Seitentriebe gleich oder nur ein wenig intensiver. Doch stellen die Seitentriebe ihr Wachstum früher ein $\left.{ }^{3}\right)$. Bei fertilen

1) Engler-Prantl, Bd. 2. I. (1889.) S. 112.

2) Sind die Endknospen fertil, so sind es auch stets die Seitenknospen.

3) Fig. 12. 
Trieben ist die Wachstumsgeschwindigkeit ebenso wie die Wachstumsdauer geringer als bei entsprechenden ${ }^{1}$ ) sterilen Trieben; sie bleiben infolgedessen kürzer als diese ${ }^{2}$ ).

Um zu untersuchen, ob und inwieweit die Knospen eines Systems während des Austreibens einander normalerweise korrelativ beeinflussen, entfernte ich vor dem Austreiben die Endknospe oder beide Seitenknospen oder eine Seitenknospe oder die Endknospe und eine Seitenknospe, und verglich das Wachstum der zurückbleibenden Knospen mit dem Wachstum entsprechender Knospen an unverletzten Systemen. Außerdem wurde das Wachstum entsprechender Triebe bei verschiedenartigen Systemen verglichen.

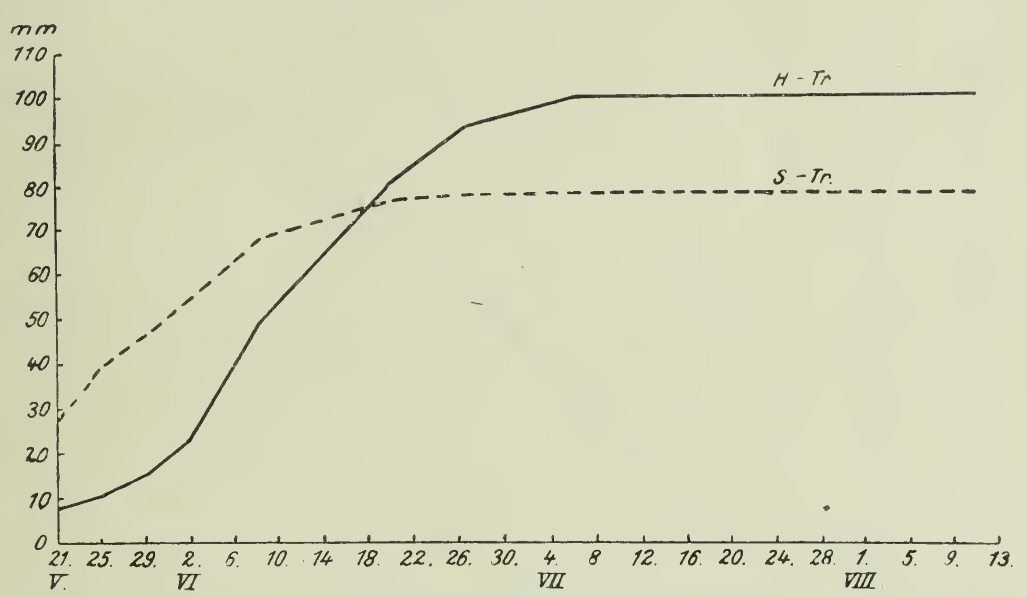

Fig. 13. Gemischtes System.

Die Ergebnisse sind folgende:

Die Richtung der Triebe wird weder durch Entfernung der Endknospe allein, noch durch Entfernung der Endknospe und einer Seitenknospe geändert; sie-ist vor dem Austreiben fixiert.

Sterile Triebe sind ohne Einfluß auf das Wachstum der übrigen Triebe des gleichen Systems.

Fertile Triebe hemmen das Wachstum der übrigen Triebe; und zwar tritt dies am deutlichsten bei gemischten Systemen zutage, wo sowohl die Wachstumsgeschwindigkeit als auch die Wachstumsdauer des sterilen Endtriebes vermindert wird. So erreichte der Endtrieb eines sterilen Systems 117,5 mm, während der sterile Endtrieb von (sechs)

1) Entsprechend sind einerseits Endtriebe, anderseits Seitentriebe.

2) Vgl. Fig. 12 und 13. 
Systemen mit fertilen Seitentrieben im Durchschnitt nur $72 \mathrm{~mm}$ lang war, der längste Endtrieb dieser sechs Systeme $89 \mathrm{~mm} 1$ ).

Weniger werden die fertilen Triebe in ihrem Wachstum beeinflußt. Wird von einem Paar fertiler Seitenknospen die eine entfernt, so wird der Trieb der andern im allgemeinen ein wenig länger, als wenn jene nicht entfernt würde. Doch ist dieser Unterschied sehr gering. Deutlicher ist der Einfluß eines fertilen Endtriebes auf die fertilen Seitentriebe, obwohl auch dieser nicht so ausgesprochen ist wie der fertiler Seitentriebe auf den sterilen Endtrieb. Von drei

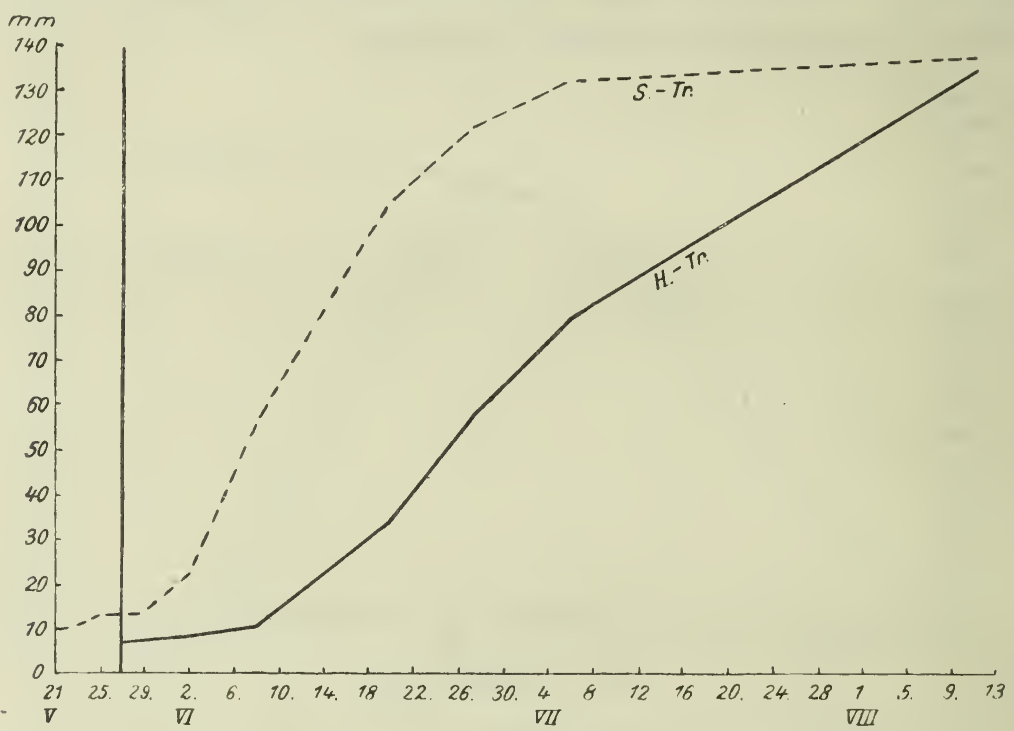

Fig. 14. Infolge der kürzeren Nadeln erscheint der Endtrieb am 12. VIlI. kürzer als der Seitentrieb. Doch beträgt die Länge des Endtriebes bis zur Basis seiner Endknospe 113 mm, die der Seitentriebe $104 \mathrm{~mm}$.

Systemen, wo sämtliche Triebe Bluiten trugen, war die Länge eines Seitentriebes im Durchschnitt $32 \mathrm{~mm}$, der kürzeste Seitentrieb war $27 \mathrm{~mm}$ lang. Die Durchschnittslänge der Seitentriebe bei sechs gemischten Systemen betrug 52,5 mm; der kürzeste war $33,5 \mathrm{~mm}$ lang.

Da die etwa gleichzeitig austreibenden Triebe eines sterilen Systems einander nicht beeinflussen, die eines fertilen Systems nur wenig, dagegen bei gemischten Systemen der sterile Endtrieb von den früher austreibenden Seitentrieben bedeutend gehemmt wird, liegt die Frage nahe, ob die Triebe steriler Systeme nicht auch die Fähigkeit gegenseitiger Hemmung besitzen, und diese nur durch die natuir-

1) Vgl. auch Tab. VIa $a_{2}$ und $b_{2}$; ferner Fig. 12 und 13. 
liche Zeitfolge (ziemliche Gleichzeitigkeit) des Austreibens zur Unwirksamkeit ausgeglichen wird.

Um dies zu entscheiden, gipste ich bei einer Reihe von Zweigen die Endknospe zeitig im Frübjahr ein, ehe noch irgend welches Zeichen des Wachstums zu erkennen war.

Um diese Zeit waren die fertilen Knospen von den sterilen nicht zu unterscheiden. Doch war dies der Fall, sobald die Seitenknospen auszutreiben begannen. In der folgenden Darstellung halte ich mich zun̈ächst lediglich an die Ergebnisse bei rein sterilen Systemen.

Entgipste ich die Endknospen Ende Mai $\left.{ }^{1}\right)$, als die Seitenknospen sich zu öfnen begannen und von der.Basis bis zur Spitze der hervorschauenden Nadeln 10-12 mm lang waren (Periode des Anklingens), sodaß das Auswachsen der ersteren nur um wenige Tage verschoben war, so begannen die Endknospen bald zu schwellen und auszutreiben, und die Endtriebe erreichten schließlich eine Länge, die der Länge von ungehemmten Endtrieben rein steriler Systeme um nichts nachstand. Doch war das Wachstum langsamer, und das Ausreifen erfolgte später bei gehemmten Endtrieben als bei ungehemmten. Auch waren die Nadeln schmaler und wurden später leicht abgeworfen, ohne daß jedoch hierdurch die Knospen des betreffenden Triebes gelitten hätten.

Entgipste ich später, Mitte Juni, wenn die Seitentriebe etwa 60\% ihrer endgültigen Länge erreicht hatten, so war das Wachstum der Endtriebe noch schwächer. Sie stellten ihr Wachstum auch eher ein, sodaß sie kaum die Länge der Seitentriebe erreichten.

Mitte Juli, wo die Seitentriebe etwa 90\% ihrer Länge erreicht hatten, brach in einem Falle die Endknospe wenige Tage nach dem Entgipsen bei einer leichten Berïhung ab. In einem andern Fall wurde bereits die noch eingegipste Knospe abgeworfen, und zwar nicht infolge äußerlich mechanischer Eingriffe, sondern nach der Bildung einer Trennungsschicht, wie wir sie beim Laubfall im Herbst ${ }^{2}$ ) und beim Abort von Knospen an einigen unserer Laubbäume ${ }^{3}$ ) finden.

Daß die Knospe während der Zeit, wo ihr Wachstum mechanisch gehemmt wird, durch die Seitentriebe korrelativ

1) Fig. 14 .

2) Pfeffer, 1904, S. $276 \mathrm{f}$.

3) Berthold, 1898, S. 142 f.; 1904, S. 40. 
beeinflußt ist, jener soeben geschilderte Abwurf der Knospe also nicht etwa auf eine Schädigung durch den Gipsverband zurückgeführt werden darf, geht aus folgenden Vergleichen hervor:

Ich entgipste Anfang Juni die Endknospe eines ziemlich schwachen Systems ${ }^{1}$, als die Seitentriebe eben begannen, ihr Wachstum einzustellen. Um ihren Einfluß auf die austreibende Endknospe auszuschalten, schnitt ich sie beim Entgipsen ab. Trotzdem erreichte der Endtrieb nur die Länge von $31,5 \mathrm{~mm}$, während der kürzeste Endtrieb der von mir beobachteten ungestörten sterilen Systeme $86 \mathrm{~mm}$ lang war. Auch war sein Wachstum sehr langsam im Gegensatz zu dem Wachstum ungestörter Endtriebe schwacher Systeme, die ihr Wachstum nur früher verklingen lassen, als dies bei kräftigeren Systemen der Fall ist.

Daß das langsame Wachstum des betreffenden Endtriebes ebenso wie der Abort der Endknospe seine Ursache nicht in einem veränderten Gesamtzustande des Baumes hat, sondern lediglich in einer durch den Zustand der Seitentriebe bedingten Hemmung, geht schon daraus hervor, daß die Triebe der Nitte Juli - also später - entgipsten Endknospen, die kräftigeren, und darum später ausreifenden Systemen angehörten, sämtlich intensiver wuchsen und länger wurden.

Ich möchte diese Tatsache durch einen weiteren Versuch belegen: Anfang August entgipste ich die Endknospe eines besonders kräftigen Systems und entfernte zugleich die Seitentriebe, die bereits $147 \mathrm{~mm}$ lang waren, jedoch ihr Wachstum noch nicht eingestellt hatten. Während bei schwächeren Systemen, deren Seitentriebe ihr Wachstum früher einstellten, die mechanisch im Wachstum gehinderten Knospen 3 Wochen früher bereits kurz nach dem Entgipsen abortiert hatten, trieb im vorliegenden Falle die Endknospe aus. Natïrlich war ihr Trieb auch bereits gehemmt und wuchs langsamer als alle andern. Er reifte auch nicht aus und erfror infolgedessen im Winter. Doch erreichte er immerhin eine Länge von $68 \mathrm{~mm}^{2}$ ). -

Nachdem ich die Abhängigkeit des Endtriebes von dem Entwicklungszustand der Seitentriebe nachgewiesen habe, erhebt sich die Frage, ob der Unterschied im Wachstum steriler Endtriebe bei gemischten und ungemischten Systemen ${ }^{3}$ ) sich allein auf die Differenz im Entwicklungszustand der fertilen und sterilen Seitentriebe zurick-

1) Triebe schw:icherer Systeme stellen ihr Wachstum früher ein als die stärkerer.

2) Vgl. mit den obigen Ausführungen im einzelnen Tab. VIa.

3) S. $613 \mathrm{f}$. 
führen läßt, wie sie in dem früheren Austreiben und dem früheren Ausreifen der ersteren bedingt ist. Um diese Frage zu beantworten, gebe ich im folgenden die Ergebnisse der Versuche, wo ich die Endknospe gemischter Systeme durch Eingipsen am rechtzeitigen Austreiben hinderte.

Von acht Fällen war bei einem einzigen die Endknospe fähig, nach dem Entgipsen auszutreiben ${ }^{1}$ ). Ich entgipste sie Ende Mai. Nach fast einem Monat begann sie sich zu öffnen, und entwickelte sich auch fernerhin so langsam, daß ihr Trieb die Länge der Seitensprosse nicht erreichte. Auch reifte der Sproß nicht aus, sodaß er während des Winters zugrunde ging. Als ich die Endknospe entgipste,

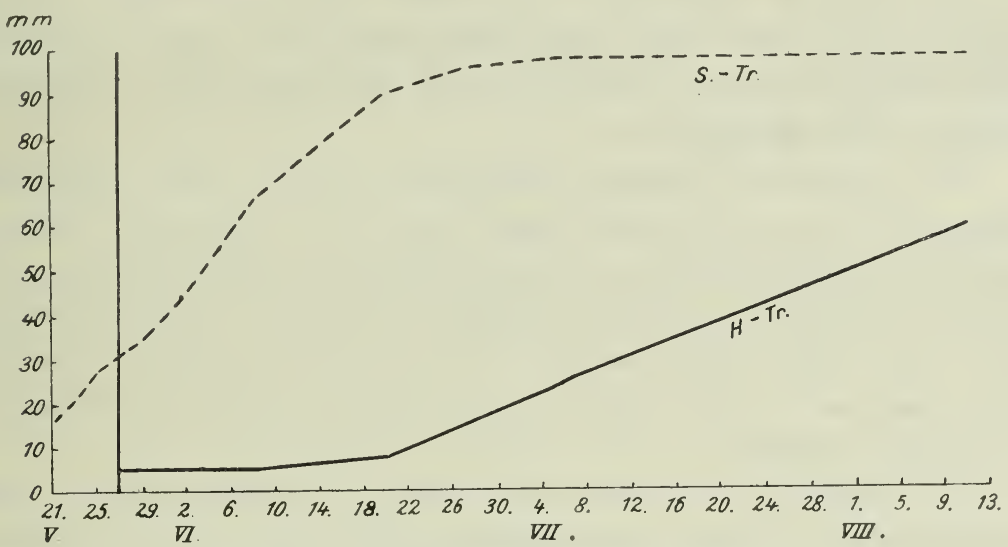

Fig. 15. Der Endtrieb erfror im folgenden Winter.

hatte der Seitentrieb erst etwa $40 \%$ seiner definitiven Länge erreicht; er war noch sehr zart und seine Blätter zusammengefaltet.

Der gleiche Zustand der Seitentriebe, wie er im Verhältnis ihrer augenblicklichen zur endgültigen Länge seinen Ausdruck findet, beeinflußt also bei gemischten Systemen die eingegipst gewesene Endknospe viel intensiver als bei sterilen, obwohl bei diesen das Wachstum des Endtriebes infolge des späteren Austreibens der Seitentriebe bedeutend länger verhindert werden mußte, als bei jenen, um den gleichen Entwicklungszustand der Seitentriebe zu erzielen ${ }^{2}$ ). Der korrelative Einfluß fertiler Seiten-

1) Fig. 15.

2) Da der Endsproß der vorliegenden Versuche steril war, so war die Zeit, um die sein Austreiben durch die Hemmung verschoben wurde, genau so gering wie bei denjenigen Versuchen mit sterilen Seitensprossen, wo die definitive Liinge des Endtriebes durchaus normal war (S. 615). 
triebe auf die am rechtzeitigen Austreiben verhinderte Endknospe ist also nicht in gleicher Weise durch das Entwicklungsstadium der Seitentriebe bedingt wie bei sterilen Systemen. Vielmehr wird der in ihrem Entwicklungszustand begründete Einfluß der Seitentriebe durch ihre Fertilität bedeutend verstärkt.

Das Ergebnis wird durch die weiteren Versuche bestätigt ${ }^{1}$ ):

Eine Endknospe, die gleichfalls Ende Mai entgipst worden war, als die Seitentriebe 50-60\% ihrer Länge erreicht hatten, schwoll zwar ein wenig an, war aber nach etwa 3 Wochen abgestorben.

Knospen, die später (Anfang Juni) entgipst wurden, abortierten in kürzerer Zeit.

Knospen, die bis Mitte oder Ende Juni noch nicht entgipst worden waren, wenn ihre Seitentriebe etwa $85 \%$ ihrer definitiven Länge erreicht hatten, abortierten sehr bald nach dem Entgipsen, bisweilen vorm Entgipsen.

Der Einfluß der fertilen Seitentriebe auf die noch eingegipste Endknospe war so stark, daß diese, wenn sie Anfang Juni entgipst und gleichzeitig die Seitentriebe abgeschnitten wurden, nicht austrieb, sondern einige Zeit nach dem Entgipsen abortierte. Die Seitentriebe waren noch nicht ausgewachsen, als sie entfernt wurden. In einem Falle waren sie $27 \mathrm{~mm}$ lang und noch lichtgrün, hatten aber bereits ihre Blätter entfaltet ${ }^{2}$ ). -

Die Endknospen, die nach dem Entgipsen durch die Seitentriebe im Austreiben und im Wachstum ihrer Triebe korrelativgehemmt werden, beeinflussen diese ebensowenig, wie dies die normal austreibenden Endknospen tun ${ }^{3}$.

Brach ich die Endknospe ab und gipste die eine der beiden Seitenknospen zeitweise ein, so waren nach dem Entgipsen die Korrelationen zwischen den beiden Seitentrieben im großen und ganzen die gleichen, wie zwischen den Seitentrieben und dem künstlich retardierten Endtrieb. Die rechtzeitig austreibende Knospe wird von der später austreibenden in keiner Weise beeinflußt, während diese in ihrem Wachstum der zeitweise eingegipsten Endknospe gleicht. Nur genügt ein früheres Entwicklungsstadium, d. h. eine

1) Vgl. hierzu S. 615.

2) Vgl. uber die Beeinflussung der Endknospe durch fertile Seitentriebe im einzelnen 'T'ab. VIb.

3) Vgl. in Tab. VI die betr. Angaben unter $a_{1}$ und $a_{2}$. 
geringere Reife des normal wachsenden Seitentriebes, um auf den zeitweise gehemmten Seitentrieb ebenso zu wirken, wie a uf den zeitweise gehemmten Endtrieb.

So wurde in einem Falle, wo der freie sterile Seitentrieb 66,5\% seiner definitiven Länge erreicht hatte, die andere Knospe kurz nach dem Entgipsen abgeworfen.

Bei dem einzigen System mit fertilen Seitentrieben, das sich unter diesen Versuchen befand, abortierte die eingegipste Knospe 11 Tage nach dem Entgipsen. Der freie Trieb hatte beim Entgipsen 53,5\% seiner Länge erreicht ${ }^{1}$ ).

Daß ein Seitentrieb durch den andern mehr beeinflußt wird als der Endtrieb durch die Seitentriebe, wurde dann besonders augenscheinlich, wenn ich die Endknospe und eine Seitenknospe zeitweise eingipste. - Auch wenn der Seitentrieb fertil war, wurde die Seitenknospe eher abgestoßen als die Endknospe. In einem Fall trieb die Endknospe aus, während die Seitenknospe abortierte.

Noch stärker wird die Beeinflussung, wenn das Wachstum einer Seitenknospe künstlich verzögert wird und der Endtrieb auf diese Weise das Übergewicht über dieselbe erlangt:

Gipste ich eine Seitenknospe ein, während ich die Endknospe und die andere Seitenknospe austreiben ließ, so war jene bald nicht mehr wachstumsfähig. Sie abortierte vor oder sehr bald nach dem Entgipsen. Und selbst in einem Falle, wo das System steril war und die frei wachsenden Triebe ihr Hauptwachstum beim Entgipsen eben begonnen hatten und sowohl der Endtrieb wie auch der Seitentrieb kaum 15\% seiner definitiven Länge erreicht hatte, war die eingegipste Knospe nach 14 Tagen abgefallen.

Hatte eine oder mehrere Knospen abortiert, so bildeten sich an der Knospennarbe oder, wenn der Mutterzweig seine Nadeln teilweise verloren hatte, auch an der Narbe einer der oberen Nadeln gern Adventivknospen.

Diese erschienen bisweilen in Mehrzahl. So fand ich an einem Zweig, wo die Endknospe und eine Seitenknospe abortiert hatte, an der Narbe der Endknospe vier Knospen. Sie trieben oft in demselben Jahr noch aus: Eine bildete einen kleinen Zweig von $12 \mathrm{~mm}$ Länge; eine andere reifte aus, ehe der Trieb noch völlig die Knospe verlassen hatte. 


\section{Picea pungens.}

Die Versuche wurden gleichfalls an einem freistehenden Baum im Botanischen Garten zu Leipzig ausgeführt, und zwar an der Nordseite des Baumes, da die Südseite desselben von andern Bäumen ungleichmäßig beschattet wurde.

Wie bei Torreya sind auch bei Picea die einzelnen Triebe des gleichen Systems während ihrer physiologischen Periode $\left.{ }^{1}\right)$ normalerweise im wesentlichen voneinander unabhängig. Die Seitenknospen beginnen meist ein wenig früher auszutreiben als die Endknospe; doch stellt deren Trieb sein Wachstum später ein als die Triebe jener, so daß er sie schließlich an Länge übertrifft.

Die Anzahl der Seitentriebe wechselt, und zwar werden sie im allgemeinen um so zahlreicher und kräftiger gebildet, je kräftiger der Mutterzweig ist. Teils stehen sie paarweise, teils einzeln; bisweilen fehlen sie ganz. Selbst wenn ein Zweig nur unter der Basis seines Endtriebes ein paar Seitentriebe trägt, sind diese meist nicht gleich lang. Der Unterschied der einzelnen Seitentriebe kommt häufig schon in der Knospe zum Ausdruck, indem diese sich nicht normal entwickelt, sondern klein und kümmerlich bleibt und bisweilen sogar ihre Wachstumsfähigkeit vor dem Austreiben verliert.

Bald sind die akralen Seitentriebe die längsten, bald verteilen sie sich so, daß dem längeren Seitentrieb ein kürzerer, dem kürzeren dagegen ein längerer tiefer an der betr. Flanke des Mutterzweiges folgt. Doch finden sich auch Fälle, wo die Triebe der einen Seite sämtlich kürzer sind als die der andern, oder völlig unterdrückt werden.

Voraussetzung für das stabile Verhalten der plagiotropen Verzweigungssysteme ist das Spitzenwachstum des gesamten Baumes; denn es ist ja bekannt ${ }^{2}$, daß die akralen Lateralzweige der Abietaceen nach Verlust des Spitzentriebes diesen ersetzen, indem sie sich in seine Richtung stellen und die iibrigen Seitentriebe in gleicher Weise korrelativ beeinflussen, wie das bis dahin der Spitzentrieb getan hat.

Um zu untersuchen, ob bei Picea in gleicher Weise wie bei Torreya die Triebe nur infolge des normalen, zeitlich geregelten Austreibens voneinander unabhängig erscheinen, hinderte ich die Endknospe durch Eingipsen am rechtzeitigen Austreiben.

Entgipste ich die Endknospe Ende Mai oder Anfang Juni (1910), als die Seitentriebe ihre definitive Länge ziemlich erreicht hatten, so öffnete sich die Endknospe nach 5-7 Tagen, und ihr Trieb begann sehr langsam zu wachsen. Und zwar wuchs er um so langsamer,

1) Sachs, 1893, S. 227; Berthold, 1904, S. 145.

2) Goebel, 1908, S. $79 \mathrm{f}$. 
je entwickelter der (längste) Seitentrieb beim Entgipsen war. Je mehr der Seitentrieb beim Entgipsen ausgewachsen war, desto länger dauerte es auch, bis der Endtrieb sein Wachstum wieder einstellte (4-9 Wochen). Das längere Wachstum war jedoch keineswegs mit einer größeren definitiven Läng'e verbunden. Vielmehr war diese im allgemeinen um so größer, je früher das Wachstum eingestellt ward, da, wie gesagt, ein früheres Einstellen des Wachstums mit einer größeren Wachstumsintensität Hand in Hand ging. Seine normale Länge erreichte der künstlich retardierte Endtrieb bei meinen Versuchen nie. Im günstigsten Fall ward er $42 \mathrm{~mm}$ lang, während der kürzeste der von mir gemessenen

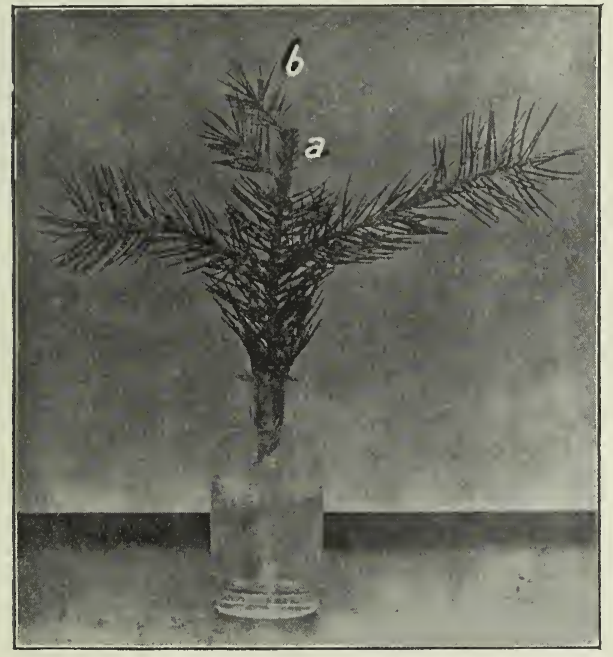

Fig. 16. Der (1910) korrelativ gehemmte Endtrieb $(a)$ entwickelte im folgenden Jahre (1911) aus seinen Knospen normale Triebe (b).

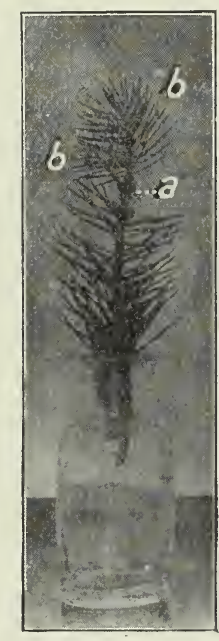

Fig. 17. Vgl. Fig. 16.

(vier) normalen Endtriebe $83 \mathrm{~mm}$ lang war ${ }^{1}$ ). Auch blieben die Nadeln klein und gedrungen, so daß der Habitus des mechanisch gehemmt gewesenen Endtriebes von dem normaler Endtriebe durchaus verschieden war $^{2}$ ).

Bei Picea excelsa beobachtete ich an Seitentrieben schwächerer Systeme gleichfalls bisweilen eine Reduktion der Nadeln; und zwar fand ich an den verschiedenen Trieben eines Baumes zwischen den Zwergnadeln und den normalen Nadeln zahlreiche Zwischenformen.

Entgipste ich die Endknospe noch später (Ende Juni), so trieb sie in einem Falle aus, wuchs aber sehr langsam und erreichte schließlich eine Länge von $18 \mathrm{~mm}$.

1) Vgl. 'Tab. VIII.

2) Fig. 16, $a$.

Archiv f. Entwicklungsmechanik. XXXVIII. 
In einem andern Fall entfernte ich beim Entgipsen zugleich die Seitentriebe. Nach 2 Monaten war die Endknospe noch geschlossen, doch bereits geschwollen. Sie öffnete sich im Herbst. Ihre Nadeln reifte sie nicht aus; die waren im nächsten Frühjahr erfroren. Dagegen war die Achse verholzt, desgleichen die Terminalknospen.

Dal3 hier eine Hemmung der Knospe bereits während der mechanischen Hemmung durch die Seitenzweige des gleichen Systems stattgefunden hat, und nicht etwa allein durch den Gesamtzustand aes Baumes, geht aus dem Verhalten einer andern, zugleich mit dieser entgipsten Endknospe hervor. Diese saß auf einem Zweig, dessen Seitenknospen sich nur kümmerlich entwickelt hatten und vor dem Austreiben abgestorben waren. Der gesamte Zweig war also schwächer als der vorige ${ }^{1)}$. Trotzdem öffnete sich die Endknospe etwa 14 Tage nach dem Entgipsen und erreichte eine Trieblänge von $37 \mathrm{~mm}$, die nur von einer einzigen, Ende Mai entgipsten Knospe übertroffen wurde. Im Habitus glich dieser Trieb durchaus den übrigen der gehemmten Endknospen.

Die infolge korrelativer Hemmung zu Zwergzweigen verkümmerten Triebe entwickelten aus ihren Knospen im nächsten Frühjahr durchaus normale Triebe mit vollständig normalen Blättern ${ }^{2}$. Verglichen mit andern Endtrieben plagiotroper Zweige waren diese Triebe zwar kurz, doch hatten sie im Verhältnis zu ihren Mutterzweigen eine anormale Länge $\left.{ }^{3}\right)$. - Auch die Endknospe, die nur einseitig ihre Hülle erst im Herbst geöffnet hatte, und deren Nadeln erfroren waren, ließ ihre Endknospe austreiben, und zwar zu einem Triebe von $39 \mathrm{~mm}^{4}$ ).

Das gleiche Verhalten zeigt normalerweise Abies alba. Die Knospen der weiblichen Blïtenzweige treiben im Jahr nach der Blüte langsamer aus als die Knospen steriler Zweige und bilden, offenbar unter dem korrelativen Einfluß der zahlreichen entwickelteren Triebe des Baumes, typische Kümmertriebe. Deren Knospen bilden im folgenden Jahre wieder normale Zweige.

\section{Untersuchungen an sympodialen Zweigsystemen von} Laubbäumen.

1. Tilia ulmifolia.

Die Untersuchungen wurden im Botanischen Garten zu Leipzig an einem kurzstämmigen Baum ausgeführt. Er stand an der Westwand des Botanischen Instituts, so daß er von etwa 11 Uhr morgens bis gegen Abend von der Sonne beschienen war. $\mathrm{Zu}$ den Versuchen wurden in der Hauptsache Zweige der Peripherie verwandt.

3) In einem Falle nur trieb die Endknospe eines Zwergzweiges nicht aus; doch war sie vollständig gesund und unverhältnismäßig groß.

4) Fig. 17. 
Bekanntlich ist Tilia sympodial verzweigt: Die Spitze der jungen Triebe wird im Frïhjahr abgestoßen ${ }^{1}$ ), sodaß der ausgereifte Zweig mit einer Seitenknospe abschließt.

Beim Austreiben im Frühjahr beginnen die Knospen im großen und ganzen etwa gleichzeitig auszutreiben; doch schwillt vielfach und mehr noch gilt dies bei proleptischem Treiben im Herbst ${ }^{2}$ ) - die Knospe des vorletzten Gliedes am frühesten und stärksten. Indes schwillt auch häufig zuerst die sekundäre Endknospe an. Das Wachstum der einzelnen Triebe eines Systems ist zunächst meist gleich intensiv, doch verklingt es im allgemeinen um so später, je näher der Trieb der Spitze des Mutterzweiges steht, sodaß der Endtrieb schließlich der längste ist, und die Länge der übrigen nach der Basis zu allmählich abnimmt ${ }^{3}$ ). Mit der Entfernung von der Spitze des Mutterzweiges nimmt auch der Winkel zu, den die Triebe mit ihm bilden.

Stellt ein Trieb sein Wachstum ein, so bleicht seine Spitze und wird abgestoßen, und zwar meist so, daß zunächst die Spitze ab-

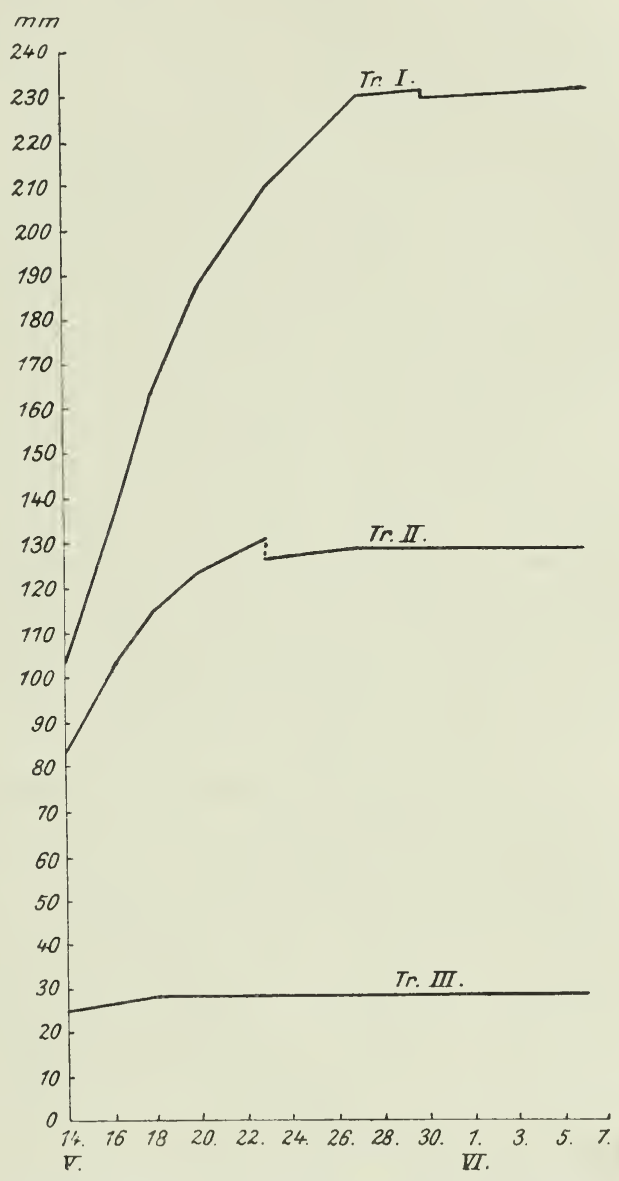

Fig. 18. Wachstum der drei obersten Triebe. Am obersten abortierte die Spitze am 30. V., am zweiten am 23. V.

1) Mohl, 1860, S. 274; Goebel, 1884, S. 202; Berthold, 1904, S. 245 f.

2) Auch von Picea excelsa berichtet Berthold (1904, S. 42), daß die Seitentriebe, wenn sie in warmen Herbsten austreiben, stärker als die Haupttriebe treiben und sich auch steiler zur Hauptachse stellen als die im Frïhjahr austreibenden Seitentriebe.

3) Vgl. Fig. 18, wobei auch zu beachten ist, daß das Wachstum des Endtriebes durch die Sistierung des Wachstums bei den übrigen Trieben nicht beschleunigt wird. Vgl. auch BerThold, 1904, S. 39. 
geworfen wird, einige Tage danach noch ein Glied, und so fort. Dieser Gliedabwurf kann sich - besonders bei tiefer inserierten Trieben bis hoch in den Sommer hinein fortsetzen und dann ziemlich ausgereifte Glieder treffen, bisweilen solche mit ausgewachsenen Blättern, die dann wie bei der herbstlichen Verfärbung gelb werden.

Oft ist das oberste der nicht abgeworfenen Glieder das längste; bald ist jedoch das vorletzte oder drittletzte das längste, während nach der sekundären Spitze zu wieder eine Verkürzung der Gliedlängen stattfindet. Das Wachstum der Knospen ist hiervon im wesentlichen unabhängig. Dagegen kommt es bisweilen vor, daß das oberste Glied nicht völlig ausreift und die Knospe infolgedessen im Winter vertrocknet; oder die sekundäre Endknospe treibt ungewöhnlich spät aus und stellt ihr Wachstum bald ein, während die zweite oder dritte Knospe den kräftigsten Trieb bildet.

Unterhalb der zweigbildenden Knospen folgen solche, die zwar gleichzeitig mit den höher gelegenen Knospen anschwellen, bisweilen auch aufbrechen, dann aber bleichen und abfallen $\left.{ }^{1}\right)$. Auf ihren Narben entwickeln sich vielfach Knospen, die allmählich die Größe und die Eigenschaften der normalen ruhenden Knospen erreichen.

Den abortierenden Knospen folgen an der Basis des Mutterzweiges die ruhenden Knospen, die garnicht zu wachsen versuchen und am Mutterzweig beharren ${ }^{2}$ ).

Die normale Gestaltung des Zweigsystems, d. h. die allmähliche Abnahme der Zweiglängen von der Spitze her und der Besitz abortierender und ruhender Knospen an der Basis, tritt um so deutlicher in Erscheinung, je länger der Mutterzweig ist, oder was dem gleichkommt: je länger und zahlreicher die Glieder desselben sind. Am schönsten ist dies der Fall an jungen Bäumen oder an verschnittenen älteren. An ganz alten Bäumen dagegen fand ich das System derartig reduziert, daß nur die sekundären Endknospen fähig waren, einen ziemlich kurzen Trieb zu bilden ${ }^{3}$ ).

Meist tragen die Äste und Zweige um so ausgebildetere Systeme, je höherer Ordnung sie sind, die Triebe werden aber um so kürzer und ihre Längenunterschiede um so geringer, je mehr höheren Systemen sie untergeordnet sind.

Ich verwandte daher zu meinen Untersuchungen in der Hauptsache peri-

1) Berthold, 1898, S. 142 f.; 1904, S. 40.

2) Berthold, 1904, S. 40.

3) Vöсhтілg, 1884, S. 12. 
pher an der Krone gelegene Endtriebe von Hauptïsten, habe jedoch zum Vergleich auch bedeutend untergeordnetere Systeme herangezogen ${ }^{1}$ ).

Das Längenverhältnis sämtlicher dem gleichen System zugehörigen Zweige wird im wesentlichen durch diezwischen ihnen bestehenden Korrelationen während ihrer physiologisch-biologischen Periode 2 ) bestimmt. Wurde vor dem Austreiben oder im frühesten Stadium des Austreibens die oberste Knospe mit dem zugehörigen Internodium entfernt, so entwuchs der ursprünglich zweiten Knospe ein Trieb, der an Länge dem der ersten Knospe normaler Zweige nicht nachstand, und so fort $\left.{ }^{3}\right)$. Entfernte ich von wohlentwickelten Zweigen vor dem Austreiben sämtliche Knospen mit Ausnahme der sekundären Endknospe, so entwickelte sich diese zu einem Trieb, der an Länge die Endzweige normaler Systeme bedeutend übertraf. Seine Länge betrug im Durchschnitt $325 \mathrm{~mm}$ (der längste beobachtete Trieb $345 \mathrm{~mm})$, während die längsten normalen Endzweige - aus der gleichen Anzahl für den Durchschnitt berechnet nur $230 \mathrm{~mm}$ lang waren (der längste beobachtete Trieb $242 \mathrm{~mm}$ ).

Daß die Zunahme der Hemmung im Wachstum der Triebe nach der Basis des Mutterzweiges hin in der Gesamtheit der höher inserierten Triebe bedingt ist, g*eht aus Versuchen hervor, wo ich von kräftig entwickelten Zweigen die zweite bis vierte Knospe abbrach. Ich veranlaßte dadurch die folgenden Knospen zur Zweigbildung, die, wie der Vergleich mit intakten Zweigen zeigte, wenigstens in der Mehrzahl abortiert hätten. Die Längenunterschiede zwischen dem Endtrieb und dem Trieb der fünften Knospe waren nicht größer, als wie sie im ungestörten System zwischen dem Trieb der ersten und zweiten Knospe waren.

Um einen Einblick in das korrelative Zusammenwirken der einzelnen verschieden hoch inserierten Triebe $\mathbf{z u}$ gewinnen, habe ich in Tabelle X sechs Fälle wiedergegeben, die in meinen Aufzeichnungen zufällig nebeneinander standen. Es gestalteten sich die Verhältnisse zwar nicht stets in der gleichen Weise, doch in den weitaus meisten

1) Auf eine Eigentïmlichkeit der Linden sowohl wie der diesen im Verzweigungssystem verwandten Ulmenarten möchte ich noch hinweisen: das Austreiben der Bäume im Fruhjahr ist großen individuellen Schwankungen unterworfen and kann bei verschiedenen Individuen unter den gleichen Bedingungen und am gleichen Ort - auch bei gleichem Alter - um 14 Tage und mehr differieren. Auch die verschiedenen Zweige und $\ddot{\text { Aste }}$ eines Individuums treiben bisweilen, besonders bei Sträuchern, ungleich aus.

2) S. 620 , Anm. 1 .

3) Tab. IX. 
Fällen, sodaß das in Tabelle X wiedergegebene Verhältnis wohl als der Haupttypus angesehen werden kann. Vergleicht man das Verhältnis des zweiten Triebes zum ersten mit dem des vierten zum dritten, so zeigt sich dieses meist größer als jenes. D. h. der hemmende Einfluß eines tieferen Triebes auf seinen Nachbartrieb ist nicht so stark wie der des Endtriebes auf dessen Nachbartrieb. Da aber jeder Trieb an und für sich die gleichen Fähigkeiten besitzt ${ }^{1}$ ), s 0 ist die geringere Überordnung tieferer Triebe über ihre Subordinaten auf eine Schwächung zurückzuführen, die ihre Ursache in der Hemmung durch die ihnen übergeordneten Triebe hat.

Anderseits wird aber auch die Hemmung durch nicht benachbarte übergeordneteTriebe um soschwächer, je mehr Triebe $z w i s c h e n d e m$ hemmenden und dem gehemmten Sproß eingeschaltet sind und infolgedessen von jenem eher gehemmt werden. Nur durch diese beiden Annahmen läßt sich eine Reihe von Systemen erklären, wo nach einer basipetalen Abnahme der Trieblängen, etwa in der Mitte des Systems, wieder eine geringe Zunahme zu bemerken ist ${ }^{2}$, sodaß sich gegen die Basis der basale Teil des oberen Systems ungefähr wiederholt ${ }^{3}$ ). Ich bezeichne solche Systeme als labile $Z_{w}$ illingssysteme, da sie im Gegensatz zu später zu besprechenden Bildungen ähnlicher Art erst durch die Korrelationen während der physiologischen Periode ihrer Triebe bedingt werden ${ }^{4}$ ).

Aus den Versuchen; wo durch Entfernung akraler oder mittlerer Knospen die normalerweise abortierenden Knospen zum Austreiben gebracht wurden ${ }^{5}$ ), geht hervor, daß der Abort der Knospen nur einen besonderen Fall des Spitzenabwurfs darstellt, indem hier das allmähliche Abstoßen von Glied um Glied in einen einzigen Abwurf sämtlicher Glieder zusammengezogen wird.

1) S. 625 .

2) Durch die Verminderung des Hemmungsreizes proportional den zwischenliegenden Trieben einerseits, anderseits durch die geschwächte Hemmungsfähigkeit tiefer gelegener Triebe ist es wohl auch za erklären, daß bei $70 \%$ der von mir untersuchten (33) Fälle das Verhältnis des dritten Gliedes zum zweiten geringer ist als das des vierten zum dritten, während das Verhältnis vom zweiten zum ersten Gliede bei $60 \%$ der Fälle größer war als das vom dritten zum zweiten Glied.

3) Tab. XI, 1-4.

4) Sie treten häufig an kräftigen Mutterzweigen auf, wurden aber dann nie beobachtet, wenn solche vor dem Austreiben bedeutend dekapitiert wurden.

5) S. 625 . 
Werden Zweige in ungünstige Bedingungen gebracht, so abortieren sämtliche Knospen, und zwar in der gleichen Reihenfolge, wie sich am normalen System die Wachstumshemmungen bemerkbar machen.

Ich schnitt gutgewachsene Zweige mit schwellenden Knospen ab und wählte eine Reihe von ihnen so aus, daß je zwei ein Paar bildeten, das an Zahl und Länge der Glieder gleich war. Je einen Zweig zerlegte ich in seine einzelnen Glieder durch Schnitte direkt über den Knospen; den andern ließ ich intakt. Sämtliche Sprosse und Sproßteile kultivierte ich in feuchtem Sand. Nach 10 Tagen lösten sich an den intakten Zweigen bei einer leisen Berührung sämtliche Knospen, mit Ausnahme der untersten ruhenden; an den zerlegten saßen jedoch die Knospen der drei obersten Glieder noch fest.

Daß der Abwurf der obersten Knospen an den unverletzten Zweigen nicht auf mangelnde Wasserversorgung infolge ihrer weiteren Entfernung von der Schnittfläche des Sprosses zurückzuführen ist ${ }^{1}$ ), geht schon daraus hervor, daß gerade die oberste Knospe, die am ungünstigsten gestellt sein müßte, zuletzt abortiert, und daß die Knospen - wie dies bei den abortierenden Laubknospen unserer Laubbäume überhaupt der Fall ist $\left.{ }^{2}\right)$ - beim Abwurf völlig turgeszent sind. Es handelt sich vielmehr um die Folgen gegenseitiger korrelativer Beeinflussung; und zwar ist der Abort der unteren Knospen bei den zerlegten Zweigen eine Nachwirkung der Beeinflussung durch die anschwellenden oberen Knospen, ehe der Zusammenhang des Zweiges gelöst wurde.

Die korrelativen Einflüsse, unter denen die Knospen während ihrer morphologischen Periode ${ }^{3}$ ) stehen, sind zunächst insofern von Bedeutung für die spätere Gestaltung des Systems, als die Reifung der untersten Knospen soweit verzögert wird, daß sie auch bei verhältnismäßig tiefer Dekapitation des Mutterzweiges nicht zu schwellen beginnen, sondern im Ruhezustand verharren, und solche dekapitierte Zweige infolgedessen keine Knospen abortieren.

Auch die akralen Knospen stehen bisweilen in ihrer Entwicklung gegen die übrigen zurück4), und zwar ist diese Erscheinung offenbar auf einek orrelative Schädigung der Mutterzweigspitze nach dem Abwurf der primären Spitze während der Reifung des Mutterzweiges zurükzuführen. Besonders auffällig ist dieser Einfluß auf die Knospen in ihrer mor-

1) Vgl. Molisch, 1886, S. 156.

2) Vgl. BüSGEN, S. 44.

3) Sachs, 1893, S. 227; Berthold, 1904, S. 145.

4) S. 623. 
phologischen Periode in solchen Fällen, wo diese im nächsten Jahre kiirzere oder wenigstens nicht bedeutend lïngere Triebe bilden als die tieferen Knospen, ohne daß sie unbedingt sp:̈ter austreiben als diese $^{1}$ ). Das System ist dann vom dritten Trieb ab basalwärts durchaus normal, während die beiden obersten Triebe in der Regel wie ein selbstïndiges schwächeres System den Zweig abschließen. Ich bezeichne solche Systeme als induzierte Zwillingssysteme, da ein Entfernen der tiefer inserierten Knospen das Wachstum der obersten Triebe wesentlich nicht fördert.

Neben diesen induzierten Zwillingssystemen, deren akrale Knospen auch nach der Entfernung sämtlicher tieferen Knospen nur kümmerliche Triebe bilden, gibt es auch solche, wo die sekundäre Endknospe nur ungewöhnlich spät austreibt und, offenbar infolgedessen, einen verhältnismäßig kurzen Trieb bildet.

Ehe ich auf die Frage eingehe, ob ein verspätetes Austreiben der sekundären Endknospe durch eine Veränderung der zwischen den einzelnen Trieben eines Mutterzweiges bestehenden Korrelationen eine Verkümmerung des Endtriebes bewirken kann, möchte ich die Tatsache nicht unerwähnt lassen, $d a \beta$ auch die Triebe mehr oder weniger benachbarter Systeme einander korrelativ beeinflussen. Entfernte ich vor dem Austreiben, d. h. zu einer Zeit, wo jede korrelative Beeinflussung ausgeschlossen scheint, sämtliche Knospen eines Systems mit Ausnahme der sekundären Endknospe, so warf der Endtrieb, obwohl er, wie bereits erwähnt, ungewöhnlich lang ward ${ }^{2}$, gleichwohl seine Spitze ab.

Schließlich möchte ich noch eine Beobachtung erwähnen, die eine Veränderung der Korrelationen durch die Entwicklung einer Galle zeigt.

Im Frühjahr 1910 fand ich an einigen Systemen Zweige, die in ihrer Spitzenregion Gallen von Contarinia tiliarum trugen ${ }^{3}$ ). Teils waren es Endtriebe, teils Triebe der zweiten Knospe.

In beiden Füllen waren die betreffenden Triebe bedeutend länger als andere ihnen entsprechende. Dies kam bei Trieb 2 viel dentlicher noch als beim Endtrieb zum Ausdruck.

Ich habe in Tab. XII unter 1-5 die Fälle zusammengestellt, wo Triebe mit Gallen vorlagen, und habe unter 6-10 die Größen von normalen Systemen angeführt, bei denen entweder der Unterschied der Längen des ersten und zweiten Triebes sehr gering war (6 und 7 ) oder der Endtrieb außergewöhnlich lang (8 und 9 ).

1) Tab. XI, 5 and 6.

2) S. 625 .

3) Die Galle befand sich in der Spitzenregion des Zweiges an der Hauptachse. 
Vergleicht man die unter 6-9 angeführten Längen des zweiten Triebes und das Verhältnis des zweiten Triebes zum ersten mit den entsprechenden Angaben von $1-4$, so sind die letzteren bedeutend höher. Dies läßt sich für 3 und 4, wo der zweite Trieb die Galle trägt, so erklären, daß dieser dadurch bis zu einem gewissen Grade gegen die Hemmung des Endtriebes immunisiert ist, für 1 und 2 aber, wo der Endtrieb die Galle trägt, nur so, daß diese den Einfluß des Endtriebes auf den zweiten Trieb selbst bedeutend schwächt ${ }^{1}$ ).

Der dritte Trieb, gleichviel ob der erste mit einer Galle behaftet ist oder der zweite, ist nicht länger als ein dritter Trieb im intakten System, und infolgedessen wird das Verhältnis vom dritten zum zweiten Trieb gegenüber normalen Fällen bedentend verringert.

Der Einfluß der Contarinia-Galle scheint indes in hohem Maße von der Gesamtheit der Korrelationen, wie sie - bis zu einem gewissen Grade - im Verzweigungsmodus des ganzen Individuums zum Ausdruck kommt, abzuhängen. So fand ich im Frühjahr 1913, daß stengelwüchsige Contarinia-Gallen an den einzelnen Systemen von Stockausschlägen am Fuße von Tilia-Stämmen die Korrelationen wesentlich nicht veränderten.

Um zu entscheiden, inwiefern ein verspätetes, nicht in der Verzögerung der Reife bedingtes Austreiben der terminalen Knospe die normale Gestaltung des Systems beeinflußt, wurden die sekundären Endknospen gut gewachsener Zweige vor dem Austreiben eingegipst, oder - was für das Ergebnis dasselbe war - die zweite Knospe nach Entfernung der sekundären Endknospe. Es wurden zu diesen Versuchen solche Knospen gewählt, deren Glied entweder dem nächsten an Länge ziemlich gleich kam oder dieses übertraf.

Mit dem Entgipsen der Endknospen begann ich Ende April, als die übrigen Knospen sich öffneten und die jungen Triebe ihre Blätter noch nicht entfaltet hatten; die letzten entgipste ich Anfang Juni, als die Triebe der übrigen im allgemeinen ihre endgültige Länge erreicht hatten.

Die Versuche wurden zum größten Teil 1910 angestellt und nur eine kleinere Anzahl 1911; bei letzteren ist dies im Text vermerkt, da die Triebe 1911 infolge der anhaltend warmen Witterung intensiver wuchsen als 1910.

Die am frühesten entgipsten Endknospen (Ende April 1911) schwollen sämtlich sehr stark an, sodaß sie nach 14 Tagen etwa das Doppelte ihrer ursprünglichen Größe erreicht hatten. Nach einiger Zeit zeigten sich an den meisten Knospen Absterbeerscheinungen, indem sie gilbten. Und nach einem Monat waren sie sämtlich abgeworfen bis

1) Nr. 5 stellt ein induziertes Zwillingssystem dar. Unter 10 habe ich einen ähnlichen Fall ohne Galle eingetragen, dessen Endtrieb gegenüber andern Fällen ungewöhnlich entwickelt war. 
auf eine einzige. Diese entwickelte sich zu einem Trieb, der jedoch sein Wachstum einstellte, nachdem er eine Länge von $50 \mathrm{~mm}$ erreicht hatte.

Daß das Verhalten der retardierten sekundären Endknospen tatsächlich in einer Beeinflussung durch die tiefer inserierten Triebe bedingt ist, geht daraus hervor, daß jene zu wohlentwickelten Trieben auswuchsen, wenn ich beim Entgipsen alle andern Knospen des betreffenden Zweiges entfernte.

Obwohl sich die entgipste Endknospe im allgemeinen korrelativen Einflüssen der übrigen Knospen gegenüber nicht halten konnte und schließlich abgestoßen wurde, ging von ihr doch eine - wenn auch geringe - Hemmung aus.

Bei fünf Versuchen, wo die Endknospe gehemmt worden war, betrug die definitive Länge des zweiten Triebes im Durchschnitt 109 mm ${ }^{1}$ ), während die Länge des obersten Triebes nach Entfernung der Endknospe vor dem Anschwellen bei fünf ungestörten Systemen im Durchschnitt $179 \mathrm{~mm}$ betrug. D. h. infolge der Hemmung durch die schwellende Endknospe wurden die in der Entwicklung ihr bereits ziemlich überlegenen basalen Triebe derartig gehemmt, daß sie nur $61 \%$ ihrer normalen definitiven Länge erreichten.

Entgipste ich (1910) die Endknospe später, von Mitte Mai an, als die obersten Zweige die Hälfte ihrer definitiven Länge noch nicht erreicht hatten, bis Mitte Juni, wo die Triebe ausgewachsen waren, so war das Verhalten der Endknospe im wesentlichen das gleiche: Sie schwoll nach dem Entgipsen an, bisweilen so stark, daß die Spitzen der Laubblätter die Schuppenblätter überragten, und zwar schwoll sie um so mehr und um so rascher an, je geringer beim Entgipsen das Verhältnis der Länge des zweiten Triebes zu seiner definitiven Länge war. Dann begann sie zu bleichen und wurde abgestoßen. Dieser Abort war in vielen Fällen dem der abortierenden basalen Knospen durchaus gleich. In andern Fällen jedoch folgte dem Gilben der Knospe ein leichtes Schrumpfen, das in seltenen Fällen soweit ging, daß der Abwurf überhaupt unterblieb und die Knospe am Mutterzweig vertrocknete ${ }^{2}$ ).

1) Diese Angabe ist infolge der Gestaltung eines der betr. Systeme eher $\mathrm{zu}$ hoch als zu niedrig.

2) Regelmäßig starb nach dem Tod der Endknospe deren Glied ab und vertrocknete. Häufig bildete sich an der Basis vor dem Absterben eine ringförmige Verdickung; vgl. LöwI, S. $1009 \mathrm{f}$. 
Was die Lebensdauer der entgipsten Knospen anbetrifft, so war diese im allgemeinen um so länger, je weniger die andern Triebe ausgereift und ausgewachsen waren ${ }^{1}$ ).

Da Systeme mit kräftig entwickelten Trieben länger wachsen und später ausreifen als schwächere, so ist die Lebensdauer der entgipsten Endknospe, falls sie nicht allzuspät entgipst wird (also im Mai), um so länger, je länger der zweite Trieb ist. Desgleichen ist ihre Lebensdauer der Wachstumsintensität des zweiten Triebes proportional, da intensiv wachsende Triebe weniger ausgereift sind als solche, die ihr Wachstum bereits verlangsamt haben.

Haben die tieferen Triebe beim Entgipsen der Endknospe bereits begonnen, ihre Blätter zu entfalten, so ist ein Einfluß der schwellenden Endknospe auf ihr Wachstum nicht nachzuwe isen.

Daß die Wachstums-

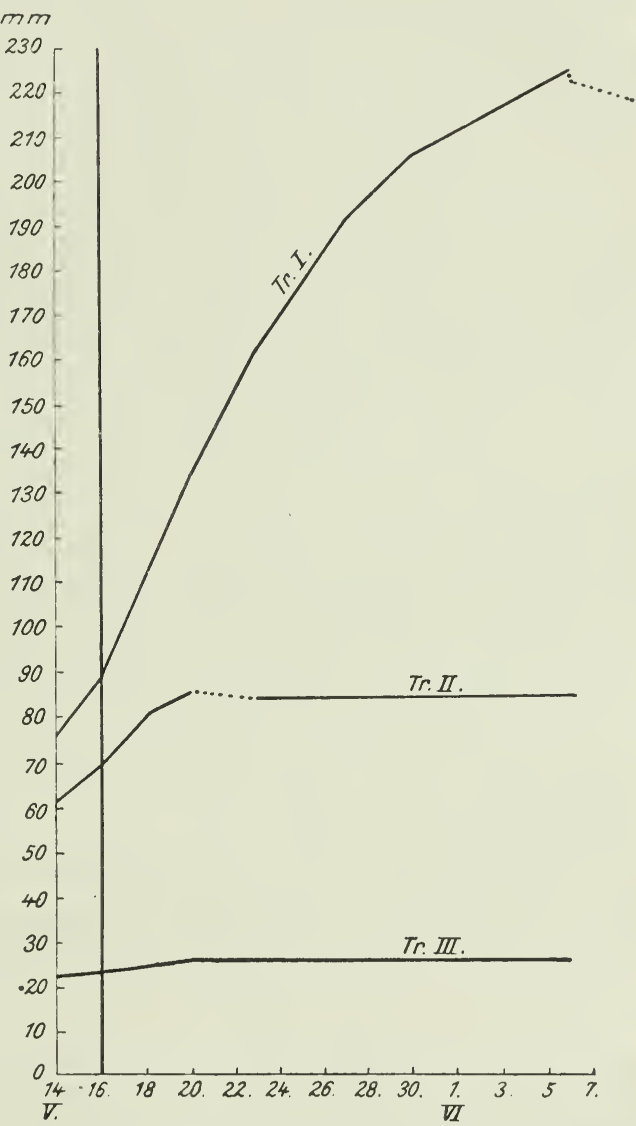
intensität des obersten Fig. 19. Die punktierten Stellen bedeuten den Abwurf der Triebes durch das EntgipSpitze während der angegebenen Tage. sen der Endknospen nicht beeinflußt wird, läßt sich deutlich aus dessen Wachstumskurve erkennen.

Ich habe in Fig. 19 einen Fall dargestellt, wo der oberste Trieb beim Entgipsen erst $40 \%$ seiner definitiven Länge erreicht hatte, d.h. noch ziemlich jung war, und gleichwohl seine Wachstumsgeschwindigkeit nicht vermindert wurde.

1) Vgl. Tab. XIII. 
Ebensowenig war durch sorgfältige Vergleichung mit intakten Systemen ein verfrühter Abschlul des Wachstums, wie er in einer geringeren endgültigen Länge des obersten Triebes zum Ausdruck kommt, nachzuweisen. -

Um zu untersuchen, ob auch eine nur zeitweise Beeinflussung des künstlich retardierten Endtriebes durch die basalen Triebe auf sein Wachstum bestimmend einwirke, schnitt ich etwa 14 Tage nach dem Entgipsen der sekundären Endknospe sämtliche Triebe des Systems ab, als die Endknospe äußerlich noch keinerlei Zeichen korrelativer Schädigung zeigte.

Gleichwohl war sie bereits stark beeinflußt, wenn auch nicht in dem gleichen Maße wie bei dauernder Beeinflussung durch die tieferen Triebe. In dem einem Fall, wo der oberste Trieb beim Entgipsen $83 \%$ seiner definitiven Länge erreicht hatte, wurde die Endknospe nachträglich abgestoßen, in einem andern, wo der oberste Trieb nur $68 \%$ seiner definitiven Länge erreicht hatte, trieb die Endknospe aus $\left.{ }^{1}\right)$ und bildete einen allerdings nur $1 \mathrm{~cm}$ langen Trieb mit zwei Blättern $\left.{ }^{2}\right)$.

Da die tieferen Triebe in beiden Fällen erst entfernt wurden als sie ihre endgültige Länge erreicht hatten, mithin die schwellende Endknospe eine Zeitlang unter dem Einfluß tieferer ausgewachsener Triebe gestanden hatte, so zeigt der Vergleich dieser Versuche, daß der Abort der Endknospe in hohem Grade von der Dauer abhängig ist, während der die ausgewachsenen tieferen Triebe auf sie wirken.

Entfernte ich die Seitentriebe zu gleicher Zeit, wo ich die sekundäre Endknospe entgipste, so zeigte sich, daß diese auch bei Tilia bereits korrelativ beeinflußt wird, während sie noch durch den Gipsverband gehemmt ist.

Bereits von den aufbrechenden Seitenknospen wird das Wachstum der eingegipsten Akralknospen induzierend bestimmt. Diese entwickelt zwar einen kräftigen Trieb, wenn jene beim Entgipsen abgebrochen werden ${ }^{3}$ ), doch erreicht er nicht die Länge normaler Endtriebe. Seine

1) Dieser Trieb war rot gefärbt.

2) Dieser korrelativen Wachstumshemmung des Endtriebes kann ein starkes Wachstum seiner Knospen parallel gehen. Die Zweige, die im nächsten Frühjahr austrieben, waren ungewöhnlich lang und kräftig. In einem Falle, wo der Endtrieb $17 \mathrm{~mm}$ lang war und vier Blätter besaß, gestaltete sich das System 1911: $250 \mathrm{~mm}-191-38$ - ruhende Knospe, während das krïftigste der 1911 von mir beobachteten normalen Systeme $232 \mathrm{~mm}-122-51$ usw. lautete.

3) S. 630. (1911.) 
Länge betrug in einem Falle $161 \mathrm{~mm}$, in einem andern $137 \mathrm{~mm}$, d. i. im Durchschnitt $149 \mathrm{~mm}$, gegenüber der durchschnittlichen Länge des Endtriebes von $180 \mathrm{~mm}$ an (4) zum Vergleich herangezogenen intakten Systemen ${ }^{1}$ ).

Sind die Seitenknospen ausgetrieben, so tritt ihr Einfluß auf die mechanisch gehemmte Terminalknospe noch deutlicher zutage. Mitte Juni entgipste ich etliche sekundäre Endknospen und entfernte zugleich die Seitentriebe: Waren diese ausgereift, so abortierte die Endknospe bereits nach 3 Tagen, waren sie dagegen noch nicht ausgereift, so hielt sie sich bedeutend länger gesund.

Daß auch bei Tilia die mechanisch gehemmte Knospe bedeutend langsamer und schwächer beeinflußt wird als die freie Knospe, zeigt folgender Vergleich: Ich ließ in einem Falle nach dem Entgipsen der Endknospe die Seitentriebe zunächst weiter wachsen. Als ich sie nach etwa 14 Tagen entfernte, entgipste ich gleichzeitig eine andere Endknospe und entfernte an diesem System zugleich die Seitentriebe. Im ersten Fall wuchs der oberste Trieb in den 3 Tagen, ehe er entfernt wurde, 6,5 mm (209-215,5 mm), im zweiten Falle in derselben Zeit nur noch 2,5 mm (239,5-241 mm), sein Wachstum war also durchaus am Verklingen. Wenn trotzdem im zweiten Fall die Endknospe austrieb, nicht aber im ersten, so war dies eine Folge des Schutzes, den mechanische Hemmung gegen korrelative Beeinflussung gewährt. Dasselbe wird auch durch die Tatsache bestätigt, daß die bis Anfang oder Mitte Juli eingegipsten Knospen nicht sofort abortierten, sondern sogar zu wachsen begannen, während sämtliche übrigen entgipsten Knospen bereits abgestoßen waren, auch wenn sie sich soweit zu entwickeln vermocht hatten, daß die Blätter die Knospe durchbrachen.

Wurden tiefer am Zweige inserierte Knospen durch Eingipsen am rechtzeitigen Austreiben verhindert, so zeigten diese, wie es nach der normalen Gestaltung des Systems auch nicht anders zu erwarten war, eine noch bedeutend größere Empfindlichkeit gegen korrelative Einflüsse als die sekundären Endknospen in den bisher dargestellten Versuchen. Hielt ich die zweite Knospe bis Mitte Mai (1910) ein-

1) W:̈hrend ein Entfernen der seitlichen Knospen vor dem Austreiben den Endtrieb verlängert (S. 625), waren also die Endtriebe, deren Knospen eine Zeitlang mechanisch gehemmt gewesen waren, trotz der Entfernung der seitlichen Triebe im Durchschnitt $26 \mathrm{~mm}$ kürzer als sich normal entwickelnde Endtriebe. 
gegipst, und entgipste sie, als der Endtrieb etwa $67 \%$ seiner definitiven Länge erreicht hatte, so abortierte sie bereits nach wenigen Tagen. Entgipste ich sie später, so brach sie entweder schon während des Entgipsens ab oder bald nach dem Entgipsen, wenn sie berührt wurde ${ }^{1}$ ).

Gipste ich die beiden höchsten Knospen gemeinsam ein und entgipste sie gleichzeitig, so wurde auch hier regelmäßig zuerst die zweite Knospe abgestoßen, obgleich diese nach dem Entgipsen bisweilen stärker anschwoll als die erste. Und zwar zeigte ein Vergleich dieser Versuche mit solchen, wo die Endknospe allein eingegipst war, und die zu derselben Zeit entgipst wurden, daß die zweite Knospe bei jenen Versuchen früher abortierte, die Endknospe in beiden Fällen etwa gleichzeitig. Daraus geht hervor, da $B$ der frühere Abort der zweiten Knospe auf den Einfluß der schwellenden Endknospe mit zurückzuführen ist, obgleich diese selbst korrelativ bis zur Lebensunfähigkeit geschädigt war.

\section{Salix aurita und Salix fragilis.}

Diese Untersuchungen führte ich an isolierten Zweigen aus. Und zwar benutzte ich nicht die mittleren Partien von Zweigen ${ }^{2}$ ), sondern Zweige mit unverletztem Gipfel, wie sie sich im vorangehenden Jahre gebildet hatten.

Der Zweig von Salix ist der Anlage nach und in den ersten Stadien seiner Entwicklung dem Tilia-Zweig durchaus homolog: Wie bei Tilia wird auch hier in der Regel bereits während der Streckung im Frühjahr die Zweigspitze abgestoßen ${ }^{3}$ ). Während aber bei Tilia der ausgereifte Zweig nach dem Spitzenabwurf an der Spitze oder wenigsten nach der Spitze zu gleich kräftig ist wie an der Basis, wie man auch aus der Größe der Knospen im Herbst an dem gleichmäßig dicken Zweige erkennen kann, ist dies bei Salix nicht der Fall.

1) Daß diese Knospen Ende Mai im Gips noch nicht abgestoßen waren, während die Mitte Mai entgipsten um diese Zeit bereits abortiert hatten, ist auch in diesem Falle darin bedingt, daß die korrelativen Einflüsse auf die mechanisch im Wachstum vollständig gehemmte Knospe viel langsamer wirken als auf eine Knospe, deren Wachstumsbestrebungen äußerlich nichts im Wege steht.

2) Vöснтing, 1878, S. 17; Kny, S. 276; Mc Callum, S. 100, Fig. 2.

3) Daß neben dieser Form des Wachsens auch dauerndes Wachstum der Zweige vorkommen kann (Magnus, S. 325), ist in der ungeordneten Art der Korrelationen bei strauchförmigem Wuchs bedingt. Auch die Ulme (S. 625, Anm. 1) z. B. bildet als Strauch neben sympodialen Zweigen ohne Spitze dauernd wachsende Zweige. Über ein ähnliches Verhalten bei Wasserreisern vgl. VoLKens, S. 125 . 
Hier bleiben die Spitzen der Zweige schwach; der Durchschnitt des Zweiges verjüngt sich nach der Spitze hin, und die Knospen werden kleiner. Im nächsten Frühjahr treiben die akralen Knospen dann bisweilen nicht aus, auch wenn man die tieferen Knospen entfernt; wenn sie austreiben, werden sie oft $\nabla$ on tieferen Trieben überholt, und bisweilen abortieren sie.

Treiben im Frühjahr die Endknospen von Salix aurita nicht aus oder abortieren sie, so stirbt die Zweigspitze, die keine lebensfähigen Knospen trägt, allmählich basipetal ab. Sie beginnt jedoch erst dann abzusterben, wenn ihre Knospen tot sind. Bei Salix fragilis bleibt die Fähigkeit, Endglieder abzustoßen, auch beim verholzten Zweige noch erhalten, und so kommt es, daß die schwachen Spitzen der Zweige im Winter vielfach abgeworfen werden. Sind im nächsten Frühjahr die Knospen an der Spitze nicht lebensfähig, so bricht diese direkt über dem obersten Jungtrieb leicht $a b^{1}$ ). Dies geschieht besonders im Freien, wo der Wind den Abwurf begünstigt. Bleibt diese äußere mechanische Hilfe aus, wie dies bei meinen Stecklingen der Fall war, so sterben die Zweigenden unter Umständen ähnlich wie bei Salix aurita $a b^{2}$ ).

Wenn bei den von mir untersuchten Stecklingen die sekundäre Endknospe seltener austrieb als bei den Zweigen am Strauch, so hat dies seine Ursache vor allem darin, daß ich die Zweige während des Austreibens in Wasser kultivierte, und hierbei die unteren Knospen den oberen gegenüber durch den größeren Feuchtigkeitsgehalt der Luft begiinstigt wurden ${ }^{3}$ ).

Das Verhalten der Knospen an der mittleren Zweigregion ließ bei Salix fragilis eine gewisse Periodizität erkennen, indem vielfach zwischen zwei austreibenden Knospen eine oder mehrere als Knospe oder als junger Trieb abortierten. An den Narben entwickelten sich wie bei Tilia ${ }^{4}$ ) ruhende Knospen.

Die Versuchspflanzen befanden sich bis Mitte April im Aquariumraum; nach dem Entgipsen stellte ich sie ins Ericaceenhaus, wo die Temperatur sich der der freien Natur näherte. In den ersten Tagen war diese ziemlich hoch und der des Aquariumraumes etwa gleich, fiel jedoch bald recht tief und hielt sich fast 4 Wochen so niedrig.

1) Doch brechen auch völlig gesunde Glieder in der gleichen Weise leicht $a b$.

2) Bei den Stecklingen gehen im allgemeinen mehr Knospen zugrunde als am Strauch.

3) Vöchting, 1906, S. 132; Mc Callum, S. 250.

4) S. 624 . 
Dieser intensive Temperaturumschlag sistierte das Wachstum der ziemlich weit ausgetriebenen Zweige, indem er ihre Empfindlichkeit gegen die zwischen ihnen bestehenden korrelativen Hemmungen erhöhte. Doch trieben diese Zweige zum Teil einige Zeit, nachdem sie ausgewachsen waren, ihre sekundäre Endknospe oder eine ihrer Seitenknospen proleptisch aus $\left.{ }^{1}\right)$. Dies geschah bei Salix aurita sowohl an solchen Stecklingen, deren entgipste Akralknospen nicht austrieben, als auch an solchen, wo dies der Fall war, in gleicher Weise und auch ungefähr gleichzeitig, bei Salix fragilis dagegen nur an solchen, deren Akralknospen nicht mehr austrieben.

Hatte ich die beiden obersten Knospen eingegipst ${ }^{2}$, so trieben diese nach dem Entgipsen nicht aus, vielmehr setzte der Sproß sein Wachstum allein durch das proleptische Treiben der bereits ausgetriebenen tieferen Zweige fort. Später starben die akralen Knospen ab, und zwar meist in akropetaler Folge.

Hatte ich die drei obersten Knospen eingegipst (Salix fragilis) ${ }^{3}$ ), so abortierten diese in einem Falle, wo die oberste freie Knospe einen ziemlich langen $(123,5 \mathrm{~mm})$ Trieb gebildet hatte. In zwei andern Fällen jedoch trieb je eine eingegipste Knospe aus: Die obersten Triebe der nicht eingegipsten Zone waren Kurztriebe, die Kätzchen getragen hatten ${ }^{4}$ ).

Hemmte ich eine größere Serie akraler Knospen (sechs), so wuchsen regelmäßig einige von diesen nach dem Entgipsen aus, und zwar um so früher, je kürzer die bereits vorhandenen und ausgewachsenen Triebe waren (Salix aurita $)^{5}$ ). Nie waren es die untersten der eingegipsten Knospen die austrieben. Vielmehr abortierte zwischen dem obersten Triebe unterhalb der gehemmten Knospen und der austreibenden Knospe eine Anzahl von Knospen. Die Triebe der eingegipsten Zone wurden stets bedeutend länger als die der basalen Zone. Doch kann ich nicht sagen, ob deren Kürze im Wachstum der akralen Triebe bedingt war, da ihr Wachstum, wie gesagt, durch den Bedingungswechsel beeinflußt war.

1) In seltenen Fällen bildete die sekundäre Endknospe den Neutrieb, häufiger die zweite oder dritte oder die Basalknospe. In allen Fällen waren aber sämtliche Glieder des Gesamttriebes kräftig und lebensfähig.

2) Tab. XIV a, b; XVa.

3) Tab. XV b-d.

4) Die Kätzchen bilden den Gipfel des Triebes.

5) Tab. XIV c, d. 


\section{Diskussion der Versuche.}

Ehe ich die einzelnen Ergebnisse meiner Untersuchungen bespreche, will ich das allgemeine Verhalten der von mir verwandten Sproßsysteme kurz darstellen. Da sich meine Versuche vor allem auf die Sproßsysteme während der physiologischen Periode erstreckten, ist diese bei den folgenden Ausführungen allein beriicksichtigt, soweit anderes nicht besonders vermerkt ist.

In erster Linie hängt die Gestaltung der betreffenden Verzweigungssysteme von der Verteilung der einzelnen Triebe an der Mutterachse ab. Ein Trieb, der normalerweise den andern überlegen ist, d. h. bei den in Betracht kommenden Fällen ein akraler Trieb, ist innerhalb bestimmter, von der Art und den äußeren Bedingungen abhängiger Grenzen auch dann noch den andern mehr oder weniger iiberlegen, wenn er diesen zunächst in der Entwicklung nachsteht, sei es infolge des spezifischen, korrelativ bedingten Entwicklungsmodus, sei es infolge zeitweiser mechanischer Hemmung. Und umgekehrt wird ein am rechtzeitigen Austreiben verhinderter normalerweise untergeordneter, $d$. h. tiefer inserierter Trieb schon nach viel kürzerer Zeit in seiner normalen Entwicklung bedeutend eingeschränkt.

Erst in zweiter Linie ist die Gestaltung des Systems vom Entwicklungszustand seiner einzelnenTriebe abhängig. Je länger ein übergeordneter Trieb gewaltsam in seiner Entwicklung gehindert wird, d. h. je größer der Unterschied zwischen seinem Entwicklungszustande und dem der übrigen wird, desto mehr wird sein Übergewicht über die andern geschwächt, und schließlich werden ihm diese mehr und mehr überlegen. Diese Überlegenheit ist je nach der Art bald in der vegetativen Entwicklung, bald in der Reife bedingt.

Sind zwei Triebe voneinander abhängig, so bleibt diese Abhängigkeit nicht labil; vielmehr wird das Wachstum der einzelnen Triebe durch diese Abhängigkeit mehr oder weniger induzierend bestimmt. Außer dem Ort, wo der korrelativ beeinflußte Sproß an der Mutterachse eingefügt ist, außer der Zahl und Anordnung der ihn beeinflussenden Sprosse, und außer deren und seinem eigenen Entwicklungszustande sind die äußeren Bedingungen für den Grad der Induktion von Bedeutung, und die Zeitdauer, während der er korrelativ beeinflußt wird. Auch wird ein Sproß viel schneller und deutlicher 
induziert, wenn erwächst, als wenner mechanisch am Wachstum verhindert ist.

Diese kurz zusammengefaßten Tatsachen sollen im folgenden näher ausgeführt werden:

\section{Die Stellung der Knospen und Triebe am Mutterzweige und deren Bedeutung für die sproßkorrelationen.}

Bei der normalen Entwicklung von Sproßsystemen ist es durchaus nichtselten, daßein dem andern übergeordneter Sproß später auszutreiben beginnt als diese. Ein solches Verhalten ist bei den rein monopodialen Zweigsystemen von Torreya ${ }^{1)}$ und Picea ${ }^{2}$ ) die Regel; es findet sich meist bei Faba-Keimlingen nach deren Dekapitation über dem ersten Primärblatt ${ }^{3}$, und nicht selten bei dem sympodialen Verzweigungsmodus von Tilia ${ }^{4}$ ): Der akrale Trieb treibt später aus als die tiefer inserierten, und hemmt diese gleichwohl in ihrem Wachstum intensiver als diese ihn ${ }^{5}$ ), sofern uiberhaupt eine gegenseitige Beeinflussung statthat $\left.{ }^{6}\right)$.

Diese Tatsache beweist allein schon die Irrigkeit der Morganschen Annahme ${ }^{7}$ ), daß die Verschiedenwertigkeit der Knospen in der größeren Reife der terminalen bedingt sei.

Die Bedingungen für das spätere Austreiben überlegener Knospen sind verschiedener Natur:

Wenn bei dekapitierten Faba-Keimlingen die Kotyledonaraxillare vor dem ersten Primärblattaxillar austreiben ${ }^{8}$, handelt es sich um sehr verwickelte Korrelationen, bei denen die Blattorgane von Bedeutung sind, in deren Achseln die Knospen inseriert sind. Bekanntlich ist das Primärblatt von Faba stark reduziert. Dekapitiert man Phaseolus-Keimlinge und entfernt zugleich die wohlentwickelten Primärblätter, so verhalten sie sich wie Faba. Läßt man dagegen die Primärblätter stehen, so treiben deren Axillare allein aus \%). Dies ist um so auffälliger, als nach den Untersuchungen DostáLs ${ }^{10}$ ) ein Laubblatt seine Achselknospe hemmt und im allgemeinen gerade Entlaubung (Insektenfraß) ein Austreiben der Achselknospen zur Folge hat11). Offenbar hemmt aber das Laubblatt nicht nur die ihm zugehörige Knospe, sondern auch die Knospe des tieferen Knotens, und zwar diese intensiver, während bei mangelnder Ausbildung der Primär-
1) S. 612 .
2) S. 620 .
3) S. 605 .
4) S. 623 .
5) S. 606,623 .
6) S. 613,620 .
7) Morgan, S. 120.
8) S. 605 .
9) S. 608 .
10) Dostíl, S. 548 f. Vgl. auch JacoBi, S. 282 ff.
11) Pfeffer, 1904, S. 196. 
blätter die Kotyledonen möglicherweise das Austreiben ihrer Axillare beschleunigen.

Anders liegen die Verhältnisse bei Tilia und Salix: Hier wird nach dem Abort der Spitze und dem sekundären Gliederabwurf das Ende eines Triebes durch die Triebe des gleichen Systems korrelativ meist noch weiter gehemmt $\left.{ }^{1}\right)$. Durch diese Hemmung wird die Verholzung der akralen Knospen nicht beeinflußt, wohl aber ihre innere Reife.

Bei Tilia steht die sekundäre Endknospe vor dem Austreiben an Größe und Ausbildung der folgenden nicht nach ${ }^{2}$ ). Wenn diese gleichwohl eher auszutreiben beginnt als jene, so ist dies offenbar auf eine verzögerte Ausbildung der inneren Fähigkeiten zurïckzuführen.

Bei Salix nimmt gegen die sekundäre Spitze des Zweiges hin die Größe der Knospen ab. Die Verzögerung des Austreibens kann sich hier im nächsten Frühjahr bis zum völligen Verlust der Wachstumsfähigkeit akraler Knospen steigern ${ }^{3}$ ).

Da das Verhalten der akralen Knospen auch bei Entfernung der tiefer inserierten das gleiche ist ${ }^{4}$ ), kann es nicht in einer von diesen und ihren Trieben ausgehenden Hemmung bedingt sein.

An und für sich können die sekundären Endknospen von Salix sehr wohl früher austreiben, wie die Bildung von proleptischen Trieben zeigt $\left.{ }^{5}\right)$. Wenn nun im Herbst oder im nächsten Frühjahr trotz Beseitigung der das proleptische Austreiben normalerweise hemmenden Blätter ${ }^{6}$ ) die akralen Knospen ungewöhnlich spät oder überhaupt nicht austreiben ${ }^{7}$ ), so ist dies offenbar hauptsächlich darin begründet, daß die vorzeitige Verholzung einer Knospe die Auswirkung ihrer inneren Fähigkeiten verzögert ${ }^{8}$ ).

Da sich bei Salix der Durchmesser des Zweiges gegen die Spitze hin verjüngt ${ }^{9}$ ), wäre es wohl möglich, daß die akralen Knospen inbezug auf Ernährung oder Wasserversorgung ungünstiger gestellt seien, und daß auch dieser Umstand das verzögerte Austreiben mit herbeiführe. Doch ist die akrale Reduktion des Zweiges von wesentlicher Bedeutung nicht, denn bei Tilia-Zweigen mit später austreiben-
1) S. $627 \mathrm{f} ., 635$.
2) S. $634 \mathrm{f}$.
3) S. 635 .
4) S. 628, 635 .
5) S. 636.
6) SpÄtII, S. 39 ff.
7) S. $624,628,635$.
8) Möglicherweise ist eine frühreife Knospe der Arbeitsleistung einer har- monisch ausgebildeten Knospe weniger fähig und braucht infolgedessen längere Zeit zum Auseinandertreiben der Knospenhiulle.

9) S. 635 . 
der sekundärer Endknospe bleibt der Zweigdurchmesser auch gegen die sekundäre Spitze hin gleich ${ }^{1}$ ).

Obwohl uiber das korrelative Verhalten eines Sprosses vor allem seine Stellung am Mutterzweige entscheidet, ist das verzögerte Austreiben akraler Knospen doch auch mehr oder weniger von Bedeutung fuir die Gestaltung des betreffenden Systems, da sie in höherem Maße von tiefer inserierten Trieben abhängig sind, als wenn sie gleichzeitig mit diesen austreiben, während diese weniger von ihnen beeinflußt werden. Da ich später die Bedeutung des Entwicklungszustandes der einzelnen Triebe eingehender bespreche ${ }^{2}$, führe ich hier als augenfällige Beispiele nur die induzierten Zwillingssysteme von Tilia an, wo außer der Entwicklungsdifferenz in der physiologischen Periode auch eine induzierende Schwächung des Triebes bereits in seiner morphologischen Periode in Betracht kommt ${ }^{3}$ ), und die sterilen Verzweigungssysteme von Torreya.

Letztere sind besonders beachtenswert, weil gerade in dem verzögerten Austreiben der Endknospe ${ }^{4}$ ) die größtmögliche Ausbildung der sterilen Systeme und damit zugleich ihre höchste assimilatorische Leistungsfähigkeit bedingt ist. Bei Torreya ist ebenso wie bei Picea die Wachstumsbahn eines jeden Triebes bereits vor dem Austreiben der Knospen fixiert ${ }^{5}$ ), wahrscheinlich infolge einer wechselseitigen Beeinflussung der Knospen in ihrer morphologischen Periode ${ }^{6}$ ). Aber wie die erblich fixierte Gestalt einer jeden Pflanzenart nur unter günstigen Bedingungen ganz zur Entfaltung kommt, unter ungünstigen Bedingungen aber auf mancherlei Weise reduziert werden kann ${ }^{7}$ ), so kommt auch die fixierte Entwicklungsbahn eines Torreya-Sprosses nur unter günstigen Bedingungen zum Ausdruck. Diese sind dann gegeben, wenn ein Trieb sich unabhängig von den andern Trieben seines Systems entwickelt ${ }^{8}$ ); sie sind aber auch dann gegeben, wenn die Triebe eines sterilen Systems sich in normaler Weise entwickeln.

Wird das Austreiben der Seitentriebe nur wenig verzögert, so werden diese durch den Endtrieb in ihrem Wachstum entschieden

1) S. 634 .

2) S. $651 \mathrm{ff}$.

3) S. 628 .

4) S. 612 .

5) S. 613.

6) Daß Knospen eines Systems tatsächlich einander bereits vorm Austreiben korrelativ beeinflussen, zeigt die Tatsache, daß Seitenknospen, die normal erst nach der Winterruhe austreiben, dies tun, ebe der Mutterzweig sein Wachstum einstellt, wenn die Endknospe entfernt wird (GoebeL, 1898, S. 179). Vgl. auch Goebel, 1884, S. 8.

7) Wiesner, 1910, S. 255 ff.; Diels, S. 7 ff.

8) d. h. wenn diese inaktiviert oder geschwächt werden (S. 613, 618). 
gehemmt ${ }^{1}$ ), während der am rechtzeitigen Austreiben verhinderte Endtrieb schwerer von den Seitentrieben zu beeinflussen ist ${ }^{2}$ ). Dadurch daß die Endknospe normalerweise später auszutreiben beginnt als die Seitenknospen, wird das Verhältnis der Entwicklungszustände der einzelnen Triebe zueinander dergestalt reguliert, daß sich die Triebe in allen einzelnen Phasen ihrer Entwicklung korrelativ neutral verhalten, $d$. $h$. weder einander hemmen noch gehemmt werden. Dies gilt jedoch allein für rein sterile Systeme ${ }^{3}$ ).

Worin das verschiedene korrelative Verhalten der einzelnen Triebe je nach ihrer Stellung am Mutterzweig bedingt ist, läßt sich im allgemeinen nicht sagen.

Bei den von mir untersuchten Fällen ist die Ausbildung des Mutterzweiges sicher nicht von wesentlicher Bedeutung. Sowohl bei Picea ${ }^{4}$ ) wie auch bei Tilia ${ }^{5}$ ) entwuchsen korrelativ stark reduzierten Mutterzweigen durchaus normale und kräftige Zweige.

Die Stelle, wo ein Trieb dem Mutterzweig inseriert ist, bestimmt an und für sich bei Tilia das Verhalten der Triebe nur insofern, als die tiefst inserierten Knospen offenbar infolge der zwischen den Knospen und möglicherweise auch ihren Tragblättern während ihrer morphologischen Periode bestehenden Korrelationen ${ }^{6}$ ) anders reifen. Für den größten Teil des Systems bestimmt die Insertionsstelle der Triebe deren Verhalten an und für sich nicht: Werden mittlere Knospen ausgebrochen oder inaktiviert, so treten die nach der Basis hin folgenden in ihrem Verhalten an deren Stelle ${ }^{7}$.

Wichtiger ist die Insertionsstelle der Triebe für ihr korrelatives Verhalten bei den monopodialen Papilionaceenkeimlingen, weil hier durch das dauernde Wachstum der Hauptachse die Seitenknospen verschieden lange und infolgedessen verschieden stark von dieser korrelativ beeinflußt werden, und zwar zunächst der Zeitfolge ihrer Anlage gemäß um so länger, je tiefer sie inseriert sind.

Dies kommt in dem verschiedenen korrelativen Verhalten von

1) S. $618 \mathrm{f}$.

4) S. 622 .

6) S. 640, Anm. 6; S. 638 . Nachtrag: Möglicherweise werden auch bei Tilia die untersten Knospen durch die wachsende Spitze ihres Muttertriebes intensiver beeinflußt als die höher inserierten Knospen, ähnlich wie dies bei den Papilionaceenkeimlingen der Fall ist (s. u.). Die oberen Knospen sind vom Muttertrieb kaum abhängig, da dieser selbst in seinem Wachstum mehr und mehr korrelativ gehemmt und infolgedessen in seinem Hemmungsvermögen beeinträchtigt wird.

7) S. 625 . 
Hauptsproß und Kotyledonaraxillaren einerseits ${ }^{1}$ ) und Primärblattaxillar und Kotyledonaraxillaren (bei dekapitiertem HauptsproB;2) anderseits nach zeitweiser mechanischer Wachstumshemmung des jeweils übergeordneten Sprosses zum Ausdruck. Der Hauptsproß wird während seines normalen Wachstums von den Axillarknospen nicht beeinflußt, während seiner Hemmung im Gipsverband sicher nur in sehr geringem Grade ${ }^{3}$. Dagegen werden die Axillarknospen vom wachsenden HauptsproB in ihrer Wachstumsgeschwindigkeit und in ihrem Hemmungsvermögen induzierend geschwächt, und zwar die Kotyledonaraxillare mehr als der Primärblattaxillar. Infolgedessen zeigt der Hauptsproßnach längerer Wachstumshemmung viel regelmäßiger eine ausgesprochene Überordnung über die an vegetativer Ausbildung ihm bedeutend überlegenen Kotyledonaraxillare, als der zeitweise gehemmte Primärblattaxillar über diese ${ }^{4}$ ).

Wenn die Korrelationen von Primärblattaxillar und Kotyledonaraxillar eine größere Variationsbreite besitzen als die von Hauptsproß und Kotyledonaraxillar5), so liegt dies zum Teil daran, daß Primärblattaxillar und Kotyledonaraxillar, ehe sie einander korrelativ beeinflussen, von dem Hauptsproß in verschiedenem Maße abhängig gewesen sind, daß also ein neuer, im einzelnen unbekannter Faktor mitwirkt. Vor allem aber kann es nicht ohne Bedeutung sein, daß die Kotyledonaraxillare vor dem ihnen überlegenen Primärblattaxillar austreiben $\left.{ }^{6}\right)$. Durch ihre individuell verschiedene vegetative Entwicklung tritt abermals ein neuer variabler Faktor wirksam in das korrelative Getriebe.

Daß die Schwächung des Hemmungsvermögens bei den Axillaren hier tatsächlich auf korrelative Einfluisse zurückzuführen ist, denen sie als Knospe ausgesetzt waren, geht aus einer Betrachtung ihrer Belaubung hervor.

Die Primärblätter des Primärblattaxillars sind Zwischenformen zwischen den einfachen Primärblättern und den normalen Laubblättern ${ }^{7}$, die der Kotyledonaraxillare dagegen sind einfache Primärblätter. Wie ich aus den Korrelationen zwischen Hauptsproß, Primärblattaxillar und Kotyledonaraxillaren festgestellt habe, steht der Primärblattaxillar in seiner Fähigkeit zu hemmen zwischen dem Hauptsproß und den Kotyledonarxillaren, ist also diesen überlegen ${ }^{4}$ ). Ferner trugen diejenigen Kotyledonaraxillare, die dem Primärblattaxillar korrelativ überlegen waren, nicht die üblichen Primärblätter, sondern Blätter, die sich dem normalen Typus des Laubblattes näherten ${ }^{8}$ ).
1) S. $593 \mathrm{ff}$.
3) S. $598 \mathrm{f}$.
6) S. 605 .

2) S. $605 \mathrm{ff}$.

4) Vgl. S. 605 ff. und S. 593 ff.

7) Goebel, 1884, S. $251 \mathrm{ff}$.
5) S. $604 \mathrm{f}$.

8) S. 606, Anm. 1. 
Ob die Annahme Goebels zu Recht besteht, daß das unterste Blatt des Primärblattaxillars auf dem Stadium der äußeren Ausbildung stehen bleibt, wo es stand, als der Primärblattaxillar durch die Dekapitation des Hauptsprosses zum Wachstum angeregt wurde1), oder ob seine Gestalt schon vorher fixiert war, ist für meine Beweisfiihrung ohne Bedeutung. Auf jeden Fall aber ist seine Gestal nicht im Wachstum seines eigenen Sprosses bedingt, sondern, ähnlich wie bei den Nadeln der Kümmertriebe von Coniferen ${ }^{2}$ ), in einer korrelativen Beeinflussung durch den Hauptsproß, da es andernfalls nicht erklärlich wäre, warum die früher angelegten Kotyledonaraxillare in der Regel einfachere Blätter bilden als der Primärblattaxillar.

Außer diesem Parallelismus von Blattreduktion und Schwächung des korrelativen Hemmungsvermögens macht es auch ein Vergleich des korrelativen Verhaltens von Kotyledonaraxillaren und HauptsproB nach zeitweiser mechanischer Hemmung des letzteren bei Faba und Phaseolus durchaus wahrscheinlich, das die korrelative Unterordnung der Axillare unter den ihnen an vegetativer Ausbildung oft weit nachstehenden Hauptsproß in der Hauptsache in ihrer Beeinflussung als Knospen durch den Hauptsproß bedingt ist: Bei Phasoleus, wo schon im normalen Verlauf der Entwicklung axillare Knospen leichter austreiben als bei $F\left(b a^{3}\right)$, die korrelative Hemmung also schwächer ist, genügt schon eine um weniges stärkere vegetative Ausbildung der Kotyledonaraxillare, um das Wachstum des entgipsten Hauptsprosses zu sistieren ${ }^{4}$ ), während sie bei Faba dem HauptsproB an vegetativer Ausbildung bedeutend überlegen sein müssen ${ }^{5}$.

Fasse ich das wesentlichste Ergebnis dieser Erörterungen über die absolute Bedeutung der Insertionsstelle der einzelnen Triebe für ihre Korrelationen kurz zusammen: Bei Tilia is t das korrelative Verhalten der einzelnen Knospen zur Zeit ihres Austreibens - wenn ich von der Verzögerung des Austreibens basaler und bisweilen akraler Knospen absehe - nicht induziert, bei den Papilionaceenkeimlingen dagegen sind die Knospen je nach ihrer Insertionsstelle in verschiedenem Grade in ihrem korrelativen Hemmungsvermögen geschwächt.

Diese Tatsache macht auch das verschiedene korrelative Verhalten erklärlich, das einerseits ein Faba-Keimling nach zeitweiser mechanischer Hemmung seines Hauptsprosses ${ }^{6}$ ) und anderseits ein

1) Goebel, 1898, S. 135 .

2) S. $615,621 \mathrm{f}$.

3) S. 608 .

5) S. 593.

6) S. 593 . 
Lindenzweig nach zeitweiser mechanischer Hemmung seiner sekundären Akralknospe ${ }^{1)}$ zeigt.

Die Polarität kommt zwar auch am Tilia-Zweig noch zum Ausdruck, indem sich eine terminale Knospe gegenüber den Einwirkungen der übrigen Triebe länger zu halten vermag als die gleichzeitig gehemmte zweite Knospe ${ }^{2}$ ), doch genügt schon eine recht geringe Entwicklungsdifferenz mit den übrigen Knospen, um den Abort der Endknospe zu veranlassen ${ }^{3}$ ), und umgekehrt ist deren Einfluß auf das Wachstum der tieferen Triebe nur bei einer geringen Wachstumsverzögerung des Endtriebes nachzuweisen ${ }^{4}$ ). Nur bei den unbedeutenden Entwicklungsdifferenzen, wie sie in der natürlichen Folge des Austreibens bisweilen bedingt sind, behält die Terminalknospe, in der Regel wenigstens, ihr Übergewicht über die tieferen.

Bei Verzweigungsystemen von Tilia und Salix entscheidet über das korrelative Verhalten der einzelnen Knospe - wenn man von der verzögerten Reife absieht - ihre Stellung am Mutterzweig allein in Beziehung auf die übrigen am Wachstum nicht verhinderten Knospen.

Neben einem schwächeren akropetalen Einfluß macht sich eine ausgesprochen basipetale Hemmung geltend, indem die Triebe durch verfrühten Wachstumsabschluß um so kürzer werden, je mehr Triebe ihnen nach der Spitze zu uibergeordnet sind ${ }^{5}$.

Wie ich im experimentellen Teil dargetan habe, wird ein Trieb, der von andern korrelativ abhängig ist, von diesem in seinem Hemmungsvermögen geschwächt; zugleich aber wird das Hemmungsvermögen eines korrelativ übergeordneten Triebes auf einen ihm untergeordneten um so schwächer, je mehr wachsende oder korrelativ ruhende Triebe oder Knospen zwischen diesem und jenem gelegen sind ${ }^{6}$ ). Als Beleg fuhrte ich vor allem die labilen Zwillingssysteme von Tilia-Zweigen an.

Deutlicher noch als bei Tilia tritt diese Erscheinung bei Salix zutage. Dort finden sich nicht nur in der basalen Zone, sondern auch höher am Zweig zwischen austreibenden Knospen solche, die abortieren ${ }^{7}$. Daß diese tatsächlich für den Hemmungsreiz gewissermaßen als Reusen dienen, ergibt sich eindeutig aus den Versuchen, wo die Gipfelknospen am Austreiben verhindert wurden, bis sich die basalen Triebe entfaltet hatten. Nur dann vermochten jene noch aus-

1) S. $629 \mathrm{f}$.

5) S. $623,625 \mathrm{f}$.
2) S. $633 \mathrm{f}$.

6) S. 626 .
3) S. 629 .

7) S. 635 .

4) S. $630,631 \mathrm{f}$. 
zutreiben, wenn sich über diesen eine größere Anzahl von Knospen befand, von denen die den Basaltrieben am nächsten inserierten fast regelmäßig abortierten ${ }^{1}$ ).

In ähnlicher Weise wie die nichtaustreibenden und später abortierenden Knospen bei Salix den Hemmungsreiz vermindern, tun dies wahrscheinlich auch die ruhenden Achselknospen der Papilionaceenkeimlinge. Wenn in einem gewissen Alter der erste Primärblattaxillar von Vicia Faba austreibt2), so hat die Pflanze bis dahin eine Anzahl von Axillarknospen gebildet, die ausreicht, den von der Spitze des Hauptsprosses ausgehenden Hemmungsreiz soweit zu schwächen, daß die korrelative Ruhe des Primärblattaxillars aufgehoben wird.

Beachtenswert scheint mir auch die Tatsache, daß die korrelative Hemmung durch zwischenliegende Sprosse nur dann geschwächt wird, wenn diese sich entsprechend den korrelativen Einflüssen, denen sie selbst ausgesetzt sind, entwickeln können, ohne durch äußere Eingriffe in ihrer Entwicklung gehemmt zu werden. Hatte ich die zweite Knospe eines Tilia-Zweiges eingegipst, so wuchsen die übrigen Triebe so, als ob die eingegipste Knospe überhaupt nicht da wäre, obwohl diese selbst korrelativ sehr stark beeinflußt wurde ${ }^{3}$. - -

Die gleiche Bẹdeutung, die der einzelne Trieb (bzw. die einzelne Knospe) je nach seiner Stellung zu den übrigen für die Gestaltung des Zweigsystems hat, hat das einzelne Zweigsystem seinerseits für die Gesamtgestalt höherer Systeme: Das gesamte Verzweigungssystem eines infolge seiner Stellung einem andern korrelativ untergeordneten Mutterzweiges wird auch von dessen Verzweigungssystem korrelativ stärker beeinflußt, als dieses von ihm. So ist z. B. der Habitus untergeordneter Systeme bei Tilia gedrungen ${ }^{4}$, da bei der Hemmung, die ihre sämtlichen Triebe erleiden, auch das Hemmungsvermögen des Terminaltriebes korrelativ geschwächt und auf diese Weise das Längenverhältnis rom zweiten Trieb zum ersten größer wird.

Nimmt die Länge der einzelnen Triebe eines Systems, wie bei Tilia, nach der Basis hin regelmäßig ab, so wird auf diese Weise die Hauptmasse der Assimilationsorgane nach der Peripherie des Gesamtorganismus verschoben. Diese Tendenz, den Blättern die zu ihrer Entwicklung und zur Ausübung ihrer Funktion günstigsten

1) S. 636 .

2) S. 591.

3) S. $633 \mathrm{f}$.

4) S. 624. Vgl. auch S. 616, Anm. 1. 
Bedingungen zu schaffen, wird noch durch die Richtung der Triebe zu ihrer Mutterachse ${ }^{1}$ ) erhöht: Je näher ein Trieb der Spitze steht, d. h. je leistungsfähiger er durch seine Ausbildung ist, desto mehr strebt er durch den steileren Winkel, den er mit dem Mutterzweig: bildet, nach der Peripherie. Außerdem werden tiefer inserierte Triebe oft lange noch nach der Verholzung abgeworfen ${ }^{2}$ ). So wird durch die Korrelationen zwischen den Trieben des einzelnen Systems hier der gleiche Erfolg erzielt, wie bei Picea und Torreyc durch die auf die äußerste Zweigspitze vorgeschobenen Knospen ${ }^{3}$ ).

Ist dagegen die Abnahme der Trieblängen eines Systems nach der Basis hin nicht kontinuierlich wie bei Salix infolge des verzögerten Austreibens der Spitzet) und der Schwächung der korrelativen Hemmung durch zwischenliegende abortierende Knospen ${ }^{5}$ ), so gestaltet sich der Gesamtwuchs viel unregelmäßiger und bedingt einen strauchförmigen Habitus.

Die Gliederung eines Baumes in Stamm und Krone ist wesentlich in korrelativen Massenwirkungen der Triebe bedingt. Die basipetale Steigerung der Hemmungen unterdrückt die basale Verzweigung und bildet auf diese Weise den Stamm. Die akropetale Steigerung der Hemmungen begrenzt das Spitzenwachstum des Baumes und gibt der Krone ihre breite, ausladende Gestalt. Und zwar wird die Gestalt der Krone bei unsern Laubbäumen außer durch den verschiedenen Grad des Wachstums verschiedenwertiger Triebe wesentlich durch die korrelative Richtungsänderung: der Zweige und $\ddot{A}$ ste und besonders des Gipfeltriebes bcdingt: Deren Winkel zur Mutterachse, beim Gipfeltrieb also zum Stamm, wird im allgemeinen um so größer $\left.{ }^{6}\right)$, je stärker sie korrelatir durch andere Zweige und $\ddot{A}$ ste beeinflußt werden ${ }^{7}$ ).

Die Abhängigkeit der Zweigrichtung von andern Trieben sieht man besonders dentlich an verschnittenen Platanen (Platanus orientalis). Die der Schnittfläche entwachsenden Wasserreiser stehen mebr oder weniger außerhalb der zwischen den regulären Trieben des ge-

1) S. 623 .

4) S. 635 .

2) BÜSGEN, S. 20.

3) S. 611 .

6) Meist ändern auch noch ausgewachsene Zweige ihre Richtung.

7) So besitzen junge Lindenbäume infolge der rein vertikalen Stellung des Gipfeltriebes eine kegelförmige Krone, ältere infolge der Auflüsung des Gipfeltriebes in Transversaläste eine abgerundete Gestalt. 
samten Baumes bestehenden Korrelationen, und stellen sich zunächst fast sämtlich vertikal. Erst allmählich machen sich korrelative Einflüsse bei ihnen geltend, und sie ändern ihre Richtung infolgedessen mit der Zeit in eine mehr oder weniger horizontale um.

Der Grad der Ablenkung, die die Zweige und Äste erleiden, ist in erster Linie natürlich von der betreffenden Art abhängig ${ }^{1}$ ). Als mitbestimmenden Faktor kommen die äußeren Bedingungen des Standortes hinzu ${ }^{2}$ ), wie auch das lokal bestimmte Auftreten unserer meisten Laubhölzer als Strauchform zeigt; und zwar ist die Strauchform von normalerweise Bäume bildenden Pflanzen auf eine verhältnismäßige Steigerung der akropetalen Beeinflussung zurückzuführen ${ }^{3}$ ).

Der Einfluß äußerer Bedingungen auf die zwischen den Zweigsystemen eines Baumes bestehenden Korrelationen läßt sich auch bei Nadelbäumen, wie Picea excelsa, gut beobachten, deren Wuchs je nach dem Standort verschieden ist: Steht sie einzeln und frei, so begünstigt Licht und Luft das Wachstum aller Systeme in gleicher Weise. Die plagiotropen Systeme vermindern das Wachstum der Spitze; der Baum wächst in die Breite und bleibt klein und gedrungen. Steht die Fichte dagegen vergesellschaftet, besonders im Wald, so ist die Mehrzahl der plagiotropen Systeme inbezug auf Licht und Luft ungünstiger gestellt als die Spitze; ihre Entwicklung ist schwächer, und damit verschieben sich die im Baume bestehenden Korrelationen zu ihren Ungunsten. So bleiben die Bäume verhältnismäßig schmächtig und wachsen schlank und schnell in die Höhe ${ }^{4}$ ).

Daß die Gliederung des Baumes in Stamm und Krone nicht

1) Winkler, 1913, S. 639.

2) Baranetzky, S. 138 ff.; Wiesner, 1910, S. 104 ff.; Noll, 1906, S. 150 . Vgl. auch Wiesner, 1895 , S. $627,685 \mathrm{f}$.

3) Ablenkung von der Vertikalen und Abkürzung des Wachstums brauchen nicht parallel zu gehen, z. B. bei Sträuchern (Selbständigkeit der Einzelhemmungen). An Stecklingen, wo die Verhältnisse leichter zu iibersehen sind, hat sich trotz aller Versuche, eine unmittelbare Wirkung äußerer Einflüsse auf die Gestaltung des Austreibens nachzuweisen (SACHs, 1880, S. 452 ff.; 1882, S. 689 ff.; KLEBS, 1903, S. 101 ff.; KüSTER, 1904, S. 279 ff.), gezeigt, daß Schwerkraft, Licht u. a. im wesentlichen nur mittelbar durch Veränderung der normalerweise zwischen den einzelnen Trieben sowie zwischen Sprossen und Wurzeln bestehenden Korrelationen die Gestaltung des Systems beeinflußt (Vöснтіng, 1878, S. 173 ff.; 1884, S. 42 ff.; 1880, S. 593 ff.; 1906, Erwiderung zu Küster, 1906; 1906, S. 101 ff.).

4) Das verschiedene Verhalten der Fichte ist durchaus zweckmäßig: im Freien ein Wachstum, das eine größtmögliche Ausnützung des Lichtes durch die Bildung einer breiten Krone gewährleistet; im Walde dagegen ist die Wachstumstätigkeit in der Richtung nach dem meisten Licht konzentriert. 
allein und unmittelbar auf ungenügende Belichtung der basalen Region zurickzuführen ist ${ }^{1}$ ), sondern in erster Linie auf die zwischen den Ästen und Zweigen bestehenden Korrelationen, die freilich durch ungleichen Lichtgenuß wesentlich beeinflußt werden ${ }^{2}$, zeigt das Verhalten von freistehenden Bäumen wie Eichen, Pappeln, Erlen und andern einerseits, und anderseits von waldbildenden Buchen:

Freiwachsende Bäume tragen häufig zwei Kronen übereinander, und zwar ist bei Eichen z. B. die obere, meist kleinere Krone vielfach offensichtlich älter.

Ich erwähnte für Tilia, daß mit zunehmendem Alter des Baumes eine Reduktion der Zweigsysteme stattfindet ${ }^{3}$ ). In dieser Reduktion außert sich nicht etwa eine Erschöpfung des gesamten Baumes, sondern lediglich eine Schwächung der Verzweigungssysteme durch die in der Krone bestehenden Sproßkorrelationen; denn wird der Baum verschnitten, so gleichen die neuen Zweigsysteme durchaus denen an jungen Bäumen.

Meiner Ansicht nach lassen sich die doppelkronigen Eichen am einfachsten so erklären, daß sich infolge des korrelativ bedingten Alterns der ursprünglichen Krone und der damit verbundenen Schwächung der basipetalen Hemmung tiefer am Stamm eine zweite Krone bildet, von der eine starke akropetale Hemmung ausgeht, die den Gipfel der alten Krone weiter schwächt und allmählich zum Absterben bringt, während der untere Teil der alten Krone zunächst in die neue Krone mit aufgenommen wird.

Daß das Altern der Baumgipfel in einer Erschwerung des Wassertransports ${ }^{4}$ ) oder in Absterbeerscheinungen der älteren Stammteile ${ }^{5}$ ) bedingt sei, ist nicht recht einzusehen, da einerseits Bäume im Wald im allgemeinen höher werden als gleichartige freistehende Bäume und anderseits gerade die jüngsten Partien des Baumes (Gipfel) zuerst absterben, während die Neubildungen von den älteren ausgehen.

Auf diese Weise findet auch die Wipfeldiurre der Pyramidenpappel ihre Erklärung, die vielfach diskutiert worden ist $\left.{ }^{6}\right)$, weil etliche Forscher in ihr eine Folge der rein vegetativen Vermehrungsweise erblickten ${ }^{7}$ ). Mit der von mir vertretenen Anschauung stimmt auch die Angabe Vuillemins ${ }^{8}$ ) überein, daß ein Entfernen der unteren Astbüschel die Wipfeldürre verhindert, nur daß Vuillemin die Ursache der Erkrankung nicht in den Korrelationen der Zweigsysteme unmittel-
1) Wiesner, 1895, S. 672.
3) S. 624 .
5) KleBS, 1903, S. 126.
7) Jessen, S. 201.

2) WiESNER, 1895, S. 608.

4) Mohl, 1850 (nach Jessen, S. 80).

6) MöвiUs, S. $40 \mathrm{ff}$.

8) MöBius, S. $44 \mathrm{f}$. 
bar sucht, sondern in einem Pilz, dessen Existenz freilich zweifelhaft ist, und der eine Hypertrophie der untersten Zweige hervorrufen soll.

Die Erlen verhalten sich ähnlich wie die waldbildenden Buchen. In einiger Entfernung unter der Hauptkrone findet sich bei diesen eine kleinere, von starken Ästen gebildete Nebenkrone, und zwar ist diese Erscheinung, wo sie auftritt, an den meisten Bäumen des bctreffenden Waldbestandes zu beobachten. Auf eine nachträgliche stärkere Belichtung der betreffenden Stammpartie läßt sich die Nebenkrone nicht zurückführen, vielmehr ganz offenbar darauf, daß die von der Hauptkrone ausgehende basipetale Hemmung in der oberen Partie des Stammes auf irgendwelche Weise - vielleicht durch ruhende Knospen - geschwächt wird. Es ist eine den labilen Zwillingsystemen verwandte Bildung $\left.{ }^{1}\right)$.

Steht eine größere Anzahl von Knospen oder Trieben dicht beieinander, aber ohne Ordnung, wie dies bei Stammund Stockausschlägen, bei Hexenbesen und bei Sproßverbänderungen der Fall ist, so bestehen zwischen den einzelnen Sprossen natürlich ebenfalls Korrelationen, doch ist deren Wirksamkeit, ihre Steigerung und Schwächung, scheinbar durchaus willkürlich.

Die Kotyledonaraxillare von Phaseolus multiflorus werden in der Regel - wenigstens bei der von mir verwandten Rasse - verbändert angelegt, sodaß an Stelle eines jeden Axillars eine Gesellschaft von Axillaren tritt ${ }^{2}$.

Dadurch daß in einer solchen axillaren Genossenschaft eine größere Anzahl von Vegetationspunkten gleichzeitig bestrebt ist zu wachsen, schwächen die einzelnen Axillare einander, sodaß der Einfluß des wachsenden Hauptsprosses a uf diese viel stärker wirkt als auf den einfachen Kotyledonaraxillar; ein verbänderter Kotyledonaraxillar ist infolgedessen nicht in der Lage, spontan auszutreiben ${ }^{3}$.

Wird der Hauptsproß durch Eingipsen inaktiviert, so treiben die Axillare in der auf S. 609 dargestellten Weise aus. Schließlich - bald früher, bald später - wächst in der Regel von jeder axillaren Genossenschaft ein einziger Sproß weiter, während die übrigen korrelativ sistiert werden, ähnlich wie dies auch beim Hexenbesen der Tanne der Fall ist ${ }^{4}$ ) und bei der von De VRIEs beschriebenen verbänderten

1) S. $644 \mathrm{f}$.

2) S. $609 \mathrm{f}$.

3) S. 610 .

4) Неск, S. 11. 
Rasse von Crepis perennis, die mit zunehmendem Alter ihre Verbänderung allmählich auflöst $\left.{ }^{1}\right)$.

Wird der Hauptsproß nach einiger Zeit wieder entgipst, so können sich die Korrelationen zwischen ihm und den Axillaren sehr verschieden gestalten, zumal wenn noch eine größere Anzahl vou Teilaxillaren wächst, je nachdem ob mehr der Hauptsproß von den zahlreichen Axillaren beeinflußt und dadurch in seinem Hemmungsvermögen geschwächt wird, oder ob diese sich selbst gegenseitig stärker beeinflussen ${ }^{2}$.

Die unmittelbare Ursache der Verbänderung ist offenbar die Gedrängtheit einer größeren Anzahl sich entwickelnder Anlagen.

Wird die junge Hauptwurzel eines Keimlings dekapitiert, so verbändern sich bekanntlich die Seitenwurzeln recht häufig ${ }^{3}$ ); da die Dekapitation deren Anzahl und damit ihre Dichte erhöht, wird in diesem Falle die Verbänderung allein durch Dekapitation, $d . h$. durch Inaktivierung der Hauptwurzel bedingt.

Bei den Kotyledonaraxillaren liegen die Verhältnisse anders: Bereits vor der Inaktivierung des Hauptsprosses sind zahlreiche Kotyledonarknospen niederer Ordnung gebildet ${ }^{4}$ ), ist also die Anlage zur Verbänderung bereits gegeben, und die Inaktivierung des Hauptsprosses hat keine andere Bedeutung für die Axillare, als daß sie ihnen das Austreiben ermöglicht.

Die Häufung der axillaren Knospen ist wahrscheinlich in den korrelativen Beziehungen bedingt, die zwischen dem Hauptsproß und den Axillaren bestehen, und zwar scheint hierbei der Entwicklungszustand des Hauptsprosses von Bedeutung zu sein5), wie die akropetale Abnahme der axillaren Knospenhäufung und mithin der Neigung zur Verbänderung zeigt ${ }^{6} \%$.

Die Vermutung Lopriones, daß der Beginn der Assimilation des Hauptsprosses für die Bildung verbänderter Axillare ungünstig werde 7 ), hat sich durch meine Versuche nicht bestätigt; ich stellte meine Versuche zum größten Teil mit solchen Keimlingen an, deren Hauptsproß bereits assimilierte.

Wenn gleichwohl mit zunehmendem Alter des Keimlings die Verbänderung. der Kotyledonaraxillare nach Inaktivierung des Hauptsprosses undeutlicher und seltener wird, so geht daraus hervor, daß sich die Korrelationen innerhalb einer axillaren Genossenschaft auch schon vor dem Austreiben allmählich zugunsten eines einzigen Teilaxillars verschieben.

1) De Vries, 1899, S. $327 \mathrm{f}$.

2) S. $610 \mathrm{f}$.

3) Lopriore, S. 306.

4) Vgl. auch Wettstein, S. $6 \mathrm{f}$.

5) Ähnlich liegen die Verhältnisse wohl dort, wo durch Infektion von Milben Verbänderung eintritt (KÜSTER, 1913, S. 126, 146 f.). Wo Verbänderung jedoch als Rassenmerkmal auftritt (De VRIES, 1906, S. $250 \mathrm{ff.}$ ), handelt es sich wahrscheinlich um die Verminderung der korrelativen Empfindlichkeit der Anlagen, die unter Umständen nur durch besonders giinstige Kulturbedingungen (De VRies, 1899, S. 290 f., 296) erreicht werden kann.

6) S. $609 \mathrm{f}$.

i) Lopriore, S. 397. 
II. Der Entwicklungszustand der einzelnen Triebe und seine Bedeutung für die Sproßkorrelationen.

Der Entwicklungszustand der einzelnen Triebe tritt normalerweise gegenuiber der Anordnung derselben an Bedeutung für die zwischen ihnen bestehenden Korrelationen zurück. Seine hohe Bedeutung tritt aber klar zutage, wenn eine Knospe oder ein Sproß durch Gipsverband zeitweise am Austreiben oder Weiterwachsen verhindert wird. Und zwar wird er nach dem Entgipsen von den übrigen um so stärker beeinflußt, je weiter sich diese entwickelt haben. Das Hemmungsvermögen eines Sprosses nimmt also - in seiner physiologischen Periode, die ich allein untersucht habe - mit seiner Entwicklung zu.

Bei den Keimlingen der Papilionaceen ${ }^{1}$ ) und bei Salix ${ }^{2}$ ) ist hierbei die vegetative Ausbildung des Sprosses wesentlich, d. h. seine Länge und Masse. Die Wachstumsgeschwindigkeit ist ohne Bedeutung. Bei den Papilionaceenkeimlingen vermag ein Sproß einen andern allerdings nur solange direkt zu beeinflussen, als er wächst; doch hemmen bei Salix auch ausgewachsene Triebe in gleicher Weise wie solche, die noch wachsen ${ }^{3}$ ).

Bei Torreya ${ }^{4}$, Picea ${ }^{5}$ ) und Tilia ${ }^{6}$ ) nimmt das Hemmungsvermögen eines Triebes mit der Reife zu; und da bei der Reifung die Wachstumsgeschwindigkeit abnimmt, so geht in diesen Fällen einer Verminderung der Wachstumsintensität eine Steigerung des Hemmungsvermögens parallel.

Allmählich verlischt das Hemmungsvermögen wieder. Ein Sproß eines Papilionaceenkeimlings beeinflußt einen andern nur solange, als sein Wachstum noch nicht $\mathrm{zu}$ verklingen beginnt $\left.{ }^{7}\right)$. Bei Salix dagegen behalten die Triebe ebenso wie bei Tilia $\left.{ }^{8}\right)$, Torreya ${ }^{9}$ ) und Picea auch nach Sistierung des Wachstums noch eine Zeitlang: ihr Hemmungsvermögen ${ }^{10}$ ). Wann sie dasselbe verlieren, läßt sich schwer feststellen, da die eingegipsten Knospen vor dem Austreiben bereits stark beeinfußt sind ${ }^{11}$.

Doch läßt sich nach dem Verhalten der Knospen auf den Narben abortierter Knospen von Torreya sagen, daß die einzelnen Komponenten der Hemmung nicht gleichzeitig

\footnotetext{
1. S. 593 f., 604 ff., 610 .

4) S. 615 .

i) S. 606,611 .

10) S. 636.
}
2) S. 636 .
3) S. 636 .
5) S. $620 \mathrm{f}$.
8) S. 632 .
6) S. $629 \mathrm{ff}$.
9) S. 619 . 
schwinden ${ }^{1}$. So bleiben bei Torreya die Bedingungen, die eine Reduktion der Streckung bei den korrelativ gehemmten Sprossen begründen, länger bestehen als die Bedingungen, die die Reifung derselben verzögern. Zugleich geht daraus hervor, daß die Hemmungen - teilweise wenigstens - bereits vor dem Beginn der Winterruhe schwinden können.

Bäume mit doppelter Jahresperiodizität, wie Quercus²) und andere, zeigen in dem von den ersten Trieben abweichenden Verhalten (z. B. einfachere Blattformen) der Johannistriebe ${ }^{3}$ ) gleichfalls die Selbständigkeit der Einzelhemmung (Teilerscheinung des korrelativen Einflusses) beim Schwinden des korrelativen Einflusses.

Bei den meisten unserer Laubbäume mit einfacher Jahresperiodizität soweit ihre Knospen proleptisch auszutreiben vermügen ${ }^{4}$ ) - ist das korrelative Hemmungsvermögen der ausgewachsenen Triebe vor der Winterruhe in der Hauptsache auch bereits erloschen. Denn die Bedingungen, unter denen die Knospen proleptisch austreiben ${ }^{5}$ ), zeigen, daß diese normalerweise nicht unmittelbar durch die Zweige daran verhindert werden, unter deren Einfluß das Wachstum ihres Mutterzweiges stand, sondern durch am Mutterzweige selbst bestehende Korrelationen. -

Die Empfindlichkeit der einzelnen Knospen und Triebe gegen korrelative Hemmungen habe ich gleichfalls nur soweit untersucht, als diese Hemmungen von Trieben ausgehen, die sich in der physiologischen Periode ihres Wachstums befinden.

Ich halte mich im folgenden lediglich an die von mir untersuchten Fälle, bei denen es sich um Knospen handelt, die im normalen Verlaufe der Entwicklung angelegt werden, ferner um verhältnismäßig einfache Korrelationen (einfache Systeme) bei beschränkter Dauer der korrelativen Einwirkungen. Ich sehe also von vornherein davon ab, solche Fälle in meine Besprechung einzubeziehen, wo embryonales Gewebe seine Fähigkeit zur Bildung von Adventivsprossen verliert ${ }^{6)}$, wo infolge verwickelter Korrelationen Knospen in Knollen 7), Zwiebeln oder Bliiten $\left.{ }^{8}\right)$ umgewandelt werden, oder infolge allzulanger korrelativer Beeinflussung zu gallenartigen Ausw üchsen ${ }^{9}$.

Von einem Sproß, der sich in der physiologischen Periode seines Wachstums befindet, wird ein anderer Sproß in seiner morphologischen Periodekaum oder nur bis zu einem gewissen Grade beeinflußt, in seiner physiologischen Periode dagegen ist eine Beeinflussung in jedem Fall möglich, und zwar ist diese im allgemeinen am intensivsten zu Be-

1) S. 619 .

3) SРÄтH, S. $33 \mathrm{ff}$.

5) Berthold, 1904, S. 42 f.; SpÄth, S. 39 ff.

6) Burns and Hedden, S. 389. Vgl. ferner Nordhausen, S. 563.

7) Vöchting, 1895, S. $79 \mathrm{ff}$; 1908 , S. $248 \mathrm{ff}$.

8) Vgl. Vöchting, 1893, S. 190 ff.

9) Sorauer, 1909, S. 852. 
ginn der physiologischen Periode (Abort der Knospen) und nimmt mit der weiteren Entwicklung allmählich ab.

Sowohl die Knospen auf den Narben abortierter Knospen ${ }^{1}$ ) als auch die Knospen an den Knoten $\left.{ }^{2}\right)$ und an der Spitze ${ }^{3}$ ) korrelativ gehemmter Zweige entwickeln sich durchaus normal, obwohl die Einflüsse zunächst stetig zunehmen, die den Abort der ersten Knospe bzw. die Wachstumshemmung des Mutterzweiges veranlaßt haben.

Hat eine Knospe einen bestimmten Entwicklungszustand erreicht, so wird ihr Wachstum durch die entwickelteren Sprosse sistiert, und sie verharrt im Ruhezustand, bis auf irgendwelche Weise die Hemmungen aufgehoben werden. Doch behält eine derartig sistierte Knospe ihre Wachstumsfähigkeit und verliert sie auch - wenigstens auf lange Zeit nicht, wenn die Hemmungen durch die übergeordneten Sprosse an Intensität zunehmen ${ }^{4}$, oder wenn die Knospe infolge ihrer Stellung am Mutterzweig lange noch korrelativ gehemmt wird, wie dies bei den ruhenden Knospen von Tilia z. B. der Fall ist.

Die physiologische Periode eines Sprosses wird bei den untersuchten Holzgewächsen ebenfalls dadurch nicht beeinflußt, daß seine morphologische Periode unter Einwirkungen steht, die die Eigenschaften des Mutterzweiges verändern. Am deutlichsten tritt dies bei den korrelativ stark reduzierten Trieben von Tilia ${ }^{2}$ ) und Picea $^{3}$ ) zutage, deren Knospen durchaus normale Jungtriebe bilden.

Im Wesen ist dies das Gleiche, als wenn sich ein durch ein Cecidium in seiner Belaubung modifizierter Zweig in einen normal beblätterten Trieb verwandelt, sobald das Wachstum die normale Grenze des Cecidiumtriebes iiberschreitet, eine Erscheinung, die Beyerinck als Reversion der Charaktere bezeichnet5).

Ein wenig anders liegen die Verhältnisse bei den monopodialen Papilionaceenkeimlingen, wo die Axillare unter dem korrelativen Einfluß des Hauptsprosses stehen. Auch hier entwickeln sich die axillaren Knospen, bis ihr Wachstum durch den Hauptsproß sistiert wird, und verlieren durch diese Sistierung des Wachstums ihre Wachstumsfähigkeit nicht wie ausgetriebene

1) S. 619,624 .

2) S. 632, Anm. 2.

3) S. 622 .

4) Vgl. S. 594 .

5) Beyerinck, S. 8 ff., 25. Vgl. hierzu Küster, 1913, S. 156 ff., und bes. Winkler, 1912, S. 89 ff. Zu Winklers Ausführungen möchte ich noch hinzufügen, daß es mir gelungen ist, die durch Apion filirostre stark veründerten Blätter von Sedum reflexum zur Bildung von Adventivsprossen anzuregen. Diese Sprosse trugen normale Sedum-Blätter.

Archiv f. Entwicklungsmechanik. XXXVIII. 
Sprosse ${ }^{1}$. Wohl aber wird ihre Wachstumsgeschwindigkeit ebenso wie ihre Fähigkeit andere Sprosse korrelativ zu hemmen durch den Einfluß des Hauptsprosses, dem sievor dem Austreiben ausgesetzt sind, induzierend geschwächt²).

Die zeitliche Beschrïnktheit des korrelativen Hemmungsvermögens einerseits, und anderseits die weitgehende Immunität der Sprosse in ihrer morphologischen Periode gegen Einflüsse, die sie in ihrer physiologischen Periode schädigen, sind Grundbedingungen des Wachstums bei sïmtlichen zusammengesetżten Pflanzen ${ }^{3}$ ) und besonders des periodischen Wachstums.

Überschreitet die Knospe den kritischen Punkt ihrer Entwicklung, wo ihr Wachstum gerade korrelativ sistiert wird, so findet ein Umsturz in ihrer Konstitution statt, der am deutlichsten in der plötzlichen Steigerung der korrelativen Empfindlichkeit zum Ausdruck kommt. Wird nunmehr das Wachstum des Sprosses durch einen andernkorrelativ sistiert, so wird er gleichzeitig wachstumsunfähig ${ }^{4}$ ).

Die korrelative Empfindlichkeit ist am größten in den frühsten Stadien der Streckung, d. h. beim Schwellen der Knospe. Besonders deutlich ist dies bei Salix, wo die Knospen in hohem Grade empfindlich sind und infolgedessen beim Austreiben der Zweige viel zahlreicher abortieren, als z. B. bei Tilia ${ }^{5}$. Daß es sich hierbei tatsächlich um eine außergewöhnlich hohe Empfindlichkeit der Knospen handelt, und nicht um eine stärkere korrelative Beeinflussung, geht daraus hervor, daß die den abortierenden Knospen benachbarten Triebe durch diese nur zeitweise vor den Einwirkungen geschïtzt sind, die den Abort der Knospen bewirken. Haben die Knospen abortiert, so wird der folgende Trieb unmittelbar von diesem Hemmungsreiz getroffen, der durch die fortschreitende Entwicklung der hemmenden Triebe an und für sich verstärkt worden ist. Trotzdem wird der untergeordnete Trieb wenig beeinflußt $\left.{ }^{6}\right)$. Es spricht sich hierin eine rapide Entwicklung der Widerstandsfähigkeit der jungen Salix-Triebe gegen korrelative Hemmungen aus, wodurch die Weide einen Kompens für die große Empfindlichkeit der schwellenden Knospen besitzt.

1) S. 594 .

2) S. $641 \mathrm{f}$.

3) Schleiden, S. 4.

4) S. 597, 599, 623 f. Natürlich gilt dies nicht von seinen Knospen, auch nicht von der Endknospe, wenn der korrelativ sistierte Zweig an seiner Spitze sich zur Knospe formt (S. 622).

5) S. $644 \mathrm{f}$.

6) Dies ist besonders bei der Hemmung zeitweise eingegipster akraler Knospen zu beobachten (S. 636). 
Das allmähliche Erstarken des Triebes in seiner physiologischen Periode läßt sich durch verschiedenzeitiges Entgipsen der am Austreiben zunächst verhinderten Terminalknospe besonders gut bei Torreya verfolgen, wo die Knospe nicht so leicht abortiert wie bei Tilia ${ }^{1}$ ): Je entwickelter der Zustand des Endtriebes bei jeder einzelnen Entwicklungsphase der Seitentriebe ist, desto weniger ist er in seinem Wachstum von diesen abhängig ${ }^{2}$; bei rechtzeitigem Austreiben ist er völlig unabhängig ${ }^{3}$ ).

Auch die Sprosse von Faba werden um so unempfindlicher gegen korrelative Einflüsse, je länger sie wachsen ${ }^{4}$ ). Beginnt jedoch ein Faba-Sproßsein Wachstum korrelativ einzustellen, so nimmt seine korrelative Empfindlichkeit wieder zu, indem ergerade dann bei Fortdauer der korrelativen Hemmung seine Wachstumsfähigkeit verliert und häufig sogar zugrunde geht5).

Außer der Stellung am Mutterzweige sowie dessen Stellung im gesamten System und dem Entwicklungszustand der einzelnen Knospen können noch mancherlei andere Umstände das korrelative Verhalten der Triebe beeinflussen. So wird bei den von Contarinia tiliarum infizierten Tilia-Trieben das Hemmungsvermögen auf den Nachbartrieb ebenso geschwächt, wie die korrelative Empfindlichkeit ${ }^{6}$. Besonders ist die Fertilität eines Sprosses von Bedeutung. Während bei Torreya das Hemmungsvermögen eines Triebes durch seine Fertilität zunimmt ${ }^{7}$ ), ist bei Bäumen, die vor der Belaubung blühen, wie der Kirsche, das Hemmungsvermögen auf die Laubtriebe zweckentsprechend nur ein zeitweises $\left.{ }^{8}\right)$. Anderseits kann bei Blïtentrieben die korrelative Empfindlichkeit vermindert werden, wie ihr Wachstum unterhalb der abortierenden Laubknospen zeigt ${ }^{9}$.

Durch ungünstige Bedingungen läßt sich die Empfindlichkeit gegen korrelative Einflüsse leicht steigern. Dies ist z. B. der Fall bei Sprossen von Faba-Keimlingen, wenn die Kotyle-

1) S. $629 \mathrm{f}$.

2) S. 615 .

3) S. 613.

4) S. $594 \mathrm{f}$.

5) S. 597, 599 .

6) S. $628 \mathrm{f}$.

7) S. $613,617 \mathrm{f}$.

8) Daß das spätere Austreiben der Laubknospen im Frühjahr tatsächlich auf einer korrelativen Hemmung durch die Blitentriebe beruht, kann man an solchen Bäumen sehen, wo ein einzelner Ast im Gegensatz zu der übrigen Krone nicht blüht: Während die blühenden Äste noch keine Laubblätter tragen, ist der sterile Ast bereits vollständig ergrünt.

9) Berthold, 1898, S. 40. 
donen entfernt werden ${ }^{1}$ ), bei bereits entfalteten Salix-Trieben infolge plötzlichen Wechsels der Bedingungen ${ }^{2}$ ), bei Knospen von Tilia an Stecklingskulturen in feuchtem Sand ${ }^{3}$ ).

Da sich die einzelnen Entwicklungsphasen eines Sprosses in seiner physiologischen Periode inbezug auf Empfindlichkeit und Hemmungsvermögen im allgemeinen entgegengesetzt verhalten, so liegt die Vermutung nahe, daß Empfindlichkeit und Hemmungsvermögen in jeder einzelnen Phase des Wachstums nur zwei verschiedene Erscheinungsformen des gleichen Zustandes sind.

Daß dem gleichwohl nicht so ist, zeigen die angeführten Beispiele, wo durch äußere Einflüsse die Empfindlichkeit der Sprosse ohne Schwächung ihres Hemmungsvermögens erhöht wurde, ebenso wie die andern, wo das Hemmungsvermögen ohne Herabsetzung der Empfindlichkeit gesteigert war $\left.{ }^{4}\right)$.

\section{Die Induktion gegenseitiger korrelativer Beeinflussung bei Sproßsystemen.}

Es sind zwar Fälle bekannt, wo das in Sproßkorrelationen bedingte Verhalten eines Triebes auch dann noch weiter besteht, wenn die Ursache der Reizerscheinung nicht mehr vorhanden ist, wie z. B. das dorsoventrale Wachstum der Araucaria-Zweige ${ }^{5}$. Gleichwohl scheint mir im allgemeinen die Ansicht zu herrschen, daß das Verhalten eines Sprosses von einem andern korrelativ nur solange beeinflußt werde, als dieser selbst noch aktiv ist. Dies gilt zum mindesten von den Korrelationen, die zwischen Sprossen gleicher Funktion bestehen, wie schon der für diese Fälle besonders angewandte Ausdruck Wachstumskompensation zeigt. Am schroffsten vertritt Herbst diese Anschauung, indem er die Sproßkorrelationen den Korrelationserscheinungen iiberhaupt nicht zurechnet 6 ).

Im Gegensatz zu dieser Anschaung fand ich bei den von mir untersuchten Pflanzen, daß das in Sproßkorrelationen bedingte Wachstum der einzelnen Triebe stets mehr oder weniger induzierend bestimmt wird, falls die einander beeinflussenden Triebe in der physiologischen Periode ihres Wachstums stehen. Und es liegt kein Grund zu der Annahme vor, daß sich andere gleichhoch organisierte Pflanzen anders verhielten.

1) S. $602 \mathrm{f}$.

2) S. 636 .

3) S. 627.

4) Vgl. auch S. 647; ferner bes. das Verhalten der Zweigsysteme von Torreya.

5) Vöchting, 1904, S. 144 ff.

6) S. 586, Anm. 2-4. 
Freilich zeigt ein Sproß, der von einem andern korrelativ beeinflußt wird, eine viel geringerekorrelative Schädigung, wenn dieser nur eine Zeitlang direkt auf ihn wirkt1), als wenn er solange unter dessen Einfluß steht, bis er korrelativ sein Wachstum eingestellt hat. Ferner sind die einzelnen Erscheinungen der Hemmung in verschiedenem Maße induzierbar.

Haben zwei voneinander abbängige Sprosse eines Faba-Keimlings Gleichmäßigkeit in ihrer (verminderten) Wachstumsgeschwindigkeit erlangt, so ist diese induziert und bleibt konstant, auch wenn der eine der beiden Sprosse entfernt wird oder sein Wachstum korrelativ einstellt ${ }^{2}$ ).

Gleichzeitig wird er immun gegen korrelative Reize, die auf Verminderung seiner Wachstumsgeschwindigkeit hinzielen: Er verlangsamt auch unter dauerndem korrelativen Einfluß eines andern Sprosses sein Wachstum nicht weiter, ehe er es einzustellen beginnt ${ }^{3}$ ).

Weniger eindeutig ist für die Papilionaceenkeimlinge die korrelative Induktion der Wachstumsdauer. Beginnt ein Sproß bereits sein Wachstum korrelativ einzustellen, indem er dasselbe verzögert, so genïgt die Entfernung des andern Sprosses, daß sein Wachstum wieder angeregt wird und die induzierte Wachstumsgeschwindigkeit wieder erlangt. Erst wenn ein Sproß sein Wachstum korrelativ völlig eingestellt hat, ist er auch nach Entfernung des andern Sprosses nicht in der Lage, dasselbe wieder aufzunehmen ${ }^{4}$ ).

Handelt es sich um die Korrelationen von Hauptsproß und Kotyledonaraxillar bei Faba, so ist die korrelative Sistierung des Wachstums unmittelbar mit dem Verlust der Wachstumsfähigkeit verbunden ${ }^{5}$ ). Daß aber der Verlust der Wachstumsfähigkeit nicht unbedingt eine Folge des korrelativ sistierten Wachstums zu sein braucht, zeigt das Verhalten der Sprosse, wenn es sich um verwickeltere Korrelationen - von Hauptsproß und erstem Primärblattaxillar oder erstem Primärblattaxillar und Kotyledonaraxillaren bei Faba ${ }^{6}$ ) oder von Sprossen bei Phaseolus (Verbänderung) ${ }^{7}$ ) - handelt: Bisweilen ist zwar auch in diesen Fällen die korrelative Sistierung des Wachstums unmittelbar mit dem Verlust der Wachstumsfähigkeit verkoppelt, doch stellt sich häufiger der Wachstumsverlust erst einige Tage nach der Sistierung des Wachstums ein, sodaß ein rechtzeitiges Abschneiden des korrelativ übergeordneten Sprosses den gehemmten
1) S. 597,632 .
2) S. 592,596 ff., 607 .
5) S. 597, 599.
6) S. 606 .
3) S. $596 \mathrm{f}$.
4) S. 597, 599 .
7) S. 611 . 
Sproß wieder zum Wachstum anregt, auch wenn er bereits zu wachsen aufgehört hat.

Wird die Wachstumsdauer eines Sprosses bei Papilionaceenkeimlingen auch bedeutend verlängert, wenn der korrelative Einfluß eines andern Sprosses auf diesen nur ein zeitlich beschränkter ist, so wird sie doch durch dessen zeitweise Einwirkung induzierend bestimmt. Ein Sproß, der eine Zeitlang unter dem korrelativen Einfluß eines andern gestanden hat, stellt sein Wachstum bedeutend früher ein als ein Hauptsproß, dessen Achselknospen im Ruhestand verharrten ${ }^{1}$.

Auch bei Tilia und Salix verlieren die Triebe infolge der zwischen ihnen bestehenden Korrelationen ihre Wachstumsfähigkeit. Der Verlust der Wachstumsfähigkeit kommt bei diesen sympodial verzweigten Laubbäumen - ebenso wie bei Phaseolus ${ }^{2}$ - dadurch besonders deutlich zum Ausdruck, daß die Zweige infolge der korrelativen Hemmung: durch andere ihre Spitze abwerfen ${ }^{3}$.

Bei Torreya und Picea ist die Wachstumsdauer der einzelnen Triebe gleichfalls induzierend bestimmt, und zwar vermutlich durch die zwischen den Trieben in ihrer morphologischen Periode bestehenden Korrelationen ${ }^{4}$ ). Während bei $F a b a^{5}$ ) und bei Tilia ${ }^{6}$ ) zwischen der korrelativen Beeinflussung und dem dadurch bedingten Abschluß des Wachstums eine Phase gleichmäßigen Wachstums liegt, ist bei den untersuchten Coniferen außerdem noch eine Periode der Ruhe eingeschaltet. In der physiologischen Periode ist dann eine weitere induzierende Abkiirzung des Wachstums möglich, dergestalt, daß ein korrelativ beeinflußter Trieb seine normale, in der morphologischen Periode bestimmte Länge nicht erreicht7).

Bei den Papilionaceenkeimlingen sowohl wie béi den sympodial verzweigten Holzgewächsen äußerst sich die Induktion der korrelativen Beeinflussung nicht nur im Verlust der Wachstumsfähigkeit eines korrelativ beeinflußten Triebes, sondern in einer weitergehenden Schädigung seiner Spitze ${ }^{8}$. Beim Sproß von Faba bleibt diese Schädigung
1) S. 599.
2) S. 611.
3) S. $623 \mathrm{f}, 634$.
4) S. $640 \mathrm{f}$.
5) S. 657.
6) S. 623, Anm. 3 .
7) S. 615 .
8) Monopodiale Zweige, die ihre Spitze bei ungiinstigen Bedingungen (KLebs, 1912, S. 262, 269) zur Knospe schließen, sind offenbar auf diese Weise gegen korrelative Schädigungen geschützt, da ja die Knospe weniger empfindlich ist (S. $652 \mathrm{f}$.). 
aber nicht auf die Spitze beschräkt, sondern schreitet in der Regel nach der Basis hin fort, sodaßder Sproß von der Spitze her allmählich abstirbt ${ }^{1}$ ).

Besonders beachtenswert scheinen mir die Fälle, wo nach zeitweiser mechanischer Hemmung des Hauptsprosses Hauptsproß und Kotyledonaraxillar ihr Wachstum gegenseitig sistieren ${ }^{2}$ ) und beide darauf zugrunde gehen. Durch eine Veränderung der normalerweise bestehenden Korrelationen wird hier ein verfrühter Tod der gesamten Pflanze herbeigeführt.

Diese Tatsache zeigt ebenso wie das ungewöhnlich hohe Alter isolierter Organe ${ }^{3}$ ) und die Erweiterung der Altersgrenze bei kurzlebigen Pflanzen durch Änderung der zwischen ihren Teilen bestehenden - von der Außenwelt mehr oder weniger mitbestimmten Korrelationen ${ }^{4}$ ) die Bedeutung der Korrelationen für das Alteru und Sterben der Pflanzen. --

Die sympodialen Laubbäume beschränken ebenso wie Phaseolus die korrelative Schädigung auf die Spitze der beeinflußten Triebe: Es werden hier in der Spitze die physiologischen Vorgänge nicht derart verändert, daß sie unmittelbar ein Absterben bedingen, sondern so, $d a \beta$ die Spitze eine andere Entwicklungsrichtung einschlägt. Sie bleicht bis zu einem der obersten Knoten des Triebes, was auf einen aktiven Abbau ihrer Produkte schließen läßt, und bildet an diesem Knoten eine Trennungsschicht, die ihre Loslösung bedingt. Auf diese Weise schützt die Pflanze den Trieb vor dem dauernden $\mathrm{Zu}$ sammenhang mit der absterbenden Spitze und damit vor dem Übergreifen der Degeneration auch auf seine gesunden Teile.

Daß bei einer Verzögerung des Spitzenabwurfs die Absterbeerscheinungen tatsächlich nach der Basis des Zweiges hin fortschreiten, zeigt das Verhalten der tiefer inserierten Tilia-Zweige: Bei diesen geht die Spitze zugrunde, wenn der gesamte Trieb von den jungen Laubblättern noch knospenartig umschlossen wird, sie.kann infolgedessen nicht rechtzeitig abfallen, und die Absterbeerscheinungen pflanzen sich meist auf die nächsten Glieder fort, die infolgedessen nach dem Abwurf der Spitze in gleicher Weise abortieren ${ }^{5}$.

Noch deutlicher tritt das basipetale Fortschreiten der Degeneration bei verhindertem Spitzenabwurf an den abortierenden Knospen ${ }^{6}$ ) zu-

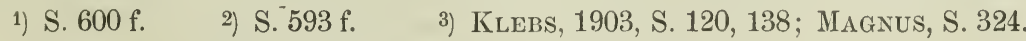

4) Vöchting, 1893, S. 197 ff.; Klebs, 1906, S. 71 ff.

5) S. 624 .

6) S. 624 . 
tage. Hier geht die Spitze noch früher zugrunde, und die Erkrankung pflanzt sich bis zur Basis fort, ehe sich die Knospe noch öffnet, sodaß der Trieb in seiner Gesamtheit als Knospe abfällt1).

Interessant ist es, daß auch bei Torreya durch starke korrelative Beeinflussung des Triebes im Beginn seiner physiologischen Periode ein Knospenabwurf erzielt werden kann2), während dies bei Picea3), die sich ihr sonst sehr ähnlich verhält, nicht der Fall ist. Möglicherweise ist diese Verschiedenheit biologiseh zu deuten: Während ein Picea-Trieb bei zunehmender korrelativer Beeinflussung in seiner physiologischen Periode seine Wachstumsgeschwindigkeit und das Ausreifen der Nadeln in gleicher Weise verzögert4) wie ein TorreyaTrieb ${ }^{5}$ ), verholzt die Achse rechtzeitig, sodaB ihre Endknospe im nächsten Frühjahr austreiben kann 6), bei Torreya dagegen wird auch die Verholzung der Achse retardiert, sodaß ein solcher Trieb während des Winters zugrunde geht ${ }^{7)}$. Durch das Abortieren der Knospe wird also die zwecklose Ausbildung eines lebensunfähigen Sprosses verhindert.

Die korrelative Beschränkung der Wachstumsfähigkeit ist gemeinsam mit den die Reversion der Charaktere bedingenden Faktoren ${ }^{8}$ ) (Schwinden des Hemmungsvermögens und weitgehende Selbständigkeit der Triebe in ihrer morphologischen Periode) bei den von mir untersuchten und ähnlichen Verzweigungssystemen eine wesentliche Grundlage des periodischen Wachstums. Möglicherweise liegen die Verhältnisse in den Fällen, wo normalerweise kontinuierlich wachsende Triebe infolge eines Wechsels der äußeren Bedingungen ihr Wachstum einstellen ${ }^{9}$ ), ganz ähnlich, indem der Bedingungswechsel hier nicht unmittelbar auf das Wachstum wirkt, sondern, wie ich dies für Salix gezeigt habe, die korrelative Empfindlichkeit der betreffenden Triebe erhöht $\left.{ }^{10}\right)$.

1) Auch noch nach der Verholzung können Glieder abgeworfen werden, und zwar hängt diese Erscheinung wahrscheinlich nicht mit der bisher dargestellten korrelativen Degeneration der Spitze zusammen: So erfolgen bekanntlich bei Tilia und zahlreichen andern Bäumen die sogenannten Zweigabsprïnge oft noch nach Jahren (BÜSGEN, S. 20), wenn nämlich die Knospen der betr. Zweige korrelativ nicht mehr auszutreiben vermögen. Und Salix fragilis vermag dauernd ganze Zweige oder einzelne Glieder abzuwerfen (S. 635), die vielfach in der Lage sind, durch Austreiben ihrer Knospen selbständig weiter zu wachsen.
2) S. $615 \mathrm{f}$.
3) S. $621 \mathrm{f}$.
4) S. $621 \mathrm{f}$.
5) S. 615 .
6) S. 622 .
8) S. $651 \mathrm{ff}$.
9) KLeBs, 1912, S. 262.
10) S. 636. Nach den Untersuchungen von KLEBS (1911, S. 50; 1912, S. 262 ff., 275), Volkens (S. 123 ff.), SpÄth (S. 4 ff., 38) u. a. (Magnus, S. 126 f.) steht es fest, daß der Wachstumsmodus der einzelnen Triebe nicht allein durch die Art bestimmt wird, sondern wesentlich auch durch die Insertionsstelle des Triebes am Gesamtorganismus und das Alter des Gesamtindividuums. Daß 
In den meisten Fällen freilich liegen die Verhältnisse verwickelter, z. B. wenn durch die Korrelationen von Blättern und Knospen des gleichen Zweiges das Austreiben der Knospen weiterhin verzögert wird ${ }^{1}$. Doch ist es eine dem periodischen Wachstum unserer Bäume verwandte, dem vieler tropischen Bäume durchaus homologe Erscheinung, wenn bei den Keimlingen von Faba oder Phaseolus nach zeitweiser mechanischer Hemmung des Hauptsprosses dieser sowohl wie auch die Kotyledonaraxillare ihr Wachstum korrelativ einstellen, und sodann bis dahin ruhende Axillarknospendas Wachstum aufnehmen ${ }^{2}$ ). Auch die meist eingeschaltete Rubeperiode der Knospen hat eine im wesentlichen verwandte Erscheinung bei FabaSprossen, wenn zwischen der korrelativen Beeinflussung eines Sprosses und dem dadurch bedingten Abschluß seines Wachstums eine $\mathrm{Phase} \mathrm{konstanten} \mathrm{Wachstums} \mathrm{eingeschaltet}$ is $\left.{ }^{3}\right)^{3}$. -

Hat ein korrelativ geschädigter Trieb seine Spitze abgestoßen, so wird seine sekundäre Spitze vielfach auch weiterhin noch induzierend beeinflußt: Dies äußert sich im Kürzerwerden der Glieder gegen die sekundäre Spitze hin ${ }^{4}$ ) und in dem davon unabhängigen späteren Austreiben der akralen Knospen, das sich zum völligen Verlust ihrer Wachstumsfähigkeit steigern kann ${ }^{5}$ ). Am deutlichsten tritt dies bei Dornen zutage, zu denen die Zweigenden von Salix bisweilen Übergänge bilden, nur daß diese noch die festere Struktur des Holzes entbehren.

Die Tatsache, daß die Knospen korrelativ beeinflußter Zweige beim Wachstum ihrer Triebe in der Regel keine Nachwirkungen jenes korrelativen Einflusses zeigen, habe ich eingehend besprochen ${ }^{6}$ ). Diesen Ausführungen muß ich jedoch eine Beschränkung anfügen.

Mit zunehmendem Alter eines Baumes erlischt die Triebkraft seiner Knospen mehr und mehr7). Wie ich auf S. 648 ausgefürt habe, ist dies nicht in einer Erschöpfung des gesamten Baumes bedingt, sondern allein in den zwischen den Zweigen bestehenden Korrelationen. Daß es sich hierbei

hierbei Sproßkorrelationen eine Rolle spielen, hat bereits KLEBS (1912, S. 50 ff.) und Magnus (S. 329) ausgesprochen.
1) $\mathrm{SpÄTH,} \mathrm{S.} 29 \mathrm{ff}$.
2) S. $594,611$.
3) S. $657 \mathrm{f}$.
4) S. 624 .
5) S. $627 \mathrm{f}$.
6) S. $652 \mathrm{f}$.
7) S. 624 . 
nicht um den Ausdruck der augenblicklich - etwa infolge der hohen Zahl der Triebe - zwischen den Zweigen bestehenden Korrelationen handelt, geht aus der lange schon bekannten Tatsache hervor, daß von alten Bäumen auf eine junge Unterlage gepfropfte Zweige ibren alten Verzweigungsmodus beibehalten ${ }^{1}$ ). Diese Erscheinung ist um so auffälliger, als im Gegensatz zu den jungen Knospen die ruhenden Knospen des gleichen Baumes trotz ihres höheren Alters, und obwohl sie infolgedessen viel lïnger korrelativen Hemmungen ausgesetzt gewesen sind, kräftige und jugendliche Triebe zu bilden vermögen ${ }^{2}$ ).

Dadurch, daß von der vegetativen Nachkommenschaft eines Zweiges Generationen hindurch jedes einzelne Glied unter dem korrelativen Einfluß anderer Triebe steht, prägt sich dieser Einfluß allmählich mehr und mehr auch den in ihrem Einzelleben gegen ihn geschützten Knospen (embryonalen Zweigen) ein. Es liegt also beim Altern der Bäume für die einzelnen Zweige eine Veränderung der spezifischen Struktur ${ }^{3}$ ) vor, die in dem Einfluß äußerer $\left.{ }^{4}\right)$ Einwirkungen durch Generationen hindurch bedingt ist, ein allmähliches (vegetatives) Erblichwerden einer vorübergehenden (revertierenden) Erscheinung ${ }^{5}$ ).

Mit dieser Steigerung der korrelativen Schwächung hängt vermutlich auch die mit dem Alter zunehmende Regelmäßigkeit im Treiben und im Laubwerfen ${ }^{6}$ ) unserer Laubbäume zusammen, die um so auffälliger ist, da gleichaltrige Bäume unter gleichen Bedingungen im Austreiben der Knospen und im Laubwerfen oft um Wochen differieren ${ }^{7}$ ).

Die Einheitlichkeit der Ruheperiode ist zwar in erster Linie klimatisch bedingt, denn sie fehlt im allgemeinen den tropischen Bäumen ${ }^{8}$, wie sie auch bei unsern Bäumen allmählich verschwindet, wenn diese dem Einfluß der wechselnden Jahreszeiten entzogen

1) Jessen, S. 207.

2) KLEBS, 1912, S. $273 \mathrm{f}$.

3) Winkler, 1912, S. 87.

4) im Sinne von KLeBs (1903, S. 138). Die äußeren Bedingungen sind natiirlich in der Organisation des Baumes gegeben.

5) Stecklinge altern natïlich nicht in dem gleichen Maße wie die Mutterpflanze, da sie der dauernden Einwirkung der iibrigen Zweige entzogen werden. Sie nähern sich erst nach und nach durch ibre eigene Entwicklung dem Zustande der Mutterpflanze.

6) Magnus, S. 313.

7) S. 625, Anm. 1; Klebs, 1911, S. 54; Magnus, S. 311 f.

8) Berthold, 1904, S. 225; vgl. dort die Literatur; Dingler, 1911, S. 130. 
werden ${ }^{1}$ ). Doch zeigen Sträucher und pathologische Bildungen wie die Wirrzopfgallen der Weiden, wo die Sproßkorrelationen sehr unregelmäßig sind, dảß z. B. der Laubwurf im Herbst sehr wohl auch bei unsern Laubhölzern an einzelnen Ästen und Zweigen unterbleiben kann ${ }^{2}$.

Jugendliche Eichen und Buchen werfen bekanntlich ihr Laub im Herbst nicht $a b$; erst mit zunehmendem Alter tritt herbstlicher Laubfall ein ${ }^{3}$ ), offenbar infolge der stärkeren korrelativen Beeinflussung der einzelnen Zweige. Dies gilt jedoch nur für die Krone. Stammausschläge, die bedeutend jünger sind, und die auch sonst von der Krone bisweilen kaum beeinflußt werden ${ }^{4}$, werfen vielfach ihre Blätter nicht, und zwar gilt dies nicht nur für Eiche und Buche, sondern auch für andere Bäume, wie z. B. Ulmus ${ }^{5}$ ). Der Grund hierfür liegt nicht in den verschiedenen Bedingungen der Umwelt, wie KLeBs ${ }^{6}$ ) annimmt, sondern in der vom Alter abhängigen Einprägung korrelativer Einflüsse ${ }^{7}$ ).

1) Berthold, 1904, S. $225 \mathrm{f}$.

2) Die meisten unserer Laubbäume beginnen iibrigens schon im Sommer ihr Laub abzuwerfen. Bei dem massenhaften Laubfall im Herbst handelt es sich offenbar um einen verfrühten Laubwurf, der in einer durch äußere Verhältnisse mitbedingten Steigerung der korrelativen Empfindlichkeit der Blätter bedingt ist, die ihrerseits nicht allein von der Art, sondern auch von dem im einzelnen Individuum bestehenden Sproßkorrelationen abhängig ist (vgl. auch VoLkens, S. 131; Magnus, S. 312 f.). Über die Folge des Blattfalles entscheiden außer dem Alter der Blätter (Dingler, 1905̃, S. 463 ff, 1911, S. 129) offenbar noch andere, in der Gesamtheit der Blätter am einzelnen Zweige bedingte Korrelationen: Bei kontinuierlich wachsenden Ulmenzweigen beginnt der Laubfall an der Basis und gleichzeitig in der mittleren Region des Zweiges im Juli und schreitet von beiden Punkten aus allmählich akropetal fort. Offenbar liegen hier die Verhältnisse ähnlich wie bei den labilen Zwillingssystemen von Zweigen (S. 626).

3) Vgl. Magnus, S. 313.

4) Bei Fraxinus excelsior pendula beobachtete ich einen Schößling, der, unterhalb der Krone dem Stamm entwachsen, zur Stammform zurïckgeschlagen und reich verästet, den ursprïnglichen Baum an Höhe überragte.

5) Dies Verhalten war nicht etwa in dem verschiedenen Alter der Blätter bedingt; vielmehr waren die Knospen des Ausschlags etwa gleichzeitig mit denen der Krone ausgetrieben.

6) KLeBS, 1912, S. 27 ว.

7) So ist die Krone von Prunus domestica, die in der Jugend korrelativ verdornte Triebe trägt, im Alter infolge der veränderten Korrelationen durchaus dornenlos, während die Stammansschläge auch im Alter stark verdornt gebildet werden. 
Die Frage, wie die gegenseitige korrelative Beeeinflussung zweier Sprosse zustande kommt, will ich eingehender nicht erörtern ${ }^{1}$ ), das Eine nur will ich hervorheben, daß bei den von mir untersuchten Fällen die Ernährung der einzelnen Sprosse eine wesentliche Rolle nicht spielt.

Die Tatsache, daß ein Sproß mit zunehmendem Alter einen andern stärker beeinflußt, während er gleichzeitig mit der Zunahme an Masse neues Material produziert, das andern Sprossen zugeleitet werden kann 2), zeigt ebenso wie das im wesentlichen gleiche Verhalten belichteter und etiolierter Papilionaceenkeimlinge ${ }^{3}$, daß die korrelative Hemmung eines Sprosses in einem Mangel an Assimilaten nicht bedingt ist.

KLEBS sucht nun die korrelative Hemmung eines Sprosses nicht auf absoluten Nahrungsmangel zurückzuführen, sondern auf ein ungünstiges Mischungsverhältnis der organischen und anorganischen Nahrung ${ }^{4}$ ). Nach seiner Ansicht ist die korrelative Sistierung des Wachstums in einer verhältnismäßigen Armut an Salzen bedingt ${ }^{5}$ ).

Doch auch diese Auffassung läßt sich mit den Tatsachen nicht in Einklang bringen. Typische korrelative Hemmungserscheinungen wie die Verdornung ${ }^{6}$ ) und der Zweigspitzenabwurf bei sympodial verzweigten Laubäumen werden gerade durch Herabsetzung der Transpiration ${ }^{7}$ ) und damit der Nährsalzaufnahme vermindert. Und anderseits werden im allgemeinen gerade jüngere, $d . h$. stark transpirierende Triebe von älteren, schwach transpirierenden Trieben gehemmt ${ }^{8}$ ).

Im Gegensatz zu der Anschaung, die die Sproßkorrelationen als eine Folge der A ufteilung der disponibeln Materialien ansieht9), scheinen vielmehr die korrelativ beeinflußten Triebe infolge des in der Änderung der Konstitution bedingten Wachstumsabschlusses die Fähigkeit zu verlieren, die vorhandene Nahrung zu verwerten. Da die

1) Vgl. SAChS, 1880 (1893, S.1181); 1882 (1893, S. 1226); KleBS, 1903, S. 33; 1906, S. 98, 105 f.; Goebel, 1898, S. 164; 1908, S. 10; Morgan, S. 120. Vgl. auch Mc Callum, S. 106, 25̃7; Errera, S. 132 f.; Noll, 1903, S. 403 f.; Nordhauden, S. 624 f.; Mc Callum, S. 263.

2) SACHS, 1863 (1892, S. 221). $\quad$ 3) S. $601 . \quad$ 4) KLEBS, 1912, S. 276.

5) KLEBS, 1911, S. 52.

6) Lothelier, S. 519. Vgl. hierzu Goebel, 1898, S. 227.

7) Wiesner, 1889, S. 4 f. Vgl. hierzu Goeber, 1898, S.179; ferner BerTHOLD, 1904, S. 246.

8) S. 615,620 f. Vgl. auch S. 602.

9) Herbst, S. $722 \mathrm{ff}$. 
korrelativen Hemmungen mit dem Alter der Pflanze zunehmen ${ }^{1}$ ), wird die Verwendung der Nahrung im Verhältnis zu ihrer Beschaffung dauernd vermindert, es findet also mit zunehmendem Alter eine stete Speicherung statt. -

Um zu einer Vorstellung von der Konstitutionsänderung korrelativ beinflußter Triebe zu gelangen, ist es nötig, die Selbständigkeit der einzelnen Wachstumsfunktionen ${ }^{2}$ ) in den Mittelpunkt der Betrachtung zu stellen.

Gelangt eine Knospe zum kritischen Punkt ihrer Entwicklung ${ }^{3}$ ), so werden ihre sämtlichen wesentlichen Wachstumsfunktionen auf irgendwelche Weise gleichmäßig sistiert und verharren nach diesem plötzlichen und vollständigen Abbruch ihrer Entwicklung in Ruhe, bis die Hemmung beseitigt ist, um dann unverändert oder wenig verändert das Wachstum fortzusetzen ${ }^{4}$ ).

Hat jedoch ein Sproß den kritischen Punkt überschritten, so werden seine einzelnen Wachstumsfunktionen in verschiedenem Maße abgeändert. Auf diese Weise lockert sich allmählich das gesamte funktionelle Gefüge, und zwar um so rascher, je entschiedener die Einzelfunktionen divergieren. Entscheidend hierfür ist auf der einen Seite der Zustand des betreffenden Sprosses, da mit fortschreitender Entwicklung des Sprosses seine Einzelfunktionen normalerweise mehr und mehr in gegenseitige Abhängigkeit geraten und fixiert werden, und auf diese Weise eine Festigung der Konstitution erreicht wird ${ }^{5}$. Auf der andern Seite ist der Zustand des hemmenden Sprosses von Bedeutung ${ }^{6}$ ), und vor allem die Dauer der Hemmung, da bei fortwirkender Hemmung die Einzelfunktionen des gehemmten Sprosses in jeder Entwicklungsetappe desselben von jenen weiter verändert werden ${ }^{7}$ ).

Ist die korrelative Beeinflussung nur eine zeitweise, so stellt sich bisweilen das konstitutionelle Gleichgewicht mehr oder weniger wieder her. Meist jedoch genügt eine zeitweise Hemmung, um die Einzelfunktionen in bestimmte, der normalen Konstitution des be-

1) S. $661 \mathrm{f}$.

2) KLebs, 1887, S. 549; KÜSter, 1903, S. 285. Unter Wachstumsfunktionen verstehe ich die einzelnen, zurzeit noch unbekannten Prozesse, die in ihrer Gesamtheit das Wachstum bedingen. Die folgenden Ausführungen sind also, soweit die Deutung der Tatsachen in Frage kommt, hypothetischer Natur.
3) S. $6 \tilde{4} 4$.
4) S. $652 \mathrm{f}$.

5) S. $654 \mathrm{f}$. Auch ungünstige äußere Bedingungen lockerṇ das auf normale Bedingungen eingestellte korrelative Gefïge (S. $655 \mathrm{f}$.).

6) S. 651 .

7) S. 657 . 
treffenden Sprosses nicht eigentiumliche Entwicklungsbahnen zu drängen. Infolgedessen divergieren die Wachstumsfunktionen bei fortschreitender Entwicklung mehr und mehr, sodaß sich das normale funktionelle Gefüge allmählich auflöst und schließlich Wachstumsunfähigkeit eintritt, wenn die Verschiebung der Einzelfunktionen die Grenze überschritten hat, innerhalb deren das für die Wachstumsfähigkeit erforderliche Gleichgewicht allein gegeben ist ${ }^{1}{ }^{1}$.

Bei Vicia Faba führt das Auseinanderklaffen der Einzelfunktionen unter Umständen zum inneren Zerfall des betreffenden Sprosses ${ }^{2}$. In zahlreichen andern Fällen dagegen schließen sich die aus dem normalen Gefüge gelösten Funktionen derartig aneinander, daß die Tätigkeit des wachstumsunfähigen Sprosses nicht sistiert, sondern in neue Bahnen geleitet wird, und auf diese Weise offenbar ein geordneter Abbau der Produkte und ein Ableiten derselben nach der Basis hin stattfindet $\left.{ }^{3}\right)$.

Da in zwangsweise gehemmten Sprossen und Knospen die Entwicklung der einzelnen Wachstumsfunktionen auf ein Minimum herabgesetzt ist, wird auch das allmähliche Auseinanderwachsen derselben bedeutend verzögert. Keineswegs aber stehen sie außerhalb des korrelativen Gefüges iberhaupt ${ }^{4}$ ).

Wird die Zwangshemmung entfernt, so ist infolge der verzögerten Entwicklung die Zerklüftung der Einzelfunktionen meist erst wenig fortgeschritten, wenn auch bisweilen mehr oder weniger eindeutig bestimmt; und so erklärt es sich, daß auch korrelativ stark abhängige Sprosse oder Knospen in der Regel nach dem Entgipsen zu wachsen beginnen ${ }^{5}$, und erst in dieser eingeschalteten Phase ihr Wachstumsvermögen in Wachstumsunfähigkeit verwandeln.

1) S. $597,5599,615,621$ f., $62 \tilde{5}, 636,657 \mathrm{f}$.

2) S. $659 \mathrm{f}$.

3) S. 6509 f. Das Ableiten der Produkte kann man aus dem Gilben mit Rücksicht auf die bei Blättern gemachten Beobachtungen schließen (STAHL, S. 152). Die histologischen Differenzierungen in einem korrelativ gehemmten Sproß sind bei der Gestaltung des Wachstums von entscheidender Bedeutung nicht. So fand Hallbauer (S. 54 f.) bei korrelativ gehemmten Sprossen das gleiche Vorriicken der Gefäße wie bei mechanisch gehemmten Sprossen. Das Entscheidende sind allein die physiologischen Veränderungen.

4) S. 597, 607, 615 f., 632 .

5) S. 597, $629 \mathrm{ff}$. 


\section{Tabellarische Belege.}

Sämtliche Längen sind in Millimetern angegeben.

\section{Keimlinge von Vicia Faba. \\ Tabelle I.}

Siehe ausführenden Teil S. 591: Anordnung der Versuche.

In den folgenden Tabellen wird hell durch $\mathrm{h}$, dunkel durch $\mathrm{d}$ bezeichnet.

\section{Tabelle II.}

Durch zeitweise mechanische Wachstumshemmung des Hauptsprosses (H.-S.) wurde das Wachstum der Kotyledonaraxillare (cot.-ax. = längerer der beiden Kotyledonaraxillare) angeregt. Beim Entgipsen war der Hauptsproß den Axillaren an Länge überlegen.

\begin{tabular}{|c|c|c|c|c|c|c|c|c|c|}
\hline & & 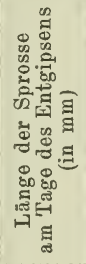 & 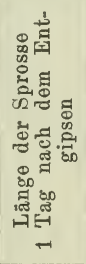 & 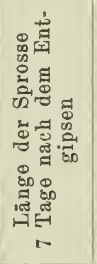 & 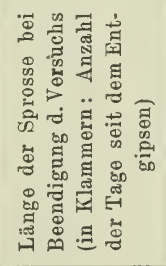 & 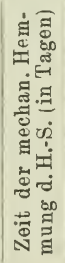 & Monat & 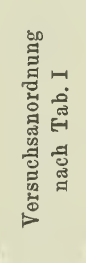 & Bemerkungen \\
\hline & $\begin{array}{l}\text { H.-S. } \\
\text { cot.-ax. }\end{array}$ & $\begin{array}{l}46,5 \\
15\end{array}$ & $\begin{array}{l}57 \\
15,2\end{array}$ & $\begin{array}{l}117 \\
19,7\end{array}$ & $\begin{array}{rr}228,5 & (13) \\
41,4 & (19)\end{array}$ & 13 & Juni & $\mathrm{h} \mathrm{d} \mathrm{d}$ & \\
\hline & $\begin{array}{l}\text { H.-S. } \\
\text { cot.-ax. }\end{array}$ & $\begin{array}{l}87 \\
34\end{array}$ & $\begin{array}{l}89 \\
36,5\end{array}$ & $\begin{array}{r}113 \\
37\end{array}$ & $\begin{aligned} 132 & (14) \\
37 & (14)\end{aligned}$ & 16 & Mai & $\mathrm{h} \mathrm{h} \mathrm{h}$ & in Sägemehl gezogen \\
\hline & $\begin{array}{l}\text { H.-S. } \\
\text { cot.-ax. }\end{array}$ & $\begin{array}{l}66 \\
35\end{array}$ & $\begin{array}{l}66,5 \\
35\end{array}$ & $\begin{array}{l}80,2 \\
35,6\end{array}$ & $\begin{array}{c}\text { entfernt }(8) \\
\text { tot }(32)\end{array}$ & 13 & August & $\mathrm{dh} \mathrm{h}$ & $\begin{array}{l}\text { Kotyled. am Tage nach } \\
\text { dem Entgipsen entfernt }\end{array}$ \\
\hline & $\begin{array}{l}\text { H.-S. } \\
\text { cot.-ax. }\end{array}$ & $\begin{array}{l}41 \\
23\end{array}$ & $\begin{array}{l}43,2 \\
27,8\end{array}$ & $\begin{array}{c}157,8 \\
36\end{array}$ & & 7 & Februar & $\mathrm{dh} \mathrm{h}$ & Fig. 1 \\
\hline & $\begin{array}{l}\text { H.-S. } \\
\text { cot.-ax. }\end{array}$ & $\begin{array}{l}57 \\
51\end{array}$ & $\begin{array}{l}65,2 \\
53,9\end{array}$ & $\begin{array}{l}75,8 \\
58\end{array}$ & $\begin{array}{l}(32) \\
(32)\end{array}$ & 13 & August & $\mathrm{dh} \mathrm{h}$ & $\begin{array}{l}\text { Kotyled. am Tage nach } \\
\text { dem Entgipsen entfernt }\end{array}$ \\
\hline
\end{tabular}


Tabelle III.

Der Kotyledonaraxillar ist beim Entgipsen dem Hauptsproß an Länge überlegen, wird aber im weiteren Verlauf der Entwicklung von diesem gehemmt und sistiert.

d. $=$ über der Basis abgeschnitten; und zwar ist der Tag der Dekapitation durch die eingeklammerte Zahl angegeben.

\begin{tabular}{|c|c|c|c|c|c|c|c|c|c|}
\hline & & \multicolumn{4}{|c|}{ Länge der Sprosse (in mm) } & \multirow[b]{2}{*}{ 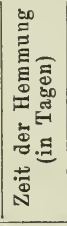 } & \multirow[b]{2}{*}{ Monat } & \multirow[b]{2}{*}{ 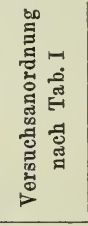 } & \multirow[b]{2}{*}{ Bemerkungen } \\
\hline & & 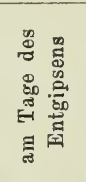 & 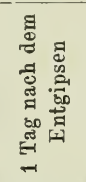 & 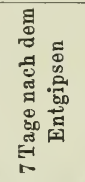 & 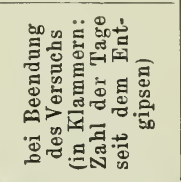 & & & & \\
\hline 1 & $\begin{array}{l}\text { H.-S. } \\
\text { cot.-ax. }\end{array}$ & $\begin{array}{c}97 \\
102,2\end{array}$ & $\begin{array}{l}102 \\
112,5\end{array}$ & & $\begin{array}{ll}124 & (3) \\
120,4 & (3)\end{array}$ & 17 & Dezbr. & $\mathrm{d} \mathrm{h} \mathrm{h}$ & $\begin{array}{l}\text { der Versuch wurde abge- } \\
\text { brochen, weil d. Pflanze } \\
\text { verletzt war }\end{array}$ \\
\hline 2 & $\begin{array}{c}\text { H.-S. } \\
\text { cot.-ax. }\end{array}$ & $\begin{array}{l}85 \\
90\end{array}$ & $\begin{array}{r}87 \\
100\end{array}$ & $\begin{array}{l}147,7 \\
127\end{array}$ & $\begin{array}{ll}520 & (23) \\
129 & (23)\end{array}$ & 7 & Mai & $\mathrm{h} \mathrm{h} \mathrm{h}$ & in Sägemehl kaltiviert \\
\hline 3 & $\begin{array}{c}\text { H.-S. } \\
\text { cot.-ax. }\end{array}$ & $\begin{array}{l}40 \\
60,4\end{array}$ & $\begin{array}{l}45 \\
72\end{array}$ & $\begin{array}{r}119,9 \\
90,5\end{array}$ & $\begin{aligned} 143,9 & (9) \mathrm{d} . \\
97,2 & \text { d. }\end{aligned}$ & 9 & Februar & $\mathrm{d} \mathrm{h} \mathrm{h}$ & \\
\hline 4 & $\begin{array}{c}\text { H.-S. } \\
\text { cot.-ax. }\end{array}$ & $\begin{array}{l}65 \\
78,1\end{array}$ & $\begin{array}{l}73,6 \\
82\end{array}$ & $\begin{array}{l}149 \\
128\end{array}$ & $\begin{array}{ll}496 & (32) \\
150 & (32)\end{array}$ & 13 & August & $\mathrm{d} \mathrm{h} \mathrm{h}$ & \\
\hline 5 & $\begin{array}{c}\text { H.-S. } \\
\text { cot.-ax. }\end{array}$ & $\begin{array}{l}36 \\
80,9\end{array}$ & $\begin{array}{l}42 \\
91\end{array}$ & $\begin{array}{l}140,6 \\
115,3\end{array}$ & $\begin{array}{l}229,3(19) \\
115,5 \quad(9) \mathrm{d} .\end{array}$ & 9 & Februar & $\mathrm{d} \mathrm{h} \mathrm{h}$ & Fig. 2 \\
\hline 6 & $\begin{array}{c}\text { H -S. } \\
\text { cot.-ax. }\end{array}$ & $\begin{array}{l}38 \\
49,9\end{array}$ & $\begin{array}{l}45,4 \\
58,4\end{array}$ & 111,2 & $\begin{array}{l}107,8 \quad(6) \mathrm{d} . \\
428 \quad(32)\end{array}$ & 13 & August & $\mathrm{d} \mathrm{h} \mathrm{h}$ & Fig. 4 \\
\hline 7 & $\begin{array}{l}\text { H.-S. } \\
\text { cot.-ax. }\end{array}$ & $\begin{array}{l}39 \\
77,3\end{array}$ & $\begin{array}{r}44 \\
103\end{array}$ & $\begin{array}{l}140,2 \\
172,7\end{array}$ & $\begin{array}{l}172,7 \quad(9) \mathrm{d} . \\
178,2(19)\end{array}$ & 9 & Februal & $\mathrm{d} \mathrm{h} \mathrm{h}$ & Fig. 3 \\
\hline 8 & $\begin{array}{l}\text { H.-S. } \\
\text { cot.-ax. }\end{array}$ & $\begin{array}{c}39 \\
187,9\end{array}$ & $\begin{array}{r}46 \\
216\end{array}$ & $\begin{array}{l}181 \\
287\end{array}$ & $\begin{array}{l}220,4 \quad(8) d . \\
289 \quad(11)\end{array}$ & $\{13$ & Juni & $d d d$ & \\
\hline 9 & $\begin{array}{c}\text { H.-S. } \\
\text { cot.-ax. }\end{array}$ & $\begin{array}{r}49 \\
195\end{array}$ & $\begin{array}{r}61 \\
210\end{array}$ & $\begin{array}{l}178 \\
281,5\end{array}$ & $\begin{array}{l}220,6(11) \text { d. } \\
292,4(15) \text { tot }\end{array}$ & 13 & Juni & $\mathrm{h} \mathrm{d} \mathrm{d}$ & \\
\hline 10\{ & $\begin{array}{l}\text { H.-S. } \\
\text { cot.-ax. }\end{array}$ & $\begin{array}{r}44,5 \\
158,5\end{array}$ & $\begin{array}{c}49 \\
187,5\end{array}$ & $\begin{array}{l}147,5 \\
324\end{array}$ & $\begin{array}{l}326 \quad(15) d . \\
365,3(24)\end{array}$ & $\{12$ & Juni & $\mathrm{d} \mathrm{h} \mathrm{h}$ & \\
\hline
\end{tabular}




\section{Tabelle IV.}

Korrelationen von Hauptsproß und Kotyledonaraxillar nach Typus II. Die Nummern der einzelnen Versuche decken sich mit denen in Tab. III.

Unter Kreuzung des Wachstums verstehe ich den Zeitpunkt, wo Hauptsproß und Kotyledonaraxillar gleich lang sind.

Bei den mit * markierten Längen wurde der Kreuzungspunkt zwar nicht erreicht, weil einer der Sprosse vorher entfernt worden war, doch war er durch den Verlauf des Wachstums bis zur Dekapitation eindeutig bestimmt.

\begin{tabular}{|c|c|c|c|c|c|c|c|c|c|}
\hline & 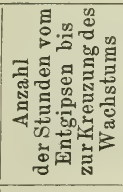 & 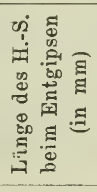 & 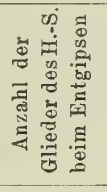 & 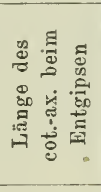 & 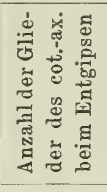 & 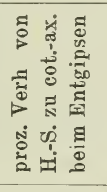 & 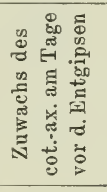 & 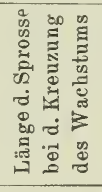 & 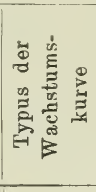 \\
\hline 1 & 60 & 97 & $1, \tilde{0}$ & 102,2 & 1,5 & 94,9 & 16,6 & 118 & a \\
\hline 2 & 65 & 85 & & 90 & & 94,4 & & 113 & a \\
\hline 3 & 80 & 40 & 1,5 & 60,4 & 2 & 66,2 & 7,9 & 80,5 & a \\
\hline 4 & 106 & 65 & 2,5 & 78,1 & 2 & 83,6 & 20,4 & 108 & b \\
\hline 5 & 134 & 36 & 2,5 & 80,9 & 2 & 44,5 & 15,9 & 114,5 & a \\
\hline 6 & 144 & 38 & 2 & 49,9 & 1,5 & 84,6 & 9,2 & 109 & b \\
\hline 7 & 216 & 39 & 2 & 77.3 & 2 & 50,5 & 20,3 & 172,7 & b \\
\hline 8 & 252 & 39 & 2 & 187,9 & 3,5 & 20,8 & 44,2 & *289 & b \\
\hline 9 & 370 & 49 & 2,5 & 195 & 3,5 & 25 & 21,3 & *292,4 & $\mathrm{b}$ \\
\hline 10 & 389 & 44,5 & 2,5 & 1508,5 & 3,5 & 28,1 & 29,1 & $* 360,5$ & b \\
\hline
\end{tabular}


Tabelle V.

1-3: Korrelation von Hauptsproß und Kotyledonaraxillar nach Typus IV.

4-6: Korrelation von Hauptsproß und Kotyledonaraxillar nach Typus III.

7: Mischtypus infolge von Entfernung der Kotyledonen, der als Typus II beginnt und als Typus III ausklingt.

\begin{tabular}{|c|c|c|c|c|c|c|c|c|c|c|c|}
\hline & & \multirow[b]{2}{*}{ 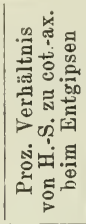 } & \multicolumn{4}{|c|}{ Länge der Sprosse (in mm) } & \multirow[b]{2}{*}{ 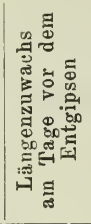 } & \multirow[b]{2}{*}{ 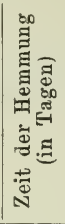 } & \multirow[b]{2}{*}{ Monat } & \multirow[b]{2}{*}{ 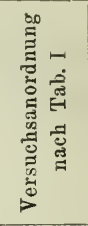 } & \multirow[b]{2}{*}{ Bemerkungen } \\
\hline & & & 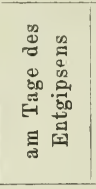 & 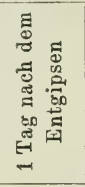 & 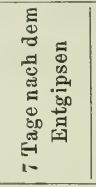 & 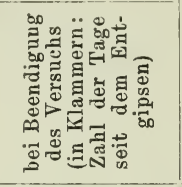 & & & & & \\
\hline 1 & $\begin{array}{l}\text { H.-S. } \\
\text { cot.-ax. }\end{array}$ & 36,4 & $\begin{array}{c}52 \\
142,8\end{array}$ & $\begin{array}{r}57 \\
166\end{array}$ & $\begin{array}{r}66 \\
323\end{array}$ & $\begin{array}{c}69,4 \text { (15) } \\
350,7 \quad(8) \mathrm{d} .\end{array}$ & $\overline{24,5}$ & 12 & Juni & $\mathrm{h} \mathrm{h} \mathrm{h}$ & Fig. 6 \\
\hline 2\{ & $\begin{array}{l}\text { H.-S. } \\
\text { cot.-ax. }\end{array}$ & 34,7 & $\begin{array}{c}56 \\
169,8\end{array}$ & $\begin{array}{r}62 \\
190\end{array}$ & $\begin{array}{r}71 \\
293\end{array}$ & $\begin{aligned} 77 & (15) \\
312 & (8) d .\end{aligned}$ & $\overline{31,4}$ & 13 & Juni & $\mathrm{h} d \mathrm{~d}$ & \\
\hline 3 & \begin{tabular}{|} 
H.-S. \\
cot.-ax.
\end{tabular} & 30,8 & $\begin{array}{r}45 \\
146\end{array}$ & $\begin{array}{r}49,6 \\
162,5\end{array}$ & & $\begin{array}{rr}52,9 & (6) \mathrm{d} . \\
234,6 & (6) \mathrm{d} .\end{array}$ & $\overline{18}$ & 13 & Aug. & $\mathrm{dh} \mathrm{h}$ & \\
\hline 4 & $\begin{array}{l}\text { H.-S. } \\
\text { cot.-ax. }\end{array}$ & 39 & $\begin{array}{r}42,5 \\
108,9\end{array}$ & $\begin{array}{r}53 \\
131\end{array}$ & $\begin{array}{r}90,5 \\
188,4\end{array}$ & $\begin{array}{r}93,5(13) \\
190,8(13)\end{array}$ & $\overline{18,9}$ & \} & Febr. & $\mathrm{d} \mathrm{h} \mathrm{h}$ & Fig. 5 \\
\hline 5 & $\begin{array}{l}\text { H.-S. } \\
\text { cot.-ax. }\end{array}$ & 35,8 & $\begin{array}{r}53 \\
148\end{array}$ & $\begin{array}{r}61 \\
167\end{array}$ & $\begin{array}{l}120 \\
200\end{array}$ & $\begin{array}{ll}122 & (22) \\
206 & (22)\end{array}$ & ? & $\{13$ & Mai & $\mathrm{h} \mathrm{h} \mathrm{h}$ & \\
\hline 6 & $\begin{array}{l}\text { H.-S. } \\
\text { cot.-ax. }\end{array}$ & 32,5 & $\begin{array}{r}65 \\
200\end{array}$ & & & $\begin{array}{ll}146 & (20) \\
325 & (20)\end{array}$ & $\bar{?}$ & $\{21$ & Juni & $\mathrm{h} \mathrm{h} \mathrm{h}$ & \\
\hline 7\{ & $\begin{array}{l}\text { H.-S. } \\
\text { cot.-ax. }\end{array}$ & 63,5 & $\begin{array}{l}61 \\
96\end{array}$ & $\begin{array}{r}62,2 \\
113,2\end{array}$ & $\begin{array}{r}76,5 \\
122,7\end{array}$ & $\begin{array}{ll}\text { tot } & (32) \\
\text { tot } & (32)\end{array}$ & $\overline{18,9}$ & $\{13$ & Aug. & $\mathrm{dh} \mathrm{h}$ & $\begin{array}{l}1 \text { Tag nach dem Ent- } \\
\text { gipsen wurden die } \\
\text { Kotyledonen entfernt } \\
\text { Fig. S. }\end{array}$ \\
\hline
\end{tabular}

\section{Monopodiale Zweigsysteme von Coniferen.}

Die Längenangaben beziehen sich auf die Länge von der Basis des Zweiges bis zur Basis der Endknospe. Lag in jugendlichen Stadien die Basis der Endknospe noch nicht frei, so wurde bis zur Spitze der obersten Nadeln gemessen. Doch habe ich die Längen, die von der Basis des Zweiges bis zur Spitze seiner obersten Nadeln gerechnet sind, eingeklammert. Zur Berechnung der Wachstumsintensität wurde stets die Länge des Zweiges bis zur Spitze seiner obersten Nadeln verwendet, um für jugendliche und ältere Stadien ein einheitliches $\mathrm{Maß}$ zu haben. 


\section{Torreya nucifera. \\ Tabelle VI.}

Normal entwickelte Systeme verglichen mit solchen, deren Endknospen eine Zeitlang mechanisch am Wachstum gehindert waren.

War bei $a_{2}$ und $b_{2}$ die definitive Länge der Seitentriebe (S.-Tr.) etwa gleich wie bei Seitentrieben unter $a_{1}$ und $b_{1}$, so wurde bei $a_{2}$ und $b_{2}$ in der Rubrik »Länge der Seitentriebe beim Entgipsen « die Lünge der Seitentriebe an dem Tage (mit vermerkt) angeführt, an dem die Endknospen der entsprechenden Systeme bei $a_{1}$ und $b_{1}$ entgipst wurden.

\begin{tabular}{|c|c|c|c|c|c|c|c|c|c|c|c|}
\hline & & 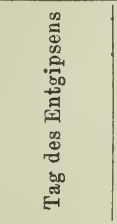 & 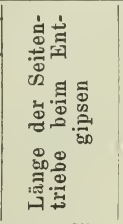 & 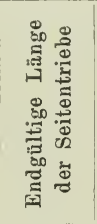 & 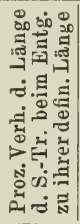 & 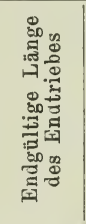 & 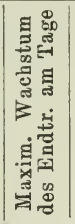 & 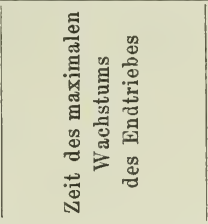 & 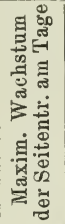 & 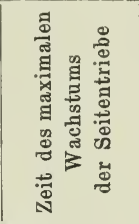 & Bemerkungen \\
\hline & 1 & 27. V. & (7) & & - & 100,5 & 3,2 & 24.-27. VI. & 31 & 15 - $20 \mathrm{VI}$ & \\
\hline. & & & & $\mathrm{krank}$ & & & & & & & \\
\hline & 2 & 27. V. & $(9,3)$ & 88 & 一 & 107,5 & 2,7 & 24.-27. VI. & 4,1 & 10.-15.VI. & \\
\hline$\frac{\pi}{0}$ & 3 & 27. V. & (13) & $\begin{array}{r}104,5 \\
74,5\end{array}$ & - & 113 & 3,2 & 24.-27. VI. & 4,9 & 4.-8. VI. & \\
\hline : & 4 & 29. V. & $(11,5)$ & 118 & - & 138,5 & 3,5 & 28. VI.-2. VII. & 5 & 5.-8. VI. & \\
\hline E & 5 & 2. VI. & $(12,3)$ & 81,5 & 一 & 79 & 2,1 & 28. VI.-2. VII. & 3,7 & 8.-15.VI. & \\
\hline 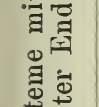 & 6 & 8. VI. & $\begin{array}{c}54,5 \\
\text { entfernt }\end{array}$ & 一 & - & 31 & 1 & 6. VII.-11.VIII. & 5,9 & 5.-8. VI. & $\begin{array}{l}\text { möglicherw. hatten } \\
\text { die S.-Tr. ihr max. } \\
\text { Wachstum noch } \\
\text { nicht erreicht }\end{array}$ \\
\hline 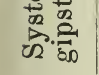 & 7 & 21. VI. & 54 & $8 \check{,}, 5$ & 63,5 & 86,3 & 2 & 6. VII.-11.VIII. & 4,3 & 12.-17.VI. & $\begin{array}{l}\text { am 11. VIII. ist der } \\
\text { Endtr. noch nicht } \\
\text { ausgewachsen }\end{array}$ \\
\hline 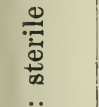 & 8 & 7. VIII. & $\begin{array}{l}142,4 \\
\text { entfernt }\end{array}$ & - & - & 69 & 0,4 & 11.VIII.-5. IX. & 5,9 & 10.-15.VI. & $\begin{array}{l}\text { Endtr. am 11. VIII } \\
\text { noch nicht ausge- } \\
\text { wachsen. Im Win. } \\
\text { ter erfroren }\end{array}$ \\
\hline$\ddot{\Xi}$ & 9 & (15. VII.) & 72 & 83 & 89 & - & - & - & 3,8 & 8.-12.VI. & $\begin{array}{l}\text { Endknospe abort } \\
\text { am 15. VII. }\end{array}$ \\
\hline कू. & 10 & - & $\begin{array}{l}\text { 27. V: } \\
14,3\end{array}$ & 86,3 & - & 117,5 & 6,2 & 5.-8. VI. & 5,4 & 4.-8. VI. & \\
\hline : : & 11 & 一 & $\begin{array}{l}\text { 21. VI: } \\
65,3\end{array}$ & 85,3 & - & 127,3 & $6, \tilde{5}$ & 4.-7. VI. & $5, \tilde{5}$ & 4.-8. VI. & \\
\hline 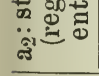 & 12 & - & $\begin{array}{l}\text { 21. VI: } \\
71,7\end{array}$ & 107 & - & $125 \check{, 5}$ & 4,9 & 8.-13. VI. & 5,3 & 4.-8. VI. & \\
\hline 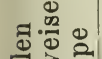 & 13 & 27. V. & $(31,8)$ & 54 & - & 37 & 1 & 23.-27. VI. & 3,5 & & $\begin{array}{l}\text { Endtrieb im Win } \\
\text { ter erfroren }\end{array}$ \\
\hline 毒: & 14 & 27. V. & $(35,8)$ & 42 & - & - & - & - & 3,2 & 24. V. & $\begin{array}{l}\text { Endknospe an } \\
\text { 20. VI. abortiert }\end{array}$ \\
\hline 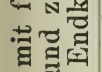 & 15 & 8. VI. & $\begin{array}{c}27,7 \\
\text { entfernt }\end{array}$ & - & - & - & - & - & 3 & 24. V. & $\begin{array}{l}\text { Endknospe in Juli } \\
\text { abortiert }\end{array}$ \\
\hline घี & 16 & 8. VI. & 35,5 & 41,5 & $8 \tilde{,}, 5$ & - & - & - & 3,3 & 24. V. & $\begin{array}{l}\text { Endknospe war am } \\
\text { 20. VI. abortiert }\end{array}$ \\
\hline 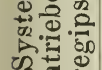 & 17 & 8. VI. & $\begin{array}{l}47,8 \\
\text { entfernt }\end{array}$ & - & - & - & - & - & 4,4 & 23. V. & $\begin{array}{l}\text { Endknospe ain } \\
\text { 20. VI. abortiert }\end{array}$ \\
\hline$\because \pm$. & 18 & (20. VI.) & $3 \check{5}, 5$ & 40,7 & 89,7 & - & - & - & 3,3 & 24. V. & $\begin{array}{l}\text { Endknospe am } \\
\text { 2). VI. abortiert }\end{array}$ \\
\hline 2.0 & 19 & 21. VI. & 34,7 & 40 & 86,2 & - & - & - & 2,8 & 23. V. & $\begin{array}{l}\text { Endknospe am } \\
\text { 21. VI. abortiert }\end{array}$ \\
\hline
\end{tabular}




\begin{tabular}{|c|c|c|c|c|c|c|c|c|c|c|c|}
\hline & & 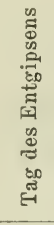 & 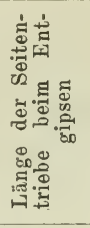 & 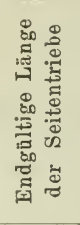 & 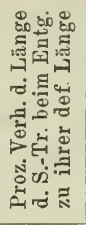 & 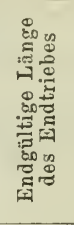 & 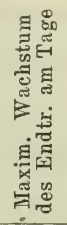 & 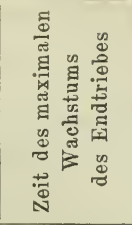 & 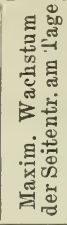 & 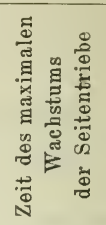 & Bemerkungen \\
\hline \multirow{4}{*}{ 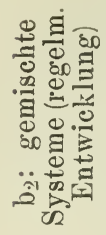 } & 20 & - & $\begin{array}{r}27 . \mathrm{V}: \\
46,8\end{array}$ & 58,5 & - & $8 \tilde{}$ & 5,1 & 4.-8. VI. & 4,8 & 24. V. & \\
\hline & 21 & - & $\begin{array}{r}\text { 27. V: } \\
46,8\end{array}$ & 50 & - & 66,5 & 3,9 & 4.-7. VI. & 4,1 & 24. V. & \\
\hline & 22 & - & - & 43 & - & 68,5 & 4,4 & 5.-8. VI. & 3,3 & 24. V. & \\
\hline & 23 & - & - & 63,8 & - & 89 & 3,9 & 7.-13. VI. & 4,3 & 24. V. & \\
\hline \multirow{2}{*}{ 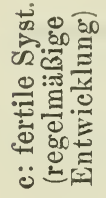 } & 24 & - & - & 33 & - & 48 & 3,5 & 24. V. & 2,8 & 24. V. & \\
\hline & 25 & - & - & 43 & - & 60 & 3,8 & 24. V. & 3,7 & 24. V. & \\
\hline
\end{tabular}

Tabelle VII.

Nach Entfernung der Endknospe war eine Seitenknospe zeitweise eingegipst. 1-5: sterile Seitentriebe, 6: fertile Seitentriebe.

\begin{tabular}{|c|c|c|c|c|c|c|c|c|c|c|}
\hline & 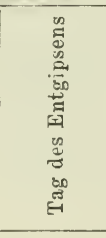 & 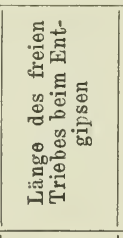 & 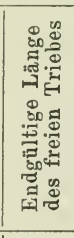 & 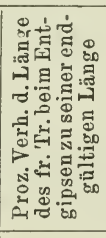 & 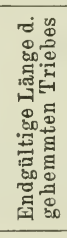 & 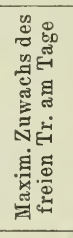 & 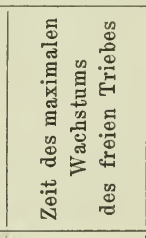 & 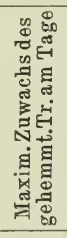 & 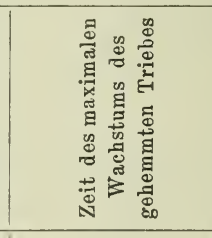 & Bemerkungen \\
\hline 1 & 2. VI. & (12) & 78,5 & - & 80,5 & 3,7 & 10.-14. VI. & 2,4 & 23.-27. VI. & \\
\hline 2 & & $\begin{array}{c}(31,5) \\
\text { entfernt }\end{array}$ & - & - & 66 & 3,1 ? & 8. VI. & 1,9 & & $\begin{array}{l}\text { möglicherweise hat } \\
\text { der freie Tr. sein }\end{array}$ \\
\hline 3 & 8. VI. & $(32)$ & 79,5 & - & 61,5 & 3,8 & 8.-15. VI. & 1,6 & etwa 7. VII. & $\begin{array}{l}\text { max. Wachstum } \\
\text { nicht erreicht }\end{array}$ \\
\hline 4 & 21. VI. & 31,7 & 68 & 57,4 & 38 & 2,9 & 12.-16. VI. & 0,9 & 20.VII.-10.VIII. & \\
\hline 5 & (20. VI.) & 55 & 82,5 & 66,7 & - & 4,5 & 5.-7. VI. & - & - & $\begin{array}{l}\text { gehemmte Knospe } \\
\text { am 20. VI. vor dem } \\
\text { Entg. abortiert }\end{array}$ \\
\hline 6 & 2. VI. & 24,5 & 51 & 53,9 & - & $3, \tilde{5}$ & 24. V. & - & - & $\begin{array}{l}\text { fertil. Gehemmte } \\
\text { Knospe am 13. VI. } \\
\text { abortiert }\end{array}$ \\
\hline
\end{tabular}


Untersuchungen über Korrelationen von Knospen und Sprossen.

2. Picea pungens.

Tabelle VIII.

Beeinflussung von zeitweise eingegipst gewesenen Endknospen und deren Trieben durch die Seitentriebe.

Mit Ausnahme von 4 waren die beiden obersten Seitentriebe bei sämtlichen Versuchen ungefähr gleich lang. Für die Angaben wurde der längere gewählt.

\begin{tabular}{|c|c|c|c|c|c|c|c|c|c|c|c|}
\hline & 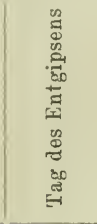 & 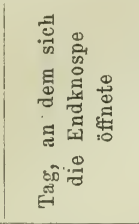 & 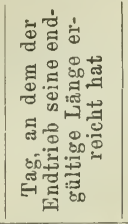 & 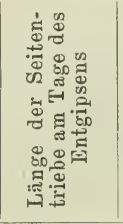 & 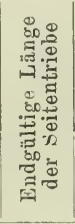 & 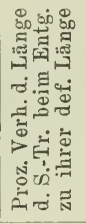 & 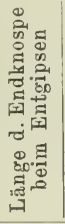 & 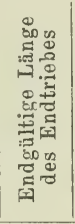 & 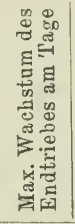 & 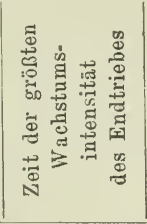 & Bemerkungen \\
\hline 1 & 27. V. & 2.-9. VI. & 27. V. & 70 & 76,5 & 91,5 & 9,5 & 42 & 1,7 & 11.-15. VI. & \\
\hline 2 & 2. VI. & 9. VI. & 5. VII. & 49 & 51,3 & $9 \tilde{5}, 5$ & 8,3 & 33,5 & 1,2 & 11.-15. VI. & \\
\hline 3 & 2. VI. & 9. VI. & 5. VII. & 52 & 54,7 & 95,1 & 5,8 & 19,5 & 0,6 & 9.-18. VI. & \\
\hline 4 & 3. VI. & 9. VI. & 10. VIII. & $\begin{array}{l}48,5 \\
71,5\end{array}$ & $\begin{array}{l}51,2 \\
71,5\end{array}$ & $\begin{array}{c}95,5 \\
100\end{array}$ & 7 & 29 & 1 & 14.-20. VI. & $\begin{array}{l}\text { der längere Seiten- } \\
\text { trieb wurde am }\end{array}$ \\
\hline 5 & 20. VI. & 5. VII. & 10. VIII. & 59,2 & 59,2 & 100 & 8 & 18 & 0,5 & 2.-5. VII. & 9. VI. entfernt \\
\hline 6 & 20. VI. & nach VIII. & - & $\begin{array}{c}54 \\
\text { entfernt }\end{array}$ & - & - & 5,5 & 一 & - & - & $\begin{array}{l}\text { eine Streckung des } \\
\text { Endtriebes hat } \\
\text { nicht statt }\end{array}$ \\
\hline 7 & 20. VI. & 5. VII. & 10. VIII. & - & - & - & 7,7 & 37 & 1,1 ? & 5. VII. & $\begin{array}{l}\text { das max. Wachstum } \\
\text { des Endtrieb. ist } \\
\text { möglicherweise zu } \\
\text { niedrig angegeb. }\end{array}$ \\
\hline
\end{tabular}

III. Sympodiale Zweigsysteme von Laubbäumen.

1. Tilia ulmifolia.

Tabelle IX.

Längen der Zweige bei unverletzten Systemen und nach Entfernung der Endknospe.

\begin{tabular}{|c|c|c|c|c|c|c|c|}
\hline & & Trieb I & Trieb II & Trieb III & Trieb IV & Trieb V & Trieb VI \\
\hline $\begin{array}{c}\text { a. } \\
\text { unverletzte } \\
\text { Systeme }\end{array}$ & $\begin{array}{l}1 \\
2 \\
3 \\
4 \\
5\end{array}$ & $\begin{array}{l}100 \\
195 \\
112 \\
54,7 \\
53\end{array}$ & $\begin{array}{l}63,5 \\
46,5 \\
25 \\
15,5 \\
24\end{array}$ & $\begin{array}{l}17 \\
129 \\
19,7 \\
12 \\
13,5\end{array}$ & $\begin{array}{l}27 \\
10,5 \\
3,5 \\
8 \\
3,5\end{array}$ & $\begin{array}{l}2,5 \\
- \\
- \\
-\end{array}$ & $\begin{array}{l}- \\
- \\
- \\
-\end{array}$ \\
\hline $\begin{array}{l}\text { b. } \\
\text { Systeme nach } \\
\text { Entfernung des } \\
\text { Endgliedes }\end{array}$ & $\begin{array}{r}6 \\
7 \\
8 \\
9 \\
10\end{array}$ & $\begin{array}{l}- \\
- \\
-\end{array}$ & $\begin{array}{c}172 \\
220 \\
179 \\
167 \\
91,5\end{array}$ & $\begin{array}{c}72 \\
77 \\
76,5 \\
110,5 \\
22\end{array}$ & $\begin{array}{l}30 \\
25 \\
17 \\
26 \\
-\end{array}$ & $\begin{array}{l}26 \\
6,5 \\
20 \\
20,3 \\
-\end{array}$ & $\begin{array}{l}10 \\
- \\
6,5 \\
- \\
-\end{array}$ \\
\hline
\end{tabular}


Tabelle $\mathrm{X}$.

Verhältnis der einzelnen Triebe zueinander.

Die Längenangaben beziehen sich auf den 6. Juni 1910 (physiologische Periode.)

\begin{tabular}{c|c|c|c|c|c|c|c|c|c|c}
\hline \hline & \multicolumn{3}{|c|}{ Länge (in mm) } & \multicolumn{3}{|c}{ Proz. Verhältnis der endgültigen Längen } \\
von
\end{tabular}

Tabelle XI.

Längen der Zweige von Zwillingssystemen.

Die römischen Zahlen bezeichnen die Triebe in basipetaler Richtung.

\begin{tabular}{c|c|c|c|c|c|c|c|c|c}
\hline \hline & I & II & III & IV & V & VI & VII & VIII & IX \\
\hline 1 & 107 & 58 & 23,5 & 32 & 32 & 8 & & & \\
2 & 100 & 63,5 & 17 & 27 & 2,5 & & & & \\
3 & 232 & 122 & 51 & 39,5 & 12,5 & 25,5 & 17,5 & 1,5 & \\
4 & 152 & 117 & 18,5 & 23 & 22 & 90 & 19 & 11 & 3 \\
5 & 195 & 46,5 & 129 & 10,5 & & & & & \\
6 & 54,5 & 16 & 189,5 & 73,5 & 50 & 21,5 & & &
\end{tabular}




\section{Tabelle XII.}

\section{Die Bedeutung von Gallen für die Gestaltung des Verzweigungs- systems.}

6-10 stellen extreme Fälle der unter 12 und 13 auf den Durchschnitt berechneten Versuchsreihe dar.

Anmerkungen zu der Rubrik „Durchschnitt von 29 Systemen«:

Bei vier Versuchen war wegen der Schwäche des Systems der 3. Trieb nicht vorhanden, soda 3 das proz. Verhältnis von Trieb III zu Trieb II $=0$ war. Schaltet man diese Versuche aus, so ergibt sich für Trieb III die Länge von $20,1 \mathrm{~mm}$, Trieb III verhält sich zu Trieb II wie $37,6 \mathrm{zu} 100$.

Anmerkungen zu der Rubrik »Durchschnitt von 33 Systemen«:

Schaltet man einen Versuch aus, wo infolge von Zwillingsbildung das Verhältnis von Trieb III zu Trieb II außerordentlich hoch ist (10), so ergibt sich füir Trieb III $=18,7 \mathrm{~mm}$, für Trieb III zu Trieb II $=32,5 \mathrm{zu} 100$.

\begin{tabular}{|c|c|c|c|c|}
\hline \multicolumn{3}{|c|}{$\begin{array}{l}\text { Längen (in mm) } \\
\text { von }\end{array}$} & $\begin{array}{c}\text { Proz. Verhältnis } \\
\text { der definitiven } \\
\text { Längen von } \\
\end{array}$ & \multirow[t]{2}{*}{ Nähere Angaben } \\
\hline $\begin{array}{c}\text { Trieb } \\
\text { I }\end{array}$ & $\begin{array}{c}\text { Trieb } \\
\text { II }\end{array}$ & $\begin{array}{l}\text { Trieb } \\
\text { III }\end{array}$ & \begin{tabular}{c|c} 
Trieb II & Trieb III \\
zu Trieb I & zu Trieb II
\end{tabular} & \\
\hline
\end{tabular}

a. Systeme mit Gallen:

\begin{tabular}{|c|c|c|c|c|c|}
\hline 253 & 183 & 39 & 72,3 & 21,3 & Triol I mit foll \\
\hline 241 & 204 & 11 & 84,6 & 5,4 & \} \\
\hline 215,5 & 197 & 44 & 91,4 & 22,3 & \\
\hline 210,5 & 174 & 23 & 80,5 & 13,2 & eo 11 mit Galle \\
\hline 195 & $46, \check{5}$ & 129 & 23,8 & $27 \tilde{0}, \tilde{0}$ & $\begin{array}{l}\text { induziertes Zwillingssystem. Trieb I } \\
\text { mit Galle }\end{array}$ \\
\hline 230 & $189, \check{5}$ & 29 & 82,2 & 15,3 & Durchschnitt der Angaben von 1-4 \\
\hline
\end{tabular}

b. Systeme ohne Gallen:

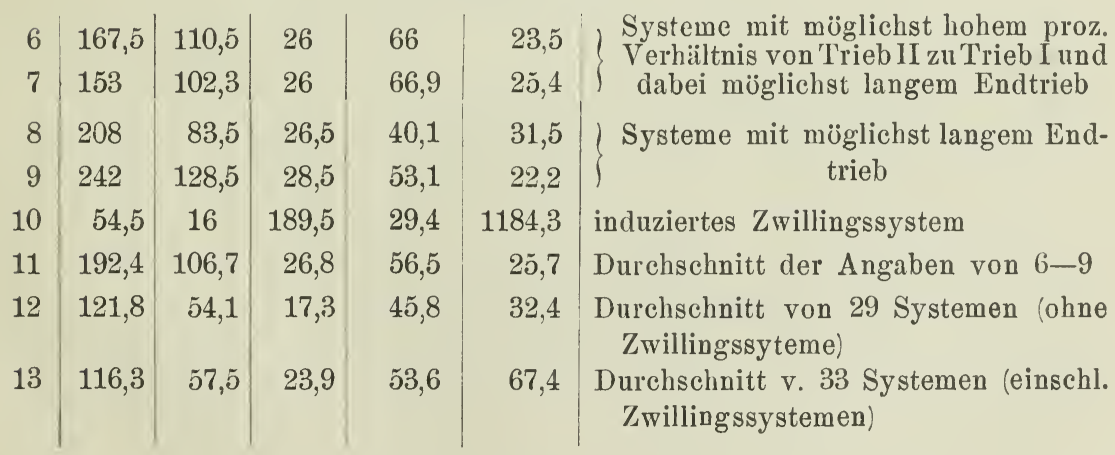




\section{Tabelle XIII.}

Bedeutung des Zustandes der Seitentriebe für die Lebensdauer entgipster Endknospen.

Tag des Entgipsens

16. V. 20. V. 3. VI.

Anzahl der Versuche

Proz. Verhältnis der Lïngen der Seitentriebe beim

Entgipsen zu deren endgültiger Länge . .

Durchschnittliche Lebensdauer der entgipsten

Knospen nach dem Entgipsen (in Tagen) . .

$63,9 \quad 85,6 \quad 100$

18

15

3

\section{Salix fragilis.}

Die Knospen und Triebe der eingegipsten Spitzenzone sind eingekastet.

\section{Tabelle XIV.}

Gestaltung des Systems bei Stecklingen, deren Spitzenregion bis zum 12. IV. eingegipst war.

Die römischen Zahlen bezeichnen die Knospen und Triebe in basipetaler Richtung. Kn. = Knospe. Abortierte Knospen oder Zweige sind durch einen wagrechten Strich markiert (-). $\quad+=$ abgestorben. $\circ=$ die Zweigspitze hat abortiert. ! = durch Austreiben der End- oder einer Seitenknospe.

\begin{tabular}{|c|c|c|c|c|c|c|c|c|c|c|c|c|}
\hline & & I & II & III & IV & $\mathrm{V}$ & VI & VII & VIII & IX & $\mathrm{x}$ & $\mathrm{XI}$ \\
\hline \multirow{3}{*}{ a } & 12. IV. & $\mathrm{Kn}$. & $\mathrm{Kn}$. & 6 & ○ & $\circ 17$ & 17,5 & $23, \tilde{\partial}$ & - & - & - & - \\
\hline & 13. V. & Kn. & Kn. & 12 & - & - & $18, \tilde{0}$ & $24, \tilde{5}$ & - & - & - & - \\
\hline & 12. VIII. & - & - & ! 24,3 & - & - & - & $! 49$ & - & - & - & - \\
\hline \multirow{3}{*}{ b } & 12. IV. & Kn. & Kn. & $\check{5}, \tilde{5}$ & 43 & $\circ 25$ & - & Kn. & $\mathrm{Kn}$. & & & \\
\hline & 13. V. & $\mathrm{Kn}$. & Kn. & $t$ & $4 \check{\partial}, \tilde{5}$ & $\circ 25$ & - & Kn. & $\mathrm{Kn}$. & & & \\
\hline & 12. VIII. & - & - & - & $! 73$ & - & - & - & - & 31 & & \\
\hline \multirow{3}{*}{ c } & 12. IV. & $\mathrm{Kn}$. & Kn. & Kn. & Kn. & $\mathrm{Kn}$. & $\mathrm{Kn}$. & - & $\circ 20,5$ & 7 & $\circ 24$ & $\mathrm{Kn}$. \\
\hline & 13. V. & 6 & Kn. & $8, \tilde{a}$ & Kn. & $\mathrm{Kn}$. & $\mathrm{Kn}$. & - & $\circ 21$ & - & $\circ 24$ & - \\
\hline & 12. VIII. & 76,5 & - & 37,3 & - & - & - & - & - & - & $! 44$ & - \\
\hline \multirow{3}{*}{ d } & 12. IV. & Kn. & $\mathrm{Kn}$. & $\mathrm{Kn}$. & $\mathrm{Kn}$. & $\mathrm{Kn}$. & $\mathrm{Kn}$. & - & - & 30 & $\circ 29$ & 39,5 \\
\hline & 13. V. & $\mathrm{Kn}$. & $\mathrm{Kn}$. & $\mathrm{Kn}$. & $\mathrm{Kn}$. & $\mathrm{Kn}$. & $\mathrm{Kn}$. & - & - & 33 & $\circ 30$ & 42 \\
\hline & 12. VIII. & - & - & 146 & - & - & - & - & - & 31,7 & - & !62,5 \\
\hline
\end{tabular}


Untersuchungen über Korrelationen von Knospen und Sprossen.

\section{Salix aurita.}

Die Knospen und Triebe der eingegipsten Zone sind eingekastet.

\section{Tabelle XV.}

Gestaltung des Systems bei Stecklingen, deren Spitzenregion bis zum 12. IV. eingegipst war.

Die römischen Zahlen bezeichnen die Knospen und Triebe in basipetaler Richtung. K. = Kätzchentrieb nach Abort des (đ̂) Kätzchens.

Im übrigen vgl. die Angaben von Tab. XIV.

\begin{tabular}{|c|c|c|c|c|c|c|c|c|c|c|}
\hline & & I & II & III & IV & $\mathrm{v}$ & VI & VII & VIII & $\mathrm{IX}$ \\
\hline & 12. IV. & Kn. & Kn. & - & 70 & 34,5 & - & - & 15 & - \\
\hline & 13. V. & $\mathrm{Kn}$. & Kn. & - & 69,5 & 33,5 & - & - & 15. & - \\
\hline & 12. VIII. & - & - & - & !111 & - & - & - & - & - \\
\hline & 12. IV. & $\mathrm{Kn}$. & $\mathrm{Kn}$. & Kn. & 123,5 & - & - & - & - & 44 \\
\hline b & 13. V. & Kn. & $\mathrm{Kn}$. & - & 123,5 & - & - & - & - & 42 \\
\hline & 12. VIII. & - & - & - & 119 & - & - & - & - & $! 47,5$ \\
\hline \multirow{3}{*}{ c } & 12.IV. & Kn. & $\mathrm{Kn}$. & Kn. & $10 \mathrm{~K}$. & $7 \mathrm{~K}$. & $7 \mathrm{~K}$. & - & - & \\
\hline & 13. V. & $\mathrm{Kn}$. & $\mathrm{Kn}$. & 27,5 & 10,5 & 7 & 7 & - & - & \\
\hline & 12. VIII. & - & - & 331 & 10,7 & - & - & - & - & \\
\hline \multirow{3}{*}{ d } & 12. IV. & Kn. & Kn. & Kn. & - & $9 \mathrm{~K}$. & $5,5 \mathrm{~K}$. & - & 76 & - \\
\hline & 13. V. & Kn. & Kn. & $\mathrm{Kn}$. & - & 9 & 5,5 & - & 88 & - \\
\hline & 12. VIII. & 210 & - & - & - & - & - & - & 86 & - \\
\hline
\end{tabular}




\section{Literaturverzeichnis.}

1894. Amelung, E., Über Etiolement. Flora. Bd. 78. S. 204 ff.

1901. Baranetzky, J., Über die Ursachen, welche die Richtung der Äste der Baum- und Straucharten bedingen. Flora. Bd. 89, Ergänzungsband. S. $138 \mathrm{ff}$.

1898. Berthold, G., Untersuchungen zur Physiologie der pflanzlichen Organisation. I. Leipzig.

1904. - II.

1888. Beyerinck, M. W., Über das Cecidium von Nematus Capreae auf Salix amygdalina. Bot. Zeitung. Bd. 46. S. $1 \mathrm{ff}, 17 \mathrm{ff}$.

1906. Burns, G. B., and Hedden, M. E., Conditions influeneing regeneration of hypocotyl. Beihefte zum Botan. Zentralbl. Bd. 19. Abt. 1. S. $383 \mathrm{ff}$.

1897. BÜSGEN, M., Bau und Leben unserer Waldbäume. Jena.

1905. Callum, Mc., Regeneration in plants. Botanical Gazette. Vol. 40. p. 97 ff., $241 \mathrm{ff}$.

1906. Diels, L., Jugendformen und Blïtenreife im Pflanzenreich. Berlin.

1905. Dingler, H., Versuche und Gedanken zum herbstlichen Laubfall. Ber. d. Deutsch. Botan. Ges. Bd. 23. S. $463 \mathrm{ff}$.

1911. — Versuche über die Periodizität einiger Holzgewächse in den Tropen. Sitzungsber. d. k. bayr. Akad. d. Wiss., math.-phys. Kl. S. 127 ff.

1911. — Über Periodizität sommergrüner Bäume Mitteleuropas im Gebirgsklima Ceylons. Ebenda. S. $217 \mathrm{ff}$.

1909. DostáL, R., Die Korrelationsbeziehung zwischen dem Blatt und seiner Achselknospe. Ber. d. Deutsch. Botan. Ges. Bd.27. S. $547 \mathrm{ff}$.

1889. Engler, A., und Prante, K., Die natürlichen Pflanzenfamilien. II. Abt. 1. Leipzig.

1906. Errera, L., Conflits de préséance et excitations inhibitoires chez les végétaux. Recueil de l'institut bot. de LÉo Errera. Tom. 6. p. $132 \mathrm{ff}$. Bruxelles.

1880. Goeber, K., Beiträge zur Morphologie und Physiologie des Blattes. Botan. Ztg. Bd. 38. S. $753 \mathrm{ff}$.

1884. — Vergleichende Entwicklungsgeschichte der Pflanzenorgane. Schenks Handbuch. Bd. 3. Abt. 1. S. 99 ff. Breslau.

1884. — Über die gegenseitigen Beziehungen der Pflanzenorgane. Sammlung gemeinverständlicher wissenschaftlicher Vorträge, herausgegeben von R. Virchow u. Fr. v. Holtzendorf. Berlin.

1898-1901, - Organographie der Pflanzen. Jena.

1903. - Weitere Studien iiber Regeneration. Flora. Bd. 92 . S. $132 \mathrm{ff}$.

1908. — Einleitung in die experimentelle Norphologie der Pflanzen. Leipzig u. Berlin.

1909. Hallbauer, W., Über den Einfluß allseitiger mechanischer Hemmung durch einen Gipsverband auf die Wachstumszone und die innere Differenzierung der Pflanzen. Leipziger Dissertation.

1913. Hannig, E., Untersuchungen über das Abstoßen von Blüten unter dem Einfluß äußerer Bedingungen. Zeitschr. f. Botan. Bd. 5. S. $417 \mathrm{ff}$.

1894. Heck, C. R., Der Weißtannenkrebs. Berlin. 
1895. Herbst, C., Über die Bedeutung der Reizphysiologie für die kausale Auffassung von Vorgängen in der tierischen Ontogenese. 2. Hauptteil: Die formativen oder morphogenen Reize. Biol. Zentralblatt. Bd. 15. S. $721 \mathrm{ff}$.

1896. Hering, F., Über Wachstumskorrelationen infolge mechanischer Hemmung des Wachsens. Jahrb. f. wiss. Botan. Bd. 29. S. $132 \mathrm{ff}$.

1910. JАCOBI, H., Über den Einfluß der Verletzung von Kotyledonen auf das Wachstum von Keimlingen. Flora. Neue Folge. Bd. 1. S. 279 ff.

185̃5. Jessen, C. F. W., Über die Lebensdauer der Gewächse. Verhandl. d. kaiserl. Leopoldinisch-Karolinischen Akad. d. Naturforscher. Bd. 27, I. S. $61 \mathrm{ff}$. Bonn u. Breslau.

1906. Johannsen, W., Das Ätherverfahren beim Frühtreiben. Jena.

1893. Jost, L., Über Beziehungen zwischen der Blattentwicklung und der Gefäßbildung in der Pflanze. Botan. Ztg. Bd. 51. S. $89 \mathrm{ff}$.

1894. — U Über den Einfluß des Lichtes auf das Knospentreiben der Rotbuche. Ber. d. Deutsch. Botan. Ges. Bd. 12 . S. $188 \mathrm{ff}$.

1895. — Über die Abhängigkeit des Laubblattes von seiner Assimilationstätigkeit. Jahrb. f. wiss. Botan. Bd. 27. S. 403 ff.

1908. — Vorlesungen iiber Pflanzenphysiologie. 2. Aufl. Jena.

1886-88. Klebs, G., Beitrïge zur Physiologie der Pflanzenzelle. 7 Untersuch. aus d. botan. Institut in Tübingen (PFEFFER). Bd. 2. S. $489 \mathrm{ff}$. Leipzig.

1903. — Willkürliche Entwicklungsïnderungen bei Pflanzen. Jena.

1904. - Probleme der Entwicklung. Biol. Zentralbl. Bd. 24. S. $257 \mathrm{ff}$, $449 \mathrm{ff}$.

1906. _ Über künstliche Metamorphosen. Abhandl. d. naturf. Ges. zu Halle. Bd. 25. (S. 135 ff.) Separatum.

1911. — Über die Rhythmik in der Entwicklung der Pflanzen. Sitzungsber. d. Heidelberger Akad. Math.-nat. Kl. II B. Hft. 23.

1912. - Über die periodischen Erscheinungen tropischer Pflanzen. Biol. Zentralbl. Bd. 32 . S. $257 \mathrm{ff}$.

1894. KNy, L., On Correlation in the Growth of Roots and Shoots. Ann. of Bot. Vol. 8. p. $265 \mathrm{ff}$.

1903. Küster, E., Pathologische Pflanzenanatomie. Jena.

1904. - Beiträge zur Kenntnis der Wurzel- und Sproßbildung an Stecklingen. Jahrb. f. wiss. Botan. Bd. 40 . S. $279 \mathrm{ff}$.

1906. —Über meine Zentrifugenversuche an Weidenstecklingen. Botan. Ztg. Bd. 64. II. S. $35 \check{3} \mathrm{ff}$.

Hierzn:

1906. Vöchting, H., Erwiderung. Botan. Ztg. Bd. 64. III. S. 356.

1913. Küster, E., Über die Gallen der Pflanzen. Neue Resultate und Streitfragen der allgemeinen Cecidiologie. Fortschr. d. naturwissenschaftl. Forschung (E. Abderhalden). Bd. 8. S. $115 \mathrm{ff}$.

1904. Lopriore, G., Künstlich erzeugte Verbänderung infolge des [Köpfens. Ber. d. Deutsch. Botan. Ges. Bd. 22 . S. $304 \mathrm{ff} ., 394 \mathrm{ff}$.

1893. Lothelier, A., Recherches sur les plantes à piquants. Revue génér. de botan. Tom. 5. p. $518 \mathrm{ff}$.

1907. LöwI, E., Untersuchungen über die Blattablösung und verwandte Erscheinungen. Sitzungeber. d. kaiserl. Akad. Wien, math.-nat. Kl. Bd. 115. Abt. 1. S. $983 \mathrm{ff}$.

1913. Magnus, W., Der physiologische Atavismus unserer Eiche und Buche. Biol. Zentralbl. Bd. 33 . S. $309 \mathrm{ff}$. 
1897. Möвıus, M., Beiträge zur Lehre von der Fortpflanzung der Gewächse. Jena.

1851. MoнL, H. v., Grundziige der Anatomie und Physiologie der vegetabilischen Zelle. Braunschweig.

1860. — Über den Ablösungsprozeß saftiger Pflanzenorgane. Botan. Ztg. Bd. 18. S. $273 \mathrm{ff}$.

1886. Molisci, H., Untersuchungen ïber Lanbfall. Sitzungsber. d. kaiserl. Akad. Wien, math.-nat. Kl. Bd.93. Abt. 1. S. $148 \mathrm{ff}$.

1908. — Über ein einfaches Verfahren, Pflanzen zu treiben. Ebenda. Bd. 117. Abt. 1.

1907. Morgan, Th. H., Regeneration. Deutsche Ausg. von M. Moszkowski. Leipzig.

1900. Noll, F., Über den bestimmenden Einfluß von Wurzelkrimmungen auf Entstehung und Anordnung der Seitenwurzeln. Landwirtschaftl. Jahrb. (THIIEL). Bd. 29. S. $361 \mathrm{ff.} \mathrm{Berlin.}$

1903. - Beobachtungen und Betrachtungen iiber embryonale Substanz. Biol. Zentralbl. Bd. 23. S. $281 \mathrm{ff}$., $321 \mathrm{ff}$, $401 \mathrm{ff}$.

1906. Physiologie. Lehrbuch der Botanik (E. Strasburger). S. $144 \mathrm{ff}$. 8. Aufl. Jena.

1907. Nordhausen, M., Über Richtung und Wachstum der Seitenwurzeln unter dem Einfluß :iußerer und innerer Faktoren. Jahrb. f. wiss. Botan. Bd. 44. S. 557.

1893. Pferfer, W., Druck- und Arbeitsleistung durch wachsende Pflanzen. Abhandl. d. kgl. sächs. Ges. d. Wiss., math.-phys. Kl. Bd.15. S. 235 ff.

1897. — Pflanzenphysiologie. I. 2. Aufl. Leipzig.

1904. - II.

1907. Pontheim, L. v., Über Formänderung durch Ernährungsstörungen mit Bezug auf das Etiolement. Sitzungsber. d. kaiserl. Akad. d. Wiss. in Wien, math.-nat. Kl. Bd. 116 . Abt. 1. S. $1359 \mathrm{ff}$.

1859. Sachs, J., Physiologische Untersuchungen über die Keimung der Schminkbohne (Phaseolus multiflorus). Sitzungsber. d. Wiener Akad. Bd. 37. S. $57 \mathrm{ff}$.

1892. Ges. Abhandlungen über Pflanzenphysiologie. Bd. 1. :S.:574 ff. Leipzig.

1863. — Über den Einfluß des Tageslichts auf Neubildung und Entfaltung verschiedener Pflanzenorgane. Botan. Ztg. Bd. 21, Beil. S. $11 \mathrm{ff}$.

1892. Zit.: Ges. Abhandlungen über Pflanzenphysiologie. Bd. 1. Leipzig. 1880-82. U Über Stoff und Form der Pflanzenorgane. Arbeiten des Botan. Inst. Würzburg. Bd. 2. Leipzig.

1893. Zit.: Ges. Abhandlungen über Pflanzenphysiologie. Bd. 2. S. 1159 ff., $1200 \mathrm{ff}$.

1893. U Über latente Reizbarkeiten. Flora. Bd. 77 1). S. $1 \mathrm{ff}$.

1893. — Über einige Beziehungen der spezifischen Größe der Pflanzen zu ihrer Organisation. Ebenda ${ }^{1}$ ). S. $59 \mathrm{ff}$.

1893. — Über Wachstumsperioden und Bildungsreize. Ebenda ${ }^{1}$ ). S. $217 \mathrm{ff}$.

1850. Schleiden, M., Grundzüge der wissenschaftlichen Botanik. Bd. 2. 3. Aufl. Leipzig.

1) Die Arbeiten von SAcHs in der Flora, Bd. 77, erschienen unter dem Gesamttitel: Physiologische Notizen. 
1909. Sorauer, P., Handbuch der Pflanzenkrankheiten. I. Berlin.

$1908 .-$ II.

1912. Sрӓтн, H., Der Johannistrieb. Berlin.

1909. Stahl, E., Zur Biologie des Chlorophylls. Jena.

1878. Vöchting, H., Über Organbildung im Pflanzenreich. I. Bonn.

1884. - II.

1880. - _ Über Spitze und Basis an den Pflanzenorganen. Botan. Ztg. Bd. 38.

S. $593 \mathrm{ff} ., 609 \mathrm{ff}$.

1891. — Über die Abhängigkeit des Laubblattes von seiner Assimilationstätigkeit. Ebenda. Bd. 49. S. $113 \mathrm{ff}$., $129 \mathrm{ff}$.

1893. — Über den Einfluß des Lichtes auf die Gestaltung und Anlage der Blïten. Jahrb. f. wiss. Botan. Bd. 25. S. $149 \mathrm{ff}$.

1895. — Za T. A. Knights Versuchen iiber Knollenbildung. Botan. Ztg. Bd. 35. S. $79 \mathrm{ff}$.

1904. — Über die Regeneration der Araucaria excelsa. Jahrb. f. wiss. Botan. Bd. 40. S. $144 \mathrm{ff}$.

1906. — Über Regeneration und Polarität bei höheren Pflanzen. Botan. Ztg. Bd. 64. S. $101 \mathrm{ff}$.

1908. — Untersuchungen zur experimentellen Anatomie und Pathologie des Pflanzenkörpers. Tübingen.

1912. Volkens, G., Laubfall und Lauberneuerung in den Tropen. Berlin.

1899. VRIEs, H. DE, Über die Abhïngigkeit der Fasziation vom Alter bei zweijährigen Pflanzen. Botan. Zentralbl. Bd. 77. S. $289 \mathrm{ff}, 321 \mathrm{ff}$.

1902f. — Mutationstheorie. II. Leipzig.

1906. - - Arten und Varietäten und ihre Entstehung durch Mutation. Deutsch v. H. Klebahn. Berlin.

1897. Wettstein, R. v., Die Innovationsverhältnisse von Phaseolus coccineus. Osterr. botan. Zeitschr. Bd. 47. S. $424 \mathrm{ff}$.

1898. Ebenda. Bd. 48. S. 4 ff.

1889. Wiesner, J., Der absteigende Saftstrom und dessen physiologische Bedeutung. Botan. Ztg. Bd. 47. S. $1 \mathrm{ff}$.

1895. - Untersuchangen ïber den Lichtgenuß der Pflanzen. Sitzungsber. d. Wien. Akad., math.-nat. Kl. Bd. 104. Abt. 1. S. $605 \mathrm{ff}$.

1910. — Der Lichtgenuß der Pflanzen. Leipzig.

1902. WinkLer, H., Über die Regeneration der Blattspreite bei einigen Cyclamenarten. Ber. d. Deutsch. Botan. Ges. Bd: 20. S. $81 \mathrm{ff}$.

1912. - Untersuchungen über Pfropfbastarde. I. Jena.

1912. - Entwicklungsmechanik oder Entwicklungsphysiologie der Pflanzen. Handwörterbnch d. Naturwissenschaften (E. Korschelt usw.). Bd. 3. S. $634 \mathrm{ff}$. Jena. 


\section{Lebenslauf.}

Tch, Walther Mogk, ev.-luth. Konfession, wurde am 12. Februar 1887 in Leipzig geboren. Meine Eltern sind Dr. phil. Eugen Mogk, Professor an der Universitait zu Leipzig, und MARGarete Mogk geb. Scheer. Nachdem ich von Ostern 1893 an die III. Höhere Bürgerschule meiner Vaterstadt besucht hatte, wurde ich Ostern 1897 auf der Thomasschule in Leipzig aufgenommen, die ich Ostern 1906 mit dem Reifezeugnis verließ. Im Sommer 1906 und wieder vom Winter 1907-08 an studierte ich an der Universität Leipzig Naturwissenschaften. Meine Lehrer waren die Herren Brahn, von Brücke, Bücher, Buder, Chun, Correns, Credner, Eulenburg, 0. Fischer, Gregory, Hantzsch, Hauck, Herre, Jungmann, Kaestner, Lamprecht, Le Blanc, Miehe, Mogk, Nathansohn, Wo. Ostwald, Partsch, Pfeffer, Rabl, Rinne, Schering, Simroth, Spranger, zur Strassen, Volkelt, Wagner, Wiener, Witkowski, WolterECK, WUNDT. 1906-1907 war ich in Höganäs (Südschweden) deutscher Hauslehrer. Im Mai 1913 legte ich in Leipzig die Prüfung für das Lehramt an höheren Schulen ab, begann am 1. Juli 1913 meinen Probedienst am Kgl. Realgymnasium in Döbeln, und setzte ihn am 1. Januar 1914 an der Oberrealschule in Leipzig fort. 

